\section{Pacific Northwest}

National Laboratory

Operated by Battelle for the

U.S. Department of Energy

\title{
Modeling EERE Deployment Programs
}

\author{
K.A. Cort \\ D.J. Hostick \\ D.B. Belzer \\ O.V. Livingston
}

November 2007

Prepared for the U.S. Department of Energy under Contract DE-AC06-76RL01830 


\title{
DISCLAIMER
}

This report was prepared as an account of work sponsored by an agency of the United States Government. Neither the United States Government nor any agency thereof, nor Battelle Memorial Institute, nor any of their employees, makes any warranty, express or implied, or assumes any legal liability or responsibility for the accuracy, completeness, or usefulness of any information, apparatus, product, or process disclosed, or represents that its use would not infringe privately owned rights. Reference herein to any specific commercial product, process, or service by trade name, trademark, manufacturer, or otherwise does not necessarily constitute or imply its endorsement, recommendation, or favoring by the United States Government or any agency thereof, or Battelle Memorial Institute. The views and opinions of authors expressed herein do not necessarily state or reflect those of the United States Government or any agency thereof.

\author{
PACIFIC NORTHWEST NATIONAL LABORATORY \\ operated by \\ BATTELLE \\ for the \\ UNITED STATES DEPARTMENT OF ENERGY \\ under Contract DE-AC06-76RL01830
}

Printed in the United States of America
Available to DOE and DOE contractors from the Office of Scientific and Technical Information, P.O. Box 62, Oak Ridge, TN 37831-0062; ph: (865) 576-8401 fax: (865) 576-5728
email: reports@adonis.osti.gov

\author{
Available to the public from the National Technical Information Service, \\ U.S. Department of Commerce, 5285 Port Royal Rd., Springfield, VA 22161 \\ ph: (800) 553-6847 \\ fax: (703) 605-6900 \\ email: orders@ntis.fedworld.gov \\ online ordering: http://www.ntis.gov/ordering.htm
}




\title{
Modeling EERE Deployment Programs
}

\author{
K.A. Cort \\ D.J. Hostick \\ D.B. Belzer \\ O.V. Livingston
}

November 2007

Prepared for

the U.S. Department of Energy

under Contract DE-AC06-76RL01830

Pacific Northwest National Laboratory

Richland, Washington 99352 


\section{Summary}

The purpose of this report is to compile information and conclusions gathered as part of three separate tasks undertaken as part of the overall project, "Modeling EERE Deployment Programs," (NREL MPO No. DEU.7-77265-01), sponsored by the Planning, Analysis, and Evaluation Office within the Department of Energy's (DOE) Office of Energy Efficiency and Renewable Energy (EERE). The purpose of the project was to identify and characterize the modeling of deployment programs within the EERE Technology Development (TD) programs, address possible improvements to the modeling process, and note gaps in knowledge in which future research is needed. The three tasks were divided as follows:

- identify and characterize each of the deployment activities within the EERE portfolio as well as the current activity-modeling efforts.

- identify knowledge gaps and possible approaches to resolving the modeling challenges for deployment programs

- analyze the modeling of information-dissemination activities within EERE.

This report presents the key findings resulting from analyses that were completed for each of the identified tasks. The current deployment activities taking place in EERE are summarized, and a characterization of the EERE Deployment structure is provided. Current deployment-modeling efforts are also characterized with respect to each program, and the steps taken to incorporate a given program into an integrated framework are described. The gaps in knowledge regarding deployment modeling are discussed, and possible modeling strategies that may address some of these gaps are presented. Conclusions and recommendations for further, more-detailed modeling work are also included.

Detailed appendices are also provided, which include information on interviews conducted and report reviewers (Appendix A), descriptions of each deployment activity for the respective EERE program (Appendix B), information on relevant modeling modules of the National Energy Modeling System (Appendix C). Appendix $D$ provides the complete set of questions, results, and analyses for two surveys conducted by the Opinion Research Corporation (ORC) on behalf of EERE. 


\section{Acronyms}

\begin{tabular}{|c|c|}
\hline AEO & Annual Energy Outlook \\
\hline AFV & Alternative Fuel Vehicles \\
\hline APP & Asia Pacific Partnership \\
\hline AWEA & American Wind Energy Association \\
\hline BT & Building Technologies (Program) \\
\hline CAPM & Capital Asset Pricing Model \\
\hline CDM & Commercial Demand Module \\
\hline CFL & Compact Fluorescents \\
\hline CIMS & Consolidated Impacts Modeling System \\
\hline CSP & Concentrating Solar Power \\
\hline DOE & Department of Energy \\
\hline EC & European Commission \\
\hline ECP & Electricity Capacity Planning \\
\hline EERE & Efficiency and Renewable Energy \\
\hline EIA & Energy Information Administration \\
\hline EMM & Electricity Market Module \\
\hline EPA & Environmental Protection Agency \\
\hline EPRI & Electric Power Research Institute \\
\hline ESPC & Energy Savings Performance Contracts \\
\hline FCVT & FreedomCAR and Vehicle Technologies \\
\hline FEMP & Federal Energy Management Program \\
\hline GATE & Graduate Automotive Technology Education \\
\hline HFCIT & Hydrogen, Fuel Cells, and Infrastructure Technologies \\
\hline HMM & Hydrogen Market Module \\
\hline IAC & Industrial Assessment Centers \\
\hline IDM & Industrial Demand Module \\
\hline IRR & Internal Rates of Return \\
\hline ITP & Industrial Technologies Program \\
\hline $\mathrm{kWh}$ & Kilowatt Hour \\
\hline LBNL & Lawrence Berkeley National Laboratory \\
\hline LT & Long-Term (Multiplier) \\
\hline MARKAL & MARket ALlocation \\
\hline NEMS & National Energy Modeling System \\
\hline $\mathrm{NH}$ & New Hampshire \\
\hline NREL & National Renewable Energy Laboratory \\
\hline ORC & Opinion Research Corporation \\
\hline ORNL & Oak Ridge National Laboratory \\
\hline PERI & Princeton Energy Resource International \\
\hline PG\&E & Pacific Gas and Electric \\
\hline PNNL & Pacific Northwest National Laboratory \\
\hline PV & Photovoltaics \\
\hline R\&D & Research and Development \\
\hline RD3 & Research, Development, Demonstration, and Deployment \\
\hline RDM & Residential Demand Module \\
\hline RFM & Renewable Fuels Module \\
\hline ROI & Return on Investment \\
\hline RPS & Renewable Portfolio Standards \\
\hline SAI & Solar America Initiative \\
\hline SEDS & Stochastic Energy Deployment Systems \\
\hline SEP & State Energy Program \\
\hline$T \& D$ & Transmission and Distribution \\
\hline TD & Technology Development \\
\hline TDM & Transportation Demand Module \\
\hline
\end{tabular}


TEAM

UESC

WAP

WES

WIP

WPA
Transformational Energy Action Management

Utility Energy Service Contracts

Weatherization Assistance Program

Wind Energy Sub-Module

Weatherization and Intergovernmental Program

Wind Powering America 


\section{Table of Contents}

INTRODUCTION

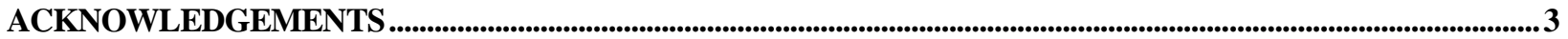

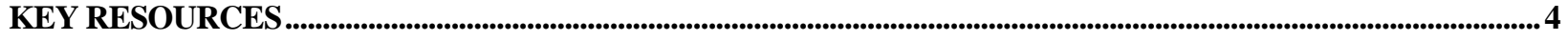

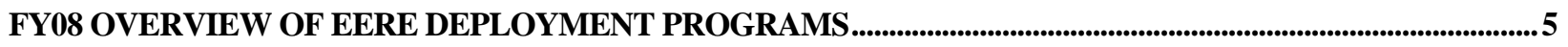

GENERAL CHARACTERIZATION AND STRUCTURE OF EERE DEPLOYMENT PROGRAMS....................13

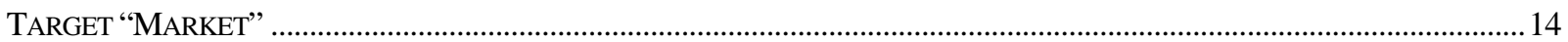

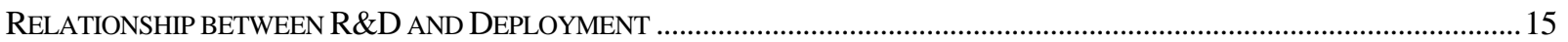

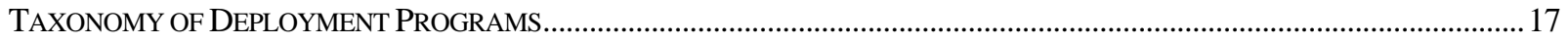

CHARACTERIZING EERE DEPLOYMENT PROGRAM MODELING ...........................................................21

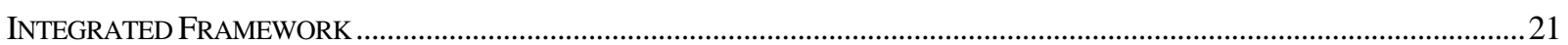

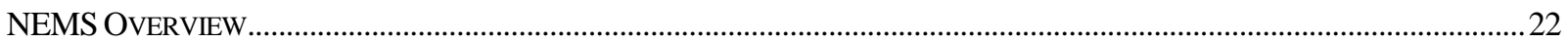

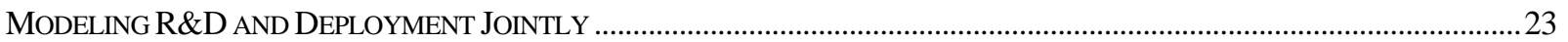

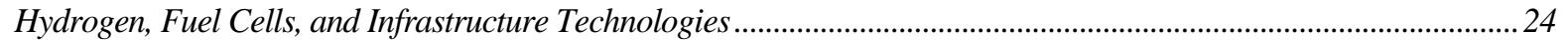

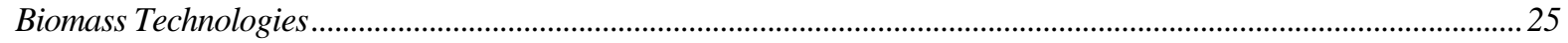

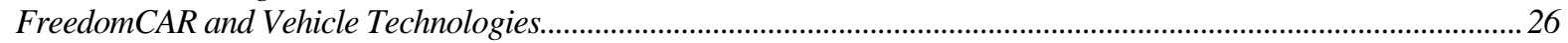

MODELING DEPLOYMENT ACTIVITIES WITHIN THE NEMS FRAMEWORK ........................................................................27

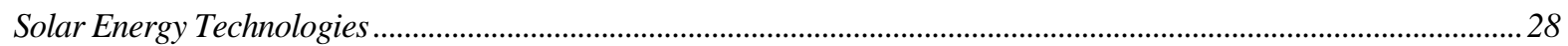

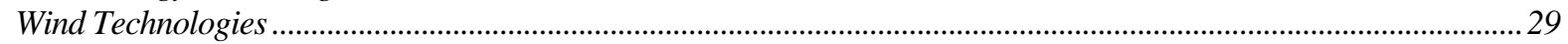

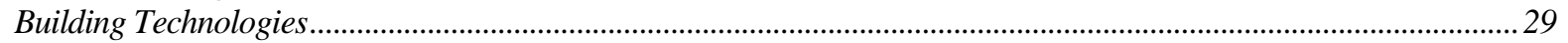

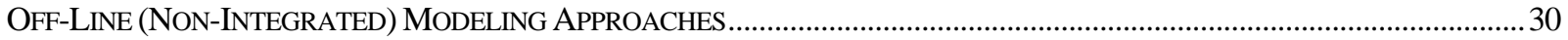

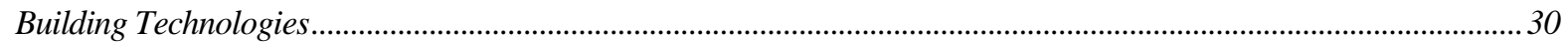

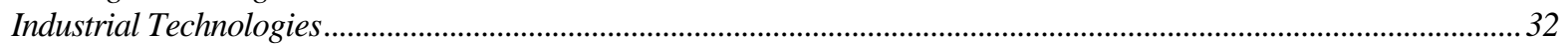

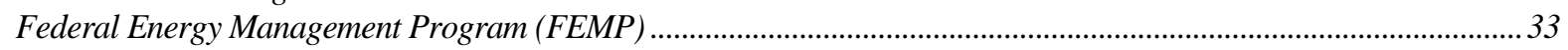

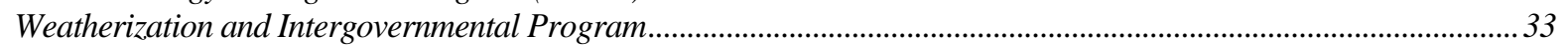

INCORPORATING DEPLOYMENT PROGRAMS INTO NEMS ...........................................................................35

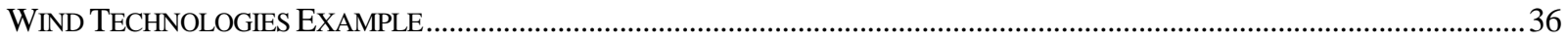

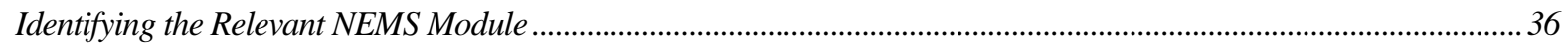

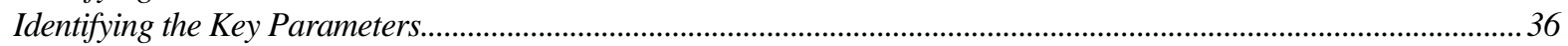

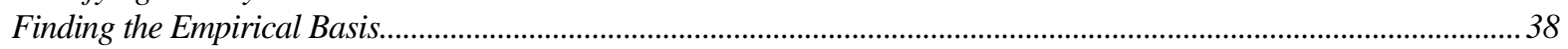

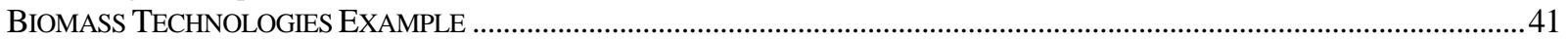

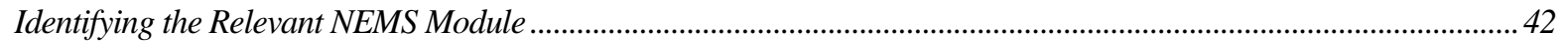

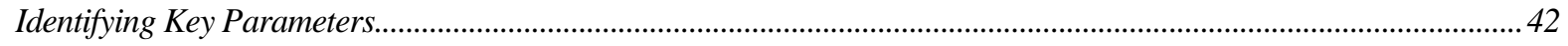

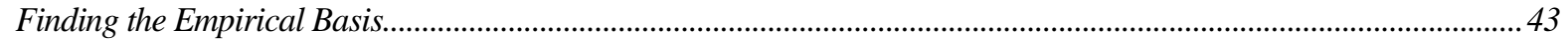

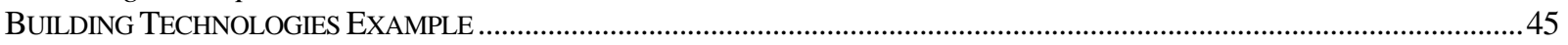

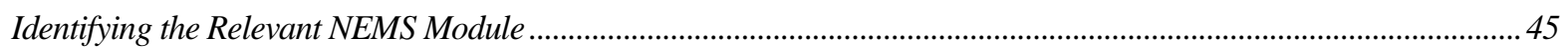

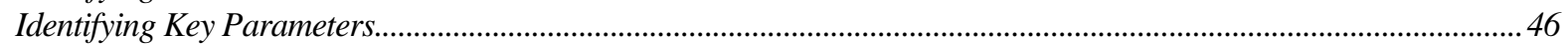

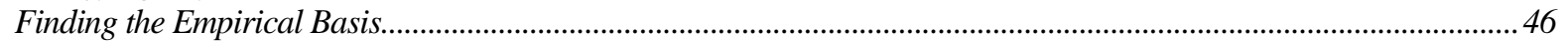

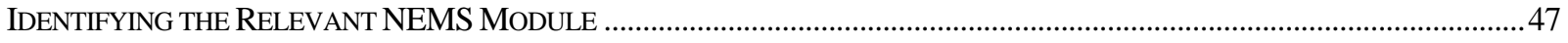

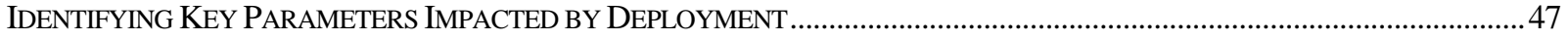

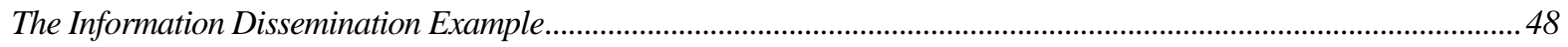

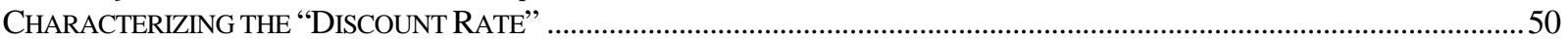

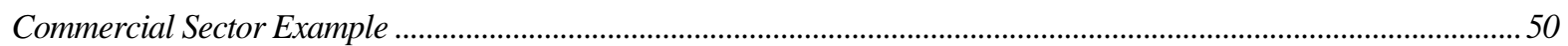

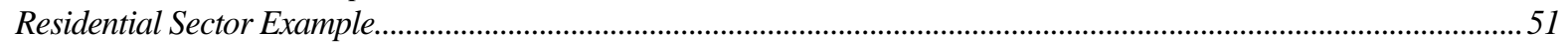

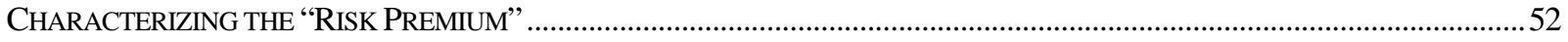

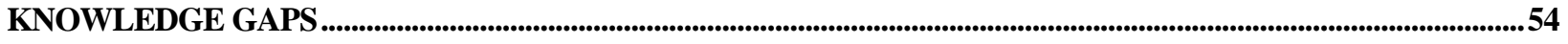

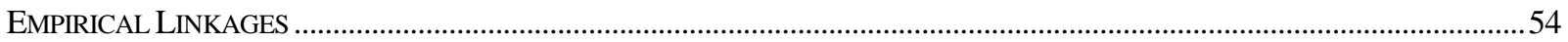

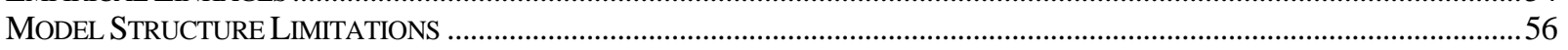

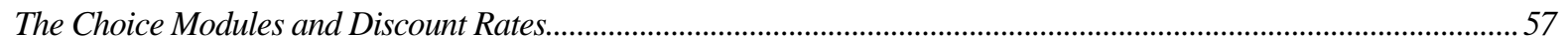


POSSIBLE MODELING APPROACHES ......................................................................................................................................61

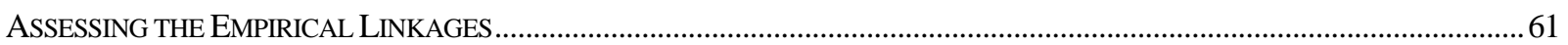

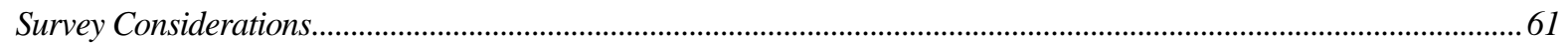

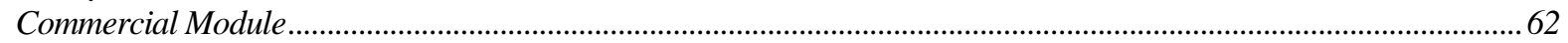

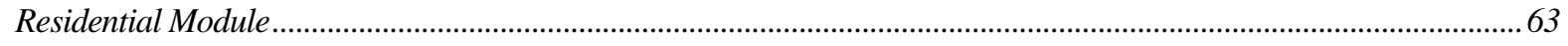

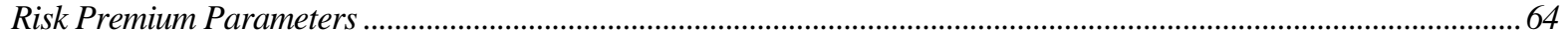

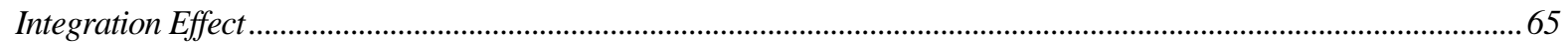

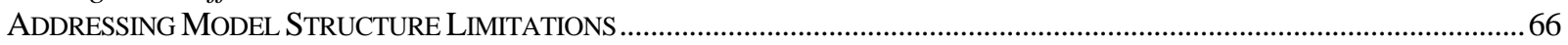

A Framework for Estimating Market Transformation Impacts ...................................................................................6 66

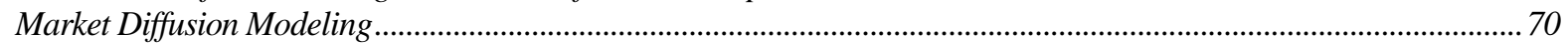

Alternative Models: CIMS and SEDS..................................................................................................................

CONCLUSIONS...............................................................................................................................................................................

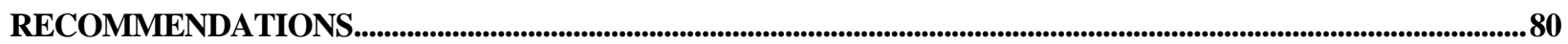

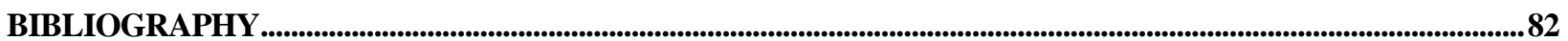

APPENDIX A - EERE CONTACTS

APPENDIX B - DEPLOYMENT PROGRAM CHARACTERIZATIONS AND MODELING APPROACHES

APPENDIX C - NEMS MODULES

APPENDIX D - ORC SURVEY RESULTS 
The Office of Energy Efficiency and Renewable Energy (EERE) of the U.S. Department of Energy (DOE) supports research and development (R\&D) and deployment efforts to provide clean, reliable, and affordable energy for America. This is accomplished through the implementation of ten programs: Hydrogen, Fuel Cells, and Infrastructure Technologies; Biomass Technologies; Geothermal Technologies; Solar Energy Technologies; Wind Energy Technologies; FreedomCAR and Vehicle Technologies; Buildings Technologies; Industrial Technologies; Federal Energy Management Program; and Weatherization and Intergovernmental Programs. These research, development, demonstration, and deployment (RD3) programs invest in high-risk, high-value R\&D that will accelerate the development of advanced clean-energy technologies and practices. These programs also have distribution components and activities that address market and behavioral barriers to specific technologies, which facilitate the deployment of advanced technologies and practices that may be either currently available or in the R\&D pipeline for future deployment.

On an annual basis, EERE develops estimates of the future benefits of its programs. Various fundamental issues arise each year regarding the consistent measurement of the value of these programs relative to one another as well as the valuation of the R\&D activities versus deployment activities. To integrate these benefit estimates, EERE employs two energy-economy models-NEMSGPRA and MARKAL-GPRA. The NEMS-GPRA model is a modified version of the National Energy Modeling System (NEMS), the midterm energy model used by the DOE's Energy Information Administration (EIA). The MARKAL-GPRA model is a modified version of the MARKet ALlocation (MARKAL) model, developed in Brookhaven National Laboratory. EERE uses NEMS-GPRA to estimate the midterm benefits of its programs, and MARKAL-GPRA to estimate the long-term benefits of its programs.

Although these robust models are able to capture energy savings in all energy sectors of the economy consistently, many of the EERE programs experience difficulty conforming program inputs into the rigid format required by these models, particularly for the diverse set of deployment activities. To assess the issues that arise when attempting to model deployment in this integrated framework, this project delineates and characterizes the modeling of implementation programs for all EERE programs in an attempt to address improvements to modeling and to identify the research needed to improve deployment modeling.

This project was completed in three parts:

TASK 1: Identify and characterize each of the deployment activities within 
the EERE portfolio and the current efforts to model these activities.

- An interim draft report describing the efforts and results of this task, entitled "Characterizing EERE Deployment Programs," was completed on April 20, 2007.

TASK 2: Identify knowledge gaps and possible approaches to addressing the modeling challenges for deployment programs.

TASK 3: Analyze the modeling of information-dissemination activities within EERE.

- An interim draft report describing the efforts and results of this task, entitled "EERE Information Dissemination Activity Analysis," was completed on July 31, 2007.

This report describes the current deployment activities and methodologies used to model these activities as part of EERE's annual effort to estimate prospective benefits of all programs in its portfolio. Much of the modeling details and deployment-activity-specific information is generalized in the body of the report, while additional modeling essentials and details on each deployment activity can be found in the appendices of this report. The report also describes the process of modeling-deployment activities in an integrated NEMS framework, and identifies the current gaps in knowledge in that process. Various approaches that may address some of the modeling challenges are also described. 


\section{Acknowledgements}

The authors would like to express appreciation to the individuals who assisted in the preparation of this document. Special thanks to the many EERE analysts and program managers who provided input during informative interviews, a list of whom is included in Appendix A of this report. Appreciation is also extended to the reviewers who provided valuable insights and recommendations to improve the content and presentation of this report. A list of all reviewers is also included in Appendix A. 
To characterize current EERE-deployment activities, this report primarily relied on information gathered from interviews conducted with EERE program managers and analysts. ${ }^{1}$ In addition, information was gathered from program websites, Budget Request documentation, ${ }^{2}$ and Multi-Year and Strategic Planning documents.

Some recent studies and planning efforts focused on EERE deployment also provided insights and a framework to help guide this process. These include the 2004 Deployment Inventory effort and the Impact Evaluation Framework for Deployment Programs (2007). The 2004 Deployment Inventory effort documented the various deployment programs in EERE in terms of its target market, market barriers, specific activities (e.g., websites, publications, etc.), and performance metrics. The reports, Impact Evaluation Framework for Deployment Programs: An Approach for quantifying retrospective energy savings and market effects ${ }^{3}$ and Overview of Evaluation Methods for R\&D Programs, ${ }^{4}$ were written to assist program managers in the development of impact evaluations to increase the effectiveness of its programs. Some of the terminology and framework for assessing deployment programs from the information compiled in these two studies is used to impart the characterizations and conclusions developed for this report.

Key resources regarding modeling techniques and activities included interviews with EERE modelers. In addition, a number of applied-academic and utility studies are referenced. The Energy Information Administration's documentation of the National Energy Modeling System (NEMS) was the primary resource for NEMS model and parameter analyses.

\footnotetext{
${ }^{1}$ Interviews included both "in-person" interviews conducted in the Forrestal Building from February 13-15, 2007, as well as a number of telephone conferences held through February and March.

${ }_{2}^{2}$ Projected Benefits of Federal Efficiency and Renewable Energy Programs FY 2008 Budget Request.

${ }^{3}$ Prepared by John H. Reed, Gretchen Jordan, and Edward Vine.

${ }^{4}$ March 2007 report produced by Rosalie Ruegg, TIA Consulting, Inc., and Gretchen Jordan, Sandia National Laboratories for the U.S. Department of Energy's EERE.
} 
The EERE portfolio is a diverse collection of programs that targets the energy supply-and-demand sectors in an attempt to accelerate the development and deployment of advanced clean-energy technologies and practices. EERE's budget request for FY08 was slightly more than $\$ 1.1$ billion dollars, of which $28 \%$-approximately $\$ 313$ million—was primarily targeted toward deployment activities $^{5}$ (see Figure 1). Nearly one-half of this amount- $\$ 144$ million-is for the Weatherization Assistance Program, which provides financing to weatherize the homes of eligible, low-income households.

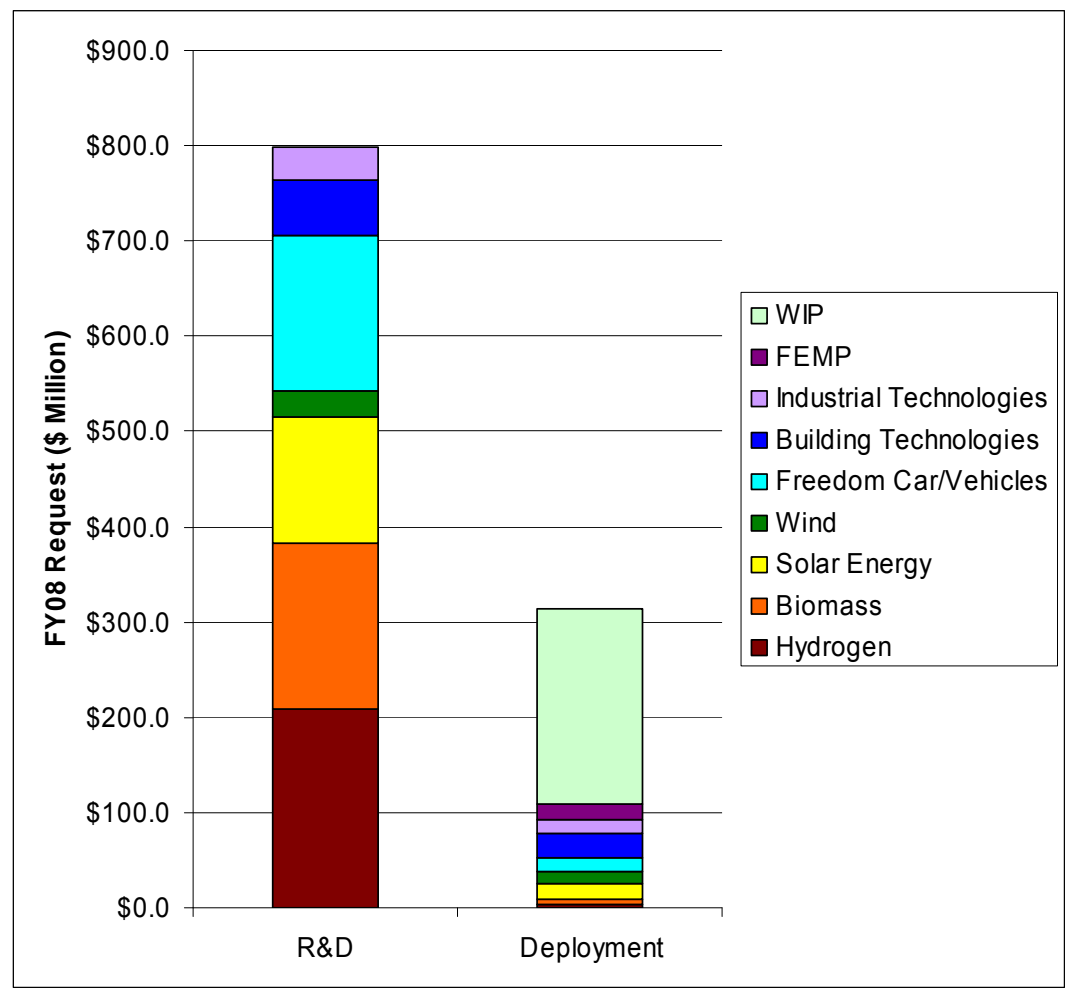

Figure 1. EERE FY08 Request by Primary Focus

Table 1 presents the FY08 budget-request data on which Figure 1 is based. ${ }^{6}$ Because not all deployment activities are funded at a line-item level, the projects were assigned either to R\&D or deployment. The appropriate characterization was selected based on the primary focus of the budget line-item. While an

\footnotetext{
${ }^{5}$ FY08 budget requests allocated to R\&D or Deployment based on primary focus; some R\&D budget will be for deployment activities, and some deployment budget will be for R\&D activities.

${ }^{6}$ The FY08 budget request for Geothermal Technologies was $\$ 0$, and as that program is currently being phased out, it was not included within the scope of this analysis. Nevertheless, funding for the Geothermal program is likely to continue, as the FY08 House Committee Report and Senate Committee Report assigned funding for this program. This budget would likely include continuance of the Geopowering the West deployment program, which develops technical assistance and outreach activities in partnership with state energy offices, utilities, other federal agencies, tribal governments, and geothermal industrial stakeholders.
} 
attempt to allocate the budget line-items between R\&D and deployment was not made, a percentage of R\&D-focused budget elements may address deployment activities. As well, a percentage of deployment-focused budget elements may address R\&D activities.

Table 1. FY08 EERE Budget Request

\begin{tabular}{|c|c|c|c|}
\hline EERE Program & R\&D Funding & $\begin{array}{l}\text { Deployment } \\
\text { Funding }\end{array}$ & $\begin{array}{l}\text { Budget Line-Item Included in } \\
\text { Deployment Classification }\end{array}$ \\
\hline Hydrogen & $\$ 209.1$ & $\$ 3.9$ & Education \\
\hline Biomass & $\$ 174.3$ & $\$ 5.0$ & $\begin{array}{l}\text { Cellulosic Ethanol Reverse } \\
\text { Auction }\end{array}$ \\
\hline Solar Energy & $\$ 132.0$ & $\$ 16.3$ & $\begin{array}{l}\text { Photovoltaic Energy Systems: } \\
\text { Technology Acceptance }\end{array}$ \\
\hline Wind & $\$ 27.2$ & $\$ 12.9$ & Technology Application \\
\hline FreedomCAR/Vehicles & $\$ 162.4$ & $\$ 13.7$ & Technology Integration \\
\hline Building Technologies & $\$ 59.5$ & $\$ 27.0$ & $\begin{array}{l}\text { Technology Validation and } \\
\text { Market Introduction and } \\
\text { Equipment Standards and } \\
\text { Analysis }\end{array}$ \\
\hline Industrial Technologies & $\$ 33.1$ & $\$ 12.9$ & $\begin{array}{l}\text { Industries of the Future: } \\
\text { Industrial Technical Assistance }\end{array}$ \\
\hline FEMP & $\$ 0.0$ & $\$ 16.8$ & All \\
\hline WIP & $\$ 0.0$ & $\$ 204.9$ & All \\
\hline Total & $\$ 797.6$ & $\$ 313.4$ & \\
\hline
\end{tabular}

The activities considered to be deployment-focused were identified based on a review of budget and planning documents. These data were also combined with the information garnered through interviews with program managers and personnel.

Although deployment activities can be defined in various ways, these authors have chosen to define deployment activities generally as "activities that promote the adoption of advanced energy-efficiency and renewable-energy technologies and practices."7 More specifically, these include activities that meet one or more of the following criteria:

- address market barriers

- address behavioral barriers

- relate to currently available technologies

- prepare the market for future technologies

- provide demonstrations replicated as showcases.

However, deployment activities would not include the following:

\footnotetext{
${ }^{7}$ This definition is in keeping with the definition presented as part of the 2004 EERE Deployment Inventory effort, prepared by an EERE Task Force.
} 
- research

- development

- first-of-a-kind or scale-up demonstrations.

Using this definition, some of EERE's activities are not technically classified as deployment. However, the activities contain pre-deployment elements and are included within this report. The budget levels associated with these activities are reported in the "R\&D" classification within Figure 1 and Table 1:

- Hydrogen's Safety and Codes and Standards, which is focused primarily on the research and development of technical data to support codes and standards, with a total request of $\$ 16$ million

- Hydrogen's Technology Validation is a "learning demonstration" and validation of the technology under real-world operating conditions, with a total request of $\$ 30$ million

- Hydrogen's Distributed Energy Fuel Cell Systems is focusing on overcoming market barriers related to stationary fuel-cell systems, including improving durability and performance, while decreasing cost. The objective of this program is to accelerate the commercialization of fuel cells by making these competitive with conventional technologies through a total request of $\$ 7.7$ million

- Biomass' Integration of Biorefinery Technologies is working to validate the near-term pathways to cost-competitive cellulosic ethanol at a demonstration scale under a total request of $\$ 92.103$ million.

The list of deployment programs and activities taking place in EERE is presented in Table 2. 
Table 2. FY08 EERE Deployment Activities

\begin{tabular}{|c|c|}
\hline EERE Program & Deployment Activity \\
\hline \multirow{4}{*}{ Hydrogen } & Hydrogen Education and Outreach (\$3.9 million) \\
\hline & Codes and Standards Program ( $\$ 16$ million, primarily code research) \\
\hline & Technology Validation ( $\$ 30$ million) \\
\hline & Distributed Energy Fuel Cell Systems (\$7.7 million) \\
\hline \multirow{6}{*}{ Biomass } & $\begin{array}{l}\text { Integration of BioRefinery Technologies (supports Biofuels Initiative) } \\
\text { (\$92.103 million) }\end{array}$ \\
\hline & Biomass Products Development ( $\$ 10$ million) \\
\hline & $\begin{array}{l}\text { Bioconversion Platform R\&D (R\&D phase with marketing analysis) } \\
\text { (\$38.3 million total; only a small percentage is for deployment) }\end{array}$ \\
\hline & $\begin{array}{l}\text { Thermochemical Platform R\&D (R\&D phase with marketing analysis) } \\
\text { (\$19.537 million total; only a small percentage is for deployment) }\end{array}$ \\
\hline & $\begin{array}{l}\text { Regional Feedstock Partners Outreach, within Feedstock Infrastructure } \\
\text { (\$9.737 million total; only a small percentage is for deployment) }\end{array}$ \\
\hline & $\begin{array}{l}\text { Education and Outreach (not called out separately within budget } \\
\text { request) }\end{array}$ \\
\hline \multirow[t]{2}{*}{ Solar Energy } & $\begin{array}{l}\text { Solar America Initiative (includes Technology Pathway Partnerships, } \\
\text { Technology Acceptance, and Technology Evaluation) (\$16.34 million is } \\
\text { primarily deployment-focused) }\end{array}$ \\
\hline & Solar Decathlon (not called out separately within budget request) \\
\hline \multirow{2}{*}{ Wind } & $\begin{array}{l}\text { Wind Resource Assessment (Systems Integration and Technology } \\
\text { Acceptance) (\$12.869 million is primarily deployment-focused) }\end{array}$ \\
\hline & $\begin{array}{l}\text { Wind Powering America (not called out separately within budget } \\
\text { request) }\end{array}$ \\
\hline \multirow{4}{*}{ FreedomCAR/Vehicles } & Clean Cities (now Vehicle Technologies Deployment, \$9.593 million) \\
\hline & Graduate Automotive Technology Education (GATE) ( $\$ 0.5$ million) \\
\hline & Advanced Vehicle Competitions (\$1.3 million) \\
\hline & Legislative and Rulemaking activities (\$1.8 million) \\
\hline \multirow{8}{*}{ Building Technologies } & $\begin{array}{l}\text { Residential R\&D: Building America (some deployment components) } \\
\text { and the National Builders Challenge Initiative ( } \$ 19.7 \text { million total; only a } \\
\text { small percentage is for deployment) }\end{array}$ \\
\hline & $\begin{array}{l}\text { Commercial Buildings R\&D (some deployment components) (\$7 million } \\
\text { total; only a small percentage is for deployment) }\end{array}$ \\
\hline & Equipment Standards and Analysis (\$13.361 million) \\
\hline & ENERGY STAR $®(\$ 6.776$ million) \\
\hline & $\begin{array}{l}\text { Rebuild America: Building Application Centers (\$2.834 million total for } \\
\text { Rebuild America) }\end{array}$ \\
\hline & $\begin{array}{l}\text { Rebuild America: EnergySmart Schools and EnergySmart Hospitals } \\
\text { (\$2.834 million total for Rebuild America) }\end{array}$ \\
\hline & $\begin{array}{l}\text { Building Energy Codes and Advanced Energy Codes Initiative ( } \$ 3.751 \\
\text { million, primarily code deployment) }\end{array}$ \\
\hline & $\begin{array}{l}\text { Rebuild America: Commercial Lighting Challenge ( } \$ 2.834 \text { million total } \\
\text { for Rebuild America) }\end{array}$ \\
\hline \multirow{2}{*}{ Industrial } & Best Practices/Save Energy Now Program (\$8.833 million) \\
\hline & Industrial Assessment Center ( $\$ 4.035$ million) \\
\hline \multirow{4}{*}{ FEMP } & Technical Guidance and Assistance (\$6.519 million) \\
\hline & Project Financing (ESPC Support, UESC Support) (\$7.935 million) \\
\hline & DOE Specific Investments (new initiative, not included in FY08 request) \\
\hline & $\begin{array}{l}\text { Federal Fleet (part of FEMP's } \$ 2.337 \text { million Planning, Reporting and } \\
\text { Evaluation activity) }\end{array}$ \\
\hline \multirow{4}{*}{ WIP } & Weatherization Assistance Program (\$144 million) \\
\hline & State Energy Program ( $\$ 45.501$ million) \\
\hline & Tribal Energy Program (\$2.957 million) \\
\hline & Asia Pacific Partnership (\$7.5 million) \\
\hline
\end{tabular}




\section{Hydrogen, Fuel Cells, and Infrastructure Technologies}

The Hydrogen, Fuel Cells and Infrastructure Technologies Program (HFCIT) works with partners to accelerate the development and successful market introduction of hydrogen and fuel-cell technologies. The program endeavors to reduce U.S. dependency on petroleum imports, improve air quality, and reduce greenhouse-gas emissions. Although the Hydrogen program is primarily considered an R\&D program, a number of deployment elements are included in the portfolio to help prepare the future markets for acceptance and uptake of new fuel-cell and hydrogen technologies. The Program's efforts are directed at four areas:

- overcoming technical barriers through research and development of hydrogen production, delivery, and storage technologies as well as fuelcell technologies for transportation, distributed-stationary power, and portable-power applications

- validating and demonstrating hydrogen and fuel cell in real-world conditions

- addressing safety concerns and expediting the development of model codes and standards.

- educating key stakeholders, whose acceptance of these technologies will determine marketplace success.

Descriptions of Hydrogen deployment activities are found in Appendix B, and are further characterized in Table 3 of this report. Further information regarding the $\mathrm{HFClT}$, in general, is available on the program website: http://www1.eere.energy.gov/hydrogenandfuelcells/.

\section{Biomass Technologies}

The Biomass Program focuses on advancing the breakthrough technologies needed to make cellulosic ethanol cost-competitive with corn-based ethanol, thus allowing greater use of this alternative fuel in an attempt to reduce future U.S. oil consumption. The Program has an assortment of R\&D programs that contain deployment elements. The Biomass Program's primary activities include:

- collaborative R\&D to advance feedstock and conversion technologies

- public/private partnerships to demonstrate large-scale, integrated-biomass technologies and systems

- market-transformation activities to accelerate deployment and commercialization of biofuels systems.

Descriptions of Biomass deployment activities are found in Appendix B, and are further characterized in Table 3 of this report. Further information regarding the Biomass Program, in general, is available at the program website: http://www1.eere.energy.gov/biomass/. 


\section{Solar Energy Technologies}

The Solar Program supports research and development activities designed to advocating significant advances in the solar-energy technologies of concentrating solar power, photovoltaics (PV), and solar heating and lighting. The President's Solar America Initiative (SAI) was launched in January 2006, as part of the Administration's Advanced Energy Initiative. The Solar America Initiative's goal is to accelerate the development of advanced photovoltaic (PV) materials that convert sunlight directly into electricity. The program's deployment approach includes outreach activities, such as various publications, websites, educational materials, partnerships, demonstration projects, and technical assistance aspiring to accelerate the market for advanced PV. Descriptions of Solar deployment activities are found in Appendix B, and are further characterized in Table 3 of this report. Further information regarding the Solar Energy Technologies program is available at the program website: http://www1.eere.energy.gov/solar/.

\section{Wind Technologies}

The Wind Program is concentrated on reducing risks that may undermine the growth potential of wind energy in the United States. This is accomplished by focusing on improving cost, performance, and reliability of large-scale land-based technology, facilitating wind energy's rapid market expansion by anticipating and addressing potential barriers (i.e., integration into the electric grid, siting, permitting, environmental issues), and investigating wind energy's application to other areas-from offshore wind technology to distributed and community-owned wind projects. Descriptions of Wind deployment activities are found in Appendix $\mathrm{B}$, and are further characterized in Table 3 of this report. Further information regarding the Wind Technologies Program, in general, is available at the program website: http://www1.eere.energy.gov/windandhydro/.

\section{FreedomCAR and Vehicle Technologies}

The FreedomCAR and Vehicle Technologies (FCVT) Program provides technology-focused research-and-development activities for: 1) improving the energy efficiency of current cars, light trucks, and heavy vehicles, and 2) developing engineering that will transition vehicles' technology away from petroleum fuels. Descriptions of FreedomCAR deployment activities are found in Appendix B, and are further characterized in Table 3 of this report. Further general information regarding FCVT is available at the program website: http://www1.eere.energy.gov/vehiclesandfuels/.

\section{Building Technologies}

The Building Technologies Program supports a wide range of activities designed to develop and facilitate widespread adoption and use of energy-saving technologies and practices in residential and commercial buildings. The program's efforts support three areas:

- advances the research and development of energy-efficient building technologies and practices for both new and existing residential and commercial buildings 
- works with state and local regulatory groups and others to improve building codes, appliance and equipment standards, and guidelines for efficient energy use

- promotes market transformation by educating homeowners, builders, and developers about the significant returns that can be achieved by adopting energy-efficient technologies and practices.

Descriptions of Building Technologies deployment activities are found in Appendix B, and are further illustrated in Table 3 of this report. Further information regarding the Buildings Technology Program is available on the program website: http://www.eere.energy.gov/buildings/.

\section{Industrial Technologies}

Through a partnership with the industrial sector, the Industrial Technologies Program (ITP) supports the development of energy-efficient, clean manufacturing technologies. ITP has embraced more lean and agile operating practices to decrease industrial energy intensity with reduced resources. The program's efforts are focused on:

- R\&D for energy intensity industries (aluminum, chemical, forest products, glass metal casting, mining, petroleum refining, and steel)

- R\&D in four key technology areas common to most energy-intensive industries: combustion, sensors and automation, industrial materials for the future, and supporting

- technology delivery and deployments activities.

Descriptions of Industrial Technologies deployment activities are found in Appendix B, and are further exemplified in Table 3 of this report. Further information regarding ITP is available on the program website:

http://www1.eere.energy.gov/industry/.

\section{Federal Energy Management Program (FEMP)}

The Federal Energy Management Program strives to enhance energy security, environmental stewardship, and cost reduction within the federal government by 1) advancing energy efficiency and water conservation, 2) promoting the use of renewable energy, alternative fuels in federal vehicle fleets, sustainable building design, and distributed energy resources, and 3) improving utility-management decisions at federal facilities. Descriptions of FEMP deployment activities are found in Appendix B, and are further delineated in Table 3 of this report. Further information regarding FEMP is available on the program website:

http://www1.eere.energy.gov/femp/.

\section{Weatherization and Intergovernmental Program}

The Weatherization and Intergovernmental Program (WIP) provides funding and technical assistance to state and local governments, American Indian tribes, and international agencies to promote the adoption of renewable energy and energyefficiency technologies. The project's subprograms include: 
- the Weatherization Assistance Program, which provides financing to reduce energy costs for low-income households by increasing the energy efficiency of the homes, while ensuring occupants' health and safety.

- the State Energy Program, which provides grants to the states that allows for the design and implementation of renewable energy and energyefficiency programs

- the Tribal Energy Program, which offers financial and technical assistance to Indian tribes to assist in the creation of sustainable renewable-energy installations on tribal lands.

- the Asia Pacific Partnership, which encourages clean-energy technology deployment among six countries: Australia, China, India, Japan, South Korea, and the United States.

Descriptions of WIP deployment activities are found in Appendix B, and are further differentiated in Table 3 of this report. Additional information regarding WIP is available on the program website: http://www.eere.energy.gov/wip/. 
There are a number of general characteristics and conclusions that can be made regarding EERE deployment activities, which may have relevance concerning how programs are modeled. The primary deployment categories of all EERE deployment activities for this 2007 characterization are in line with the activities revealed in the 2004 Deployment Inventory, and include the following:

- general information-dissemination activities (these activities usually involve some combination of website, conferences or workshops, publications, and databases)

- targeted training and workshops

- partnerships with local governments, institutions, and private companies to solve technical and administrative issues related to the implementation of systems and technologies related to energy efficiency and renewable energy

- recognition for key products and awards for products, institutions and/or individuals making advances in and promoting energy efficiency and renewable energy

- sponsoring and promoting competitions to solve specific deployment issues

- purchasing enabling technologies and programs to promote the adoption of energy-efficient and renewable-energy technologies

- developing and implementing standards and regulations related to EERE technologies and designs

- providing technical assistance to "early adopters"

- providing privileges and incentives to adopt EERE technologies

- demonstrations of key technologies, systems, and designs.

Based on interviews with program managers, some of the key market barriers currently targeted by EERE deployment programs include the following:

- Information Awareness: A general lack of information and awareness exists about the product, design and/or technology.

- Policy/Regulation: Policies and/or regulations may inhibit the implementation of the product, design, or technology.

- Cost and Financing: High "first" costs and/or insufficient available financing options to pay for projects may deter implementation.

- Technical Capacity: A lack of knowledge and technical capacity may delay the end user or business from efficiently implementing or mass-manufacturing the product, design, or technology.

- Risk Aversion: A product/design/technology may face considerable risk aversion in the market because of fears regarding the reliability of the product or safety concerns and/or concerns regarding financial loss.

- Performance Issues and System Integration: In some cases, the key challenge involves putting various components together to maximize 
efficiency performance.

- Applications and Infrastructure Development: The current infrastructure does not allow for the promotion of technology deployment.

- Market Structure: Market structure barriers could include one or more of the following market barriers:

- Market Fragmentation: The overall fragmentation of the market place does not lend itself to complete acceptance of a given technology. Consumers are left to invest considerable time and energy to gather information about the various choices of products. This, in turn, increases "search costs" and uncertainty related to implementing the given product, design, or technology. On the supply side, individual producers of new technologies do not have the financial resources to disseminate credible information about the benefits of the available products.

- Principal-Agent Problem: This problem arises when one person-the agent-performs tasks on behalf of another person-the principal—but the agent performs the expected tasks in a way contrary to the principal's best interests. This commonly occurs between home builders and prospective buyers, or renters and landlords. The builder or building owner does not pay utilities; therefore, the incentive to install efficient equipment does not exist. Conversely, the renter does not pay utilities; thus, the lack of incentive to conserve.

- Externalities: External costs-also referred to as externality costsmay include, for example, the environmental-damage costs associated with an action. These costs may also include the market alternatives to the energy-efficient/renewable technology that are not realized or internalized by the consumer. Thus, the market is skewed in favor of the non-efficient/renewable products and technologies.

- Public Good: This product, design, or technology has elements of a "public good." Therefore, no one can be effectively excluded from using and benefiting from this good (non-excludable). This situation often leads to under-investment in the good, as no one entity can own the benefits.

Target "Market"

Past discussions of deployment activities have included characterizations of target markets/sectors and target audiences. As this report focuses on modeling, distinguishing the target audience from the target sector is important. The Impact Evaluation Framework discusses that deployment activities typically engage one or more of four groups. These groups are often referred to as the target audience and include: the knowledge community (educators and educational institutions), public governmental and community entities (public infrastructure), manufacturers and businesses, and end-users.

From a modeling perspective, it is important to note the eventual program-goal 
outcome-energy savings or renewable energy production. This outcome will be revealed in a targeted energy-market sector, which will include the commercial buildings sector, residential buildings, industrial sector, transportation, utilities, and possibly the agricultural sector. As an example, a deployment program that develops and promotes fuel use-reduction technologies and practices in vehicles may choose to do one or more of the following:

1) engage the knowledge community by teaming with universities with advancedautomotive engineering programs to influence curriculum and programs

2) engage public officials by promoting certain standards or enabling infrastructure

3) engage automotive companies through workshops, training, and incentive programs

4) directly engage vehicle owners and car buyers by informing decisions associated with buying and maintaining a vehicle.

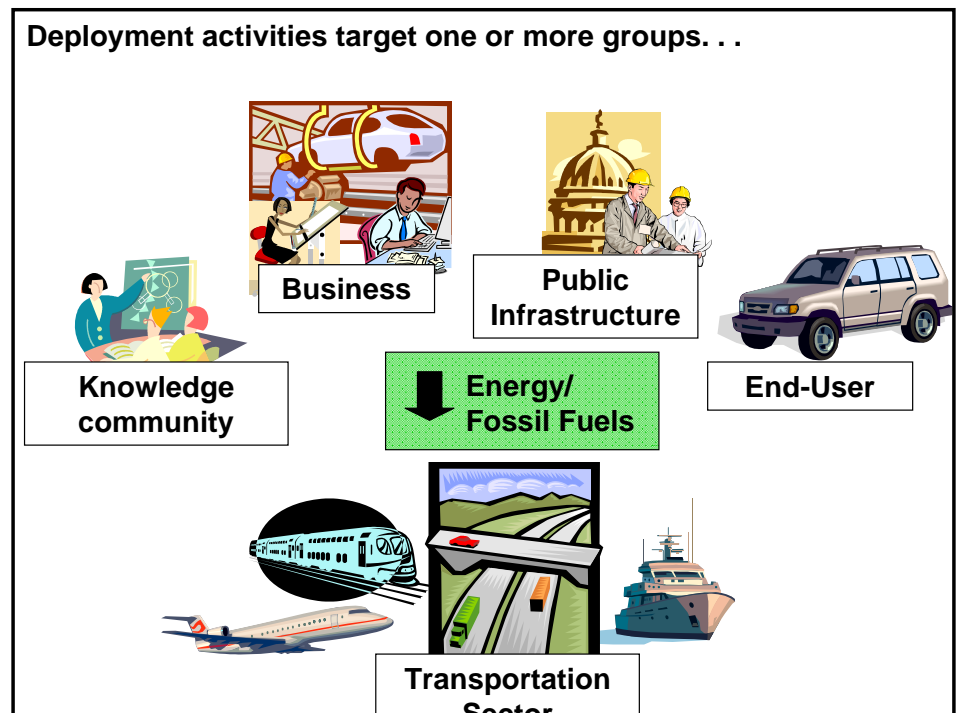

Fiaure 2. Taraet Audience/Taraet Sector --Transbortation Examble

For this example, the objective for all contacts and engagements would be to eventually reduce energy use in the transportation sector or possibly replace fossil fuels with renewable energy sources (See Figure 2).

\section{Relationship between $R \& D$ and Deployment}

When characterizing deployment programs for modeling purposes, the assessment of the associated relationship with related Research and Development (R\&D) activities is also important. In recent EERE budget and planning exercises, the generalized EERE Logic Model ${ }^{8}$ simplifies the relationship between program inputs and outcomes by separating R\&D programs and milestones from those of deployment efforts. Deployment activities are predominantly implemented at the downstream phase of the technologydevelopment cycle. In reality, however, some deployment activities will take place in the "R\&D Phase" of the program as well. Some R\&D types of activities may also occur in the support of implementation of technologies, systems, and designs (see Figure 3). Distinguishing the specific outcomes or benefits of a

\footnotetext{
${ }^{8}$ The logic model is a fundamental program planning-and-evaluation tool. In its simplest form, a logic model identifies the relationship between budget and other inputs to a program, activities conducted by the program, and the resulting outputs and outcomes of those activities. (FY08 Budget Request)
} 
particular deployment activity from the benefits of related R\&D activities can pose significant modeling challenge.

Recent efforts by EERE to implement a "Stage-Gate" approach to R\&D emphasize the link between R\&D and deployment during all stages of the R\&D process. In "Stage-Gate" terminology, R\&D must continually keep its focus on technology development and product development equally. Technology and market-related deployment work go hand-in-hand, and are conducted in every stage, even very early stages of R\&D, when eventual product deployment could be decades into the future (assuming successful R\&D outcome). With the "Stage-Gate" approach, it is as important for a project to show market-related merit (deployment effort) as it is to make technical progress (R\&D effort).

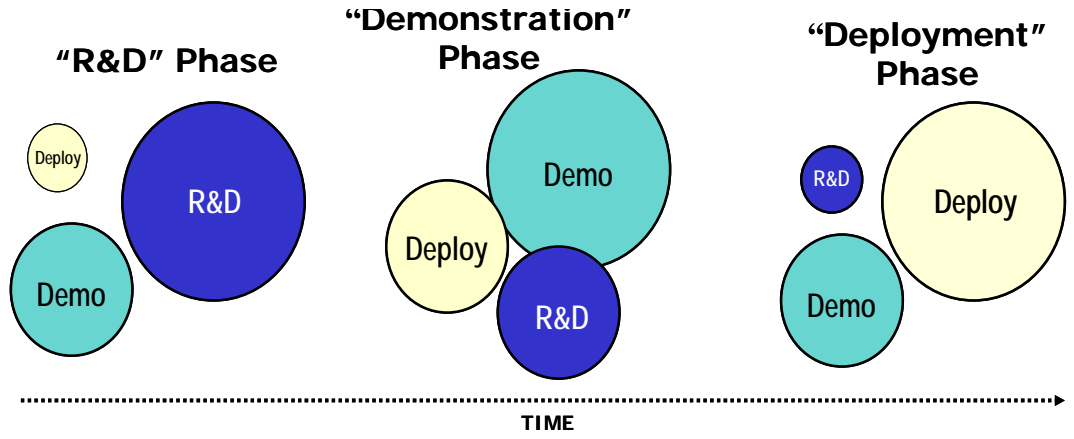

Figure 3. RD3 Activities over Development Timeline ${ }^{10}$

A number of "Stage-Gate-appropriate" deployment activities are present within the EERE R\&D portfolio. In an effort to appropriately tailor the R\&D to market demand and market structure, marketing and product issues are considered early in the R\&D phase. Some deployment activities, such as education and outreach programs, and codes and standards programs, may also appear early in the R\&D phase in an attempt to prepare consumers and the market for the introduction of a new technology. The Hydrogen and Biomass Programs appear to provide a number of examples of these categories of informal (or pre-) deployment activities (See Table 3).

Likewise, R\&D classes of activities appear in the "deployment phase" of a program (see Figure 3), and where the line between R\&D and deployment is drawn is not always clear. A number of activities are included in deployment programs that involve a significant amount of "research" and "development" to accelerate distribution and meet implementation goals. How closely R\&D and

\footnotetext{
${ }^{9}$ Stage-Gate is a process to improve the success rate of new products with a risk-management approach. The approach is designed to help R\&D managers make difficult decisions, first in selecting appropriate projects to pursue and then managing scarce resources by continually assessing each stage for all projects in the portfolio throughout the life of their development.

${ }^{10}$ From internal PAE documents produced by the 2004 EERE Deployment Task Force
} 
deployment activities are linked, and whether or not these can reasonably be decoupled, possesses important modeling implications.

\section{Taxonomy of Deployment Programs}

Table 3 provides a classification of various EERE deployment activities, according to the targeted audience (table column categories) the program engages (with examples of typical activities) and the targeted energy sector (table row categories). The types and degree of activities that take place and how these may impact the targeted audience will have unmistakable modeling implications. If enough empirical information can be obtained to generalize certain relationships between, for example, training activities and the response from specific audiences, quantification and modeling of some of these activities in the respective energy sector are possible.

The unique structure of the specific energy sector where energy savings and benefits are revealed can also pose significant modeling implications. For example, a program may have the goal of saving energy in all buildings-both residential and commercial—using one basic deployment approach. However, the residential- and commercial-building energy sectors as well as the NEMS residential and commercial modules are structured quite differently. As a result, a deployment-modeling approach that modifies an individual parameter, such as a discount rate, may be possible in the commercial module, but not practicable in the residential module. This eventuation may be due to structural differences both in the sector and in the underlying NEMS model.

The two left-most columns of Table 3 include deployment activities that take place in relatively early stages of the R\&D process. These could include deployment types of marketing and information studies to help guide the R\&D process. Some deployment activities focused on advanced preparation of the market and engaging public entities and the knowledge community (educational institutions). 


\begin{tabular}{|c|c|c|c|c|c|c|c|}
\hline $\begin{array}{l}\begin{array}{r}\text { Stage-Avenue } \\
\text { (Prelim } \\
\text { Audience) }\end{array} \\
\text { Target } \\
\text { Sector } \\
\text { (Modeling) }\end{array}$ & $\begin{array}{l}\text { Data } \\
\text { Gathering/ } \\
\text { Market } \\
\text { Research (In } \\
\text { support of } \\
\text { R\&D) }\end{array}$ & $\begin{array}{l}\text { Advanced Market } \\
\text { Preparation and } \\
\text { Infrastructure } \\
\text { Development (R\& D } \\
\text { stage) }\end{array}$ & $\begin{array}{l}\text { Identifying } \\
\text { Promising } \\
\text { Technologies (In } \\
\text { support of } \\
\text { deployment) }\end{array}$ & $\begin{array}{l}\text { Public Infrastructure } \\
\text { and Policy, Regulation }\end{array}$ & $\begin{array}{l}\text { Manufacturing } \\
\text { and Business } \\
\text { Infrastructure }\end{array}$ & $\begin{array}{l}\text { Technology } \\
\text { Adoption Supports } \\
\text { ("knowledge } \\
\text { community" and } \\
\text { end-users) }\end{array}$ & $\begin{array}{l}\text { Marketing } \\
\text { and Outreach } \\
\text { (end-users) }\end{array}$ \\
\hline $\begin{array}{l}\text { Examples of } \\
\text { Typical } \\
\text { Activities }\end{array}$ & $\begin{array}{l}\text { Marketing/ } \\
\text { economic } \\
\text { studies }\end{array}$ & $\begin{array}{l}\text { Workshops, } \\
\text { Information and } \\
\text { education, local govt. } \\
\text { partnerships }\end{array}$ & $\begin{array}{l}\text { Demos, Information, } \\
\text { Database, Analysis, } \\
\text { Workshops }\end{array}$ & $\begin{array}{l}\text { Federal purchases, } \\
\text { partnerships, policies } \\
\text { regulation, financial } \\
\text { assistance, information }\end{array}$ & $\begin{array}{l}\text { Partnerships, } \\
\text { privileges, } \\
\text { incentives, } \\
\text { competitions }\end{array}$ & $\begin{array}{l}\text { Information and } \\
\text { education, } \\
\text { partnerships, } \\
\text { technical assistance, } \\
\text { direct financial } \\
\text { assistance, tax } \\
\text { incentives }\end{array}$ & $\begin{array}{l}\text { Information } \\
\text { and outreach, } \\
\text { recognition } \\
\text { and awards. }\end{array}$ \\
\hline $\begin{array}{l}\text { Commercial } \\
\text { Buildings }\end{array}$ & & $\begin{array}{l}\text { Hydrogen: } \\
\text { Education and } \\
\text { Outreach }\end{array}$ & $\begin{array}{l}\text { BT: Com R\&D (ZEB } \\
\text { research) }\end{array}$ & $\begin{array}{l}\text { BT: EnergySmart } \\
\text { Schools and Hospitals } \\
\text { BT: Building Energy } \\
\text { Codes } \\
\text { BT: Advanced Energy } \\
\text { Codes } \\
\text { BT: Equip Standards } \\
\text { WIP: State Energy } \\
\text { Program } \\
\text { FEMP: Project } \\
\text { Financing }\end{array}$ & $\begin{array}{l}\text { BT: Commercial } \\
\text { Lighting Challenge } \\
\text { Solar: Solar } \\
\text { America Initiative } \\
\text { (SAI) }\end{array}$ & $\begin{array}{l}\text { BT: Com R\&D } \\
\text { design software } \\
\text { WIP: Tribal Energy } \\
\text { FEMP: Technical } \\
\text { Guidance and } \\
\text { Assistance } \\
\text { Solar: Solar America } \\
\text { Initiative (SAI) }\end{array}$ & $\begin{array}{l}\text { BT: ENERGY } \\
\text { STAR } \\
\text { (commercial } \\
\text { applications) }\end{array}$ \\
\hline $\begin{array}{l}\text { Residential } \\
\text { Buildings }\end{array}$ & & & $\begin{array}{l}\text { BT: Res R\&D (ZEB } \\
\text { research) }\end{array}$ & $\begin{array}{l}\text { BT: Building Energy } \\
\text { Codes } \\
\text { WIP: Weatherization } \\
\text { Assistance } \\
\text { WIP: State Energy } \\
\text { Program }\end{array}$ & $\begin{array}{l}\text { BT: National } \\
\text { Builder's } \\
\text { Challenge } \\
\text { Solar: Solar } \\
\text { America Initiative } \\
\text { (SAI) }\end{array}$ & $\begin{array}{l}\text { BT: Building } \\
\text { Application Centers } \\
\text { BT: Res R\&D Best } \\
\text { Practices } \\
\text { WIP: Tribal Energy } \\
\text { Solar: Solar America } \\
\text { Initiative (SAI) } \\
\text { Solar: Solar } \\
\text { Decathlon }\end{array}$ & $\begin{array}{l}\text { BT: ENERGY } \\
\text { STAR } \\
\text { (residential } \\
\text { applications) }\end{array}$ \\
\hline Industrial Sector & & $\begin{array}{l}\text { Hydrogen: } \\
\text { Education and } \\
\text { Outreach }\end{array}$ & $\begin{array}{l}\text { ITP: ITP } \\
\text { Partnerships }\end{array}$ & & $\begin{array}{l}\text { ITP: Best } \\
\text { Practices/Save } \\
\text { Energy Now }\end{array}$ & $\begin{array}{l}\text { ITP: Industrial } \\
\text { Assessment Centers }\end{array}$ & \\
\hline
\end{tabular}




\begin{tabular}{|c|c|c|c|c|c|c|c|}
\hline $\begin{array}{l}\begin{array}{r}\text { Stage-Avenue } \\
\text { (Prelim } \\
\text { Audience) }\end{array} \\
\text { Target } \\
\text { Sector } \\
\text { (Modeling) }\end{array}$ & $\begin{array}{l}\text { Data } \\
\text { Gathering/ } \\
\text { Market } \\
\text { Research (In } \\
\text { support of } \\
\text { R\&D) }\end{array}$ & $\begin{array}{l}\text { Advanced Market } \\
\text { Preparation and } \\
\text { Infrastructure } \\
\text { Development (R\& D } \\
\text { stage) }\end{array}$ & $\begin{array}{l}\text { Identifying } \\
\text { Promising } \\
\text { Technologies (In } \\
\text { support of } \\
\text { deployment) }\end{array}$ & $\begin{array}{l}\text { Public Infrastructure } \\
\text { and Policy, Regulation }\end{array}$ & $\begin{array}{l}\text { Manufacturing } \\
\text { and Business } \\
\text { Infrastructure }\end{array}$ & $\begin{array}{l}\text { Technology } \\
\text { Adoption Supports } \\
\text { ("knowledge } \\
\text { community" and } \\
\text { end-users) }\end{array}$ & $\begin{array}{l}\text { Marketing } \\
\text { and Outreach } \\
\text { (end-users) }\end{array}$ \\
\hline $\begin{array}{l}\text { Transportation } \\
\text { Sector }\end{array}$ & & $\begin{array}{l}\text { Hydrogen: Codes } \\
\text { and Standards } \\
\text { Hydrogen: } \\
\text { Distributed Energy } \\
\text { Fuel Cell Systems } \\
\text { Hydrogen: } \\
\text { Education and } \\
\text { Outreach } \\
\text { Biomass: } \\
\text { Thermochemical } \\
\text { Platform (economic } \\
\text { analysis) } \\
\text { Biomass: } \\
\text { Bioconversion } \\
\text { Platform R\&D } \\
\text { (economic analysis) }\end{array}$ & $\begin{array}{l}\text { FreedomCAR: Fuel } \\
\text { Partnerships with } \\
\text { auto companies }\end{array}$ & $\begin{array}{l}\text { FreedomCAR: Clean } \\
\text { Cities (e.g. ethanol } \\
\text { infrastructure) }\end{array}$ & $\begin{array}{l}\text { Biomass: } \\
\text { Integration of } \\
\text { Biorefinery } \\
\text { Technologies } \\
\text { (partnerships) } \\
\text { Biomass: } \\
\text { Product } \\
\text { Development } \\
\text { FreedomCAR: } \\
\text { Clean Cities } \\
\text { (partnerships) } \\
\text { FreedomCAR: } \\
\text { Advanced Vehicle } \\
\text { Competitions } \\
\text { Biomass: } \\
\text { Regional } \\
\text { Feedstock } \\
\text { Partners (Ag) } \\
\text { Outreach } \\
\text { Hydrogen: } \\
\text { Distributed Energy } \\
\text { Fuel Cell Systems }\end{array}$ & $\begin{array}{l}\text { Biomass: Integration } \\
\text { of Biorefinery } \\
\text { Technologies (TA) } \\
\text { FreedomCAR: Clean } \\
\text { Cities (training and } \\
\text { TA) } \\
\text { FreedomCAR: } \\
\text { GATE } \\
\text { Solar: SAI-Solar } \\
\text { Challenge }\end{array}$ & $\begin{array}{l}\text { Biomass: } \\
\text { Education and } \\
\text { Outreach } \\
\text { Biomass: } \\
\text { Buy Bio } \\
\text { Initiative }\end{array}$ \\
\hline $\begin{array}{l}\text { Utilities/ } \\
\text { Independent } \\
\text { Power Producers }\end{array}$ & & & & $\begin{array}{l}\text { Wind: Technology } \\
\text { Application - Systems } \\
\text { Integration and } \\
\text { Technology Acceptance }\end{array}$ & $\begin{array}{l}\text { Wind: Wind } \\
\text { Powering America, } \\
\text { (e.g., wind project } \\
\text { analysis) }\end{array}$ & $\begin{array}{l}\text { Wind: Wind } \\
\text { Powering America } \\
\text { (e.g., TA tools, } \\
\text { guidebooks) } \\
\text { Solar: SAl- } \\
\text { Technology } \\
\text { Acceptance }\end{array}$ & \\
\hline
\end{tabular}




\begin{tabular}{|c|c|c|c|c|c|c|c|}
\hline $\begin{array}{l}\begin{array}{r}\text { Stage-Avenue } \\
\text { (Prelim } \\
\text { Audience) }\end{array} \\
\text { Target } \\
\text { Sector } \\
\text { (Modeling) }\end{array}$ & $\begin{array}{l}\text { Data } \\
\text { Gathering/ } \\
\text { Market } \\
\text { Research (In } \\
\text { support of } \\
\text { R\&D) }\end{array}$ & $\begin{array}{l}\text { Advanced Market } \\
\text { Preparation and } \\
\text { Infrastructure } \\
\text { Development (R\& D } \\
\text { stage) }\end{array}$ & $\begin{array}{l}\text { Identifying } \\
\text { Promising } \\
\text { Technologies (In } \\
\text { support of } \\
\text { deployment) }\end{array}$ & $\begin{array}{l}\text { Public Infrastructure } \\
\text { and Policy, Regulation }\end{array}$ & $\begin{array}{l}\text { Manufacturing } \\
\text { and Business } \\
\text { Infrastructure }\end{array}$ & $\begin{array}{l}\text { Technology } \\
\text { Adoption Supports } \\
\text { ("knowledge } \\
\text { community" and } \\
\text { end-users) }\end{array}$ & $\begin{array}{l}\text { Marketing } \\
\text { and Outreach } \\
\text { (end-users) }\end{array}$ \\
\hline $\begin{array}{l}\text { Public Sector } \\
\text { State and Local } \\
\text { Governments } \\
\text { (may also be } \\
\text { included in } \\
\text { Commercial, } \\
\text { Residential, and } \\
\text { Transportation } \\
\text { Sectors) } \\
\end{array}$ & & $\begin{array}{l}\text { Hydrogen: } \\
\text { Education and } \\
\text { Outreach }\end{array}$ & & $\begin{array}{l}\text { FreedomCAR: Clean } \\
\text { Cities (e.g. ethanol } \\
\text { infrastructure) } \\
\text { FEMP: Federal Fleet }\end{array}$ & & $\begin{array}{l}\text { WIP: } \\
\text { AssistanceTribal } \\
\text { Energy Program } \\
\text { WIP: State Energy } \\
\text { Program } \\
\text { FEMP: Technical } \\
\text { Guidance and } \\
\text { Assistance }\end{array}$ & \\
\hline \multicolumn{8}{|l|}{ Agriculture } \\
\hline Other & & & & & & & \\
\hline
\end{tabular}


Each year, EERE develops a projection of benefits that represents the potential outcomes and advantages of the EERE program objectives. As previously discussed, the EERE TD portfolio is extremely diverse, incorporating activities throughout the range of research, development, and deployment. Figure 3 displays the deployment activities that are ideally included, even in the early stages of product development, although modeling these separately may be difficult at this stage. For those products that are primarily in the early R\&D stage, the issue of attribution must be addressed if the program attempts to allocate benefits to the different activities (e.g., R\&D versus deployment). This can be difficult to calculate, and sometimes results in somewhat arbitrary attributionsdeployment relies on R\&D to develop a product, and R\&D relies on deployment to prepare the market and promote the product once it has been developed. Additionally, attribution of benefits can be complicated by circumstances, such as collaboration with industry in the R\&D phase. This type of activity benefits the R\&D by allowing for cost-sharing, in addition to increasing the chances of commercialization because the product then will have a form of industry acceptance or buy-in. However, determining the net benefits attributable to the government-sponsored portion of the R\&D remains difficult.

EERE contains three general approaches to modeling deployment programs for its annual integrated benefit-estimation process, which include:

1) modeling R\&D and deployment jointly within the integrated modeling framework

2) modeling deployment within the integrated-modeling framework with modifications specific to deployment activity

3) off-line (non-integrated) approaches.

Integrated Framework

To integrate the EERE benefits estimates, the program employs two energyeconomy models-NEMS-GPRA and MARKAL-GPRA. The MARKAL-GPRA model is a modified version of the MARKet ALlocation (MARKAL) model, which is a technology-driven linear-optimization model of the U.S. energy system that runs in five-year intervals over a 50-year projection period. MARKAL provides a framework to evaluate all resource and technology options within the context of the entire energy/materials system, and captures the market interaction among fuels to meet demands (e.g., competition between gas and coal for electric generation). The model unambiguously tracks the vintage structure of all capital stock in the economy that produces, transports, transforms, or uses energy.

Because EERE uses NEMS-GPRA to estimate the midterm benefits of its programs, and MARKAL-GPRA to estimate the long-term benefits of its 
programs, this report examines the NEMS-GPRA framework in more depth. This was done because deployment program benefits are more suitably modeled in the near-term or midterm rather than the long-term. Some of the longer-term deployment programs, created jointly with R\&D, are appropriately modeled in MARKAL. For these programs, the modeling procedure within MARKAL would primarily involve adjusting cost and performance parameters in a similar manner to the approach taken when modeling the program in NEMS.

NEMS Overview

To understand the modeling approaches taken by various EERE programs, a brief discussion will be conducted regarding the overall structure of the National Energy Modeling System (NEMS). This system provides a basis for the integrated modeling framework.

NEMS is an energy-economy modeling system of U.S. energy markets for the midterm period (through 2030). Overall, NEMS represents the behavior of energy markets and the respective interactions with the U.S. economy. The model achieves a supply/demand balance in the end-use demand regions. This balance is accomplished by solving for the prices of each energy product that will balance the quantities producers are willing to supply with the quantities consumers wish to consume. The system reflects market economics, industry structure, and existing energy policies and regulations, which influence market behavior. NEMS projects the production, imports, conversion, consumption, and prices of energy, subject to assumptions on macroeconomic and financial factors, world-energy markets, resource availability and costs, behavioral and technological choice criteria, cost and performance characteristics of energy technologies, and demographics (EIA 2003). For many of the programs, R\&D and deployment activities are modeled within NEMS by modifying parameters related to behavioral- and technological-choice criteria as well as cost and performance characteristics of the energy technologies.

NEMS consists of four supply modules (oil and gas, natural gas transmission and distribution, coal, and renewable fuels), two conversion modules (electricity and petroleum refineries), four end-use demand modules (residential, commercial, transportation, and industrial), one module to simulate energy/economy interactions (macroeconomic activity), one module to simulate world oil markets (international energy activity), and one module that provides the mechanism to achieve a general market equilibrium among all the other modules (integrating module). Additional "add-on" sub-modules within the modules are available, such as equipment-choice modules and the distributed-generation/CHP sub-module included within the residential and commercial modules (see Appendix C).

The version of NEMS used by EERE for its GPRA analysis has been modified to include a representation of hydrogen supply for consumption by end-use markets, such as vehicles. The new hydrogen market module (HMM) approximates 
production and delivery pathways for hydrogen based on a suite of technology options. Figure 4 depicts the high-level structure of NEMS used by EERE for its GPRA analysis.

The modularity of the NEMS design provides the flexibility for each component of the U.S. energy system, and the capability to execute the modules individually or in collections of modules. This, in turn, expedites the development and analysis of the separate component modules. EERE modelers will typically work with specific modules, depending on the sector targeted by the program (See Table 3). EERE projects will potentially impact all demand modules as well as the Electricity Market Conversion Module, Hydrogen Market Module, and the Renewable Fuels Supply Module (see circled modules in Figure 4). Expanded detail on the way each module is structured can be found in Appendix $C$ of this document.

\section{National Energy Modeling System Used by EERE (NEMS-GPRA)}

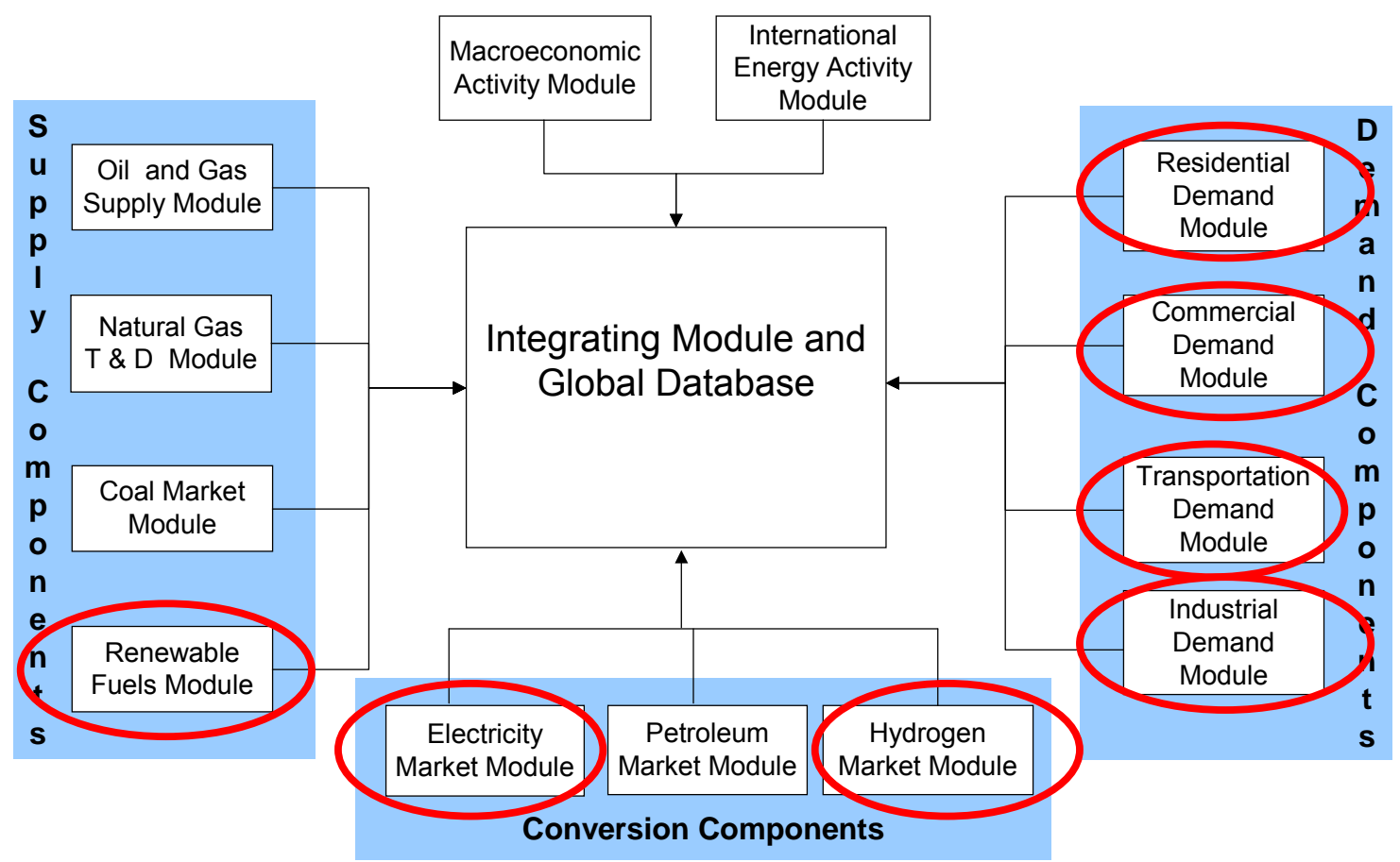

Figure 4. National Energy Modeling System ${ }^{11}$

Modeling R\&D and Deployment J ointly

For the programs that consider the relatively long-term R\&D and future technology development as the foundation of the programs (e.g., Hydrogen,

\footnotetext{
${ }^{11}$ As modified for EERE GPRA use. The diagram provided by Frances Wood, OnLocation, which is a modified version from original NEMS documentation, U.S. Department of Energy, Report \#: DOE/EIA-0581(2003). Released March 4, 2003. Downloadable from the Internet (09/2007) at: http://www.eia.doe.gov/oiaf/aeo/overview/summary_tbl.html.
} 
Biomass, FreedomCAR/Vehicles), analysts focus benefit estimates on an allencompassing R\&D portfolio that includes particular deployment elements. Consequently, the deployment activities are implicitly modeled as part of the overall R\&D program. Although some efforts have been made to develop methods to measure the value of deployment to the overall programs, the programs do not have much incentive to expend the effort of extracting the net benefit from deployment activities by modeling the actions separately from R\&D. The following briefly describes the programs that model R\&D jointly with deployment, and the approach taken to model these programs. In all cases, the foci of discussion is on the approach, rather than the specific numeric modeling inputs or outputs, or the empirical justification upon which modeling assumptions and adjustments are made. More information on these aspects of the models is available in EERE's FY 2008 GPRA Benefits Estimates report, which documents modeling assumptions.

\section{Hydrogen, Fuel Cells, and Infrastructure Technologies}

Currently, Hydrogen, Fuel Cells, and Infrastructure Technologies (HFCIT) are definitively included in NEMS-GPRA. The new Hydrogen Market Model (HMM) endogenously calculates the price of hydrogen based on production and delivery costs, as impacted by the HFCIT. The R\&D technology goals are modeled, but no separate representation of the deployment programs is immediately identified. The deployment activities (e.g., Education/Codes and Standard types of activities) are necessary for the overall successful implementation of the hydrogen technology (and the model inherently assumes the activities are successful), and these activities cannot be unbundled from R\&D within the model.

Cost and performance parameters are developed for future hydrogen-powered vehicles and fuel cells, which are then modeled in competition with other technologies in NEMS. Outside of the NEMS framework, analysts model a type of cost-benefit trade-off between technological characteristics, such as hydrogen purity and degradation, and the cost of the specific technology. These results drive the cost and performance inputs for NEMS. The vehicle-choice sub-module in NEMS is based on a modified discrete-choice structure. In this framework, the probability that a consumer will choose a particular type of vehicle depends upon the price of the vehicle, fuel economy, and other attributes. ${ }^{12}$ These other attributes include: 1) range (miles between refueling), 2) maintenance cost and acceleration, 3) top speed, and 4) luggage space.

The Distributed Generation (DG) and CHP sub-module in the NEMS commercialbuilding module projects electricity generation, fuel consumption, and water and space heating supplied by 10 distributed generation technologies. The characterized technologies include: photovoltaics, natural gas (fuel cells, reciprocating engines, turbines and microturbines), diesel engines, coal-fired

\footnotetext{
${ }^{12}$ Note that there are no analogous parameters for "other attributes" within MARKAL.
} 
CHP, municipal solid waste and wood generators, and hydroelectric technology. The penetration rates for the generation technologies are dependent upon a modified payback criterion-using a cash-flow analysis covering 30 years from the date of the investment. Penetration rates into new buildings can be high as $30 \%$ in a single year when the payback is one year. The penetration into existing floor space is limited in the model to reflect the much higher cost and complexity of installing these systems in existing buildings. Learning-cost effects are also included in the projection of market penetration for several of the distributed generation technologies, including photovoltaics, fuel cells, and microturbine generators. The learning-cost functions are endogenous to the model and depend upon cumulative shipments. The derived learning-cost feature in the DG sub-module, for example, could represent the influence of bulk-purchase governmental programs that would lower overall manufacturing costs and increase subsequent market penetration. Demonstratively, hydrogen prices are calculated endogenously within the HMM.

The DG sub-module in the NEMS residential module is very similar in structure to that used in the NEMS commercial module. In the residential sector, this submodule allows fuel cells and solar photovoltaic systems to compete for on-site electricity generation. As with the commercial module, the penetration rates of these systems are computed through the use of a cash-flow formulation, but with different treatment of taxes and depreciation. If feasible, the electricity generated from these systems is deducted from total household use, or may be sold back to the grid. Similar to the commercial sector, the residential DG sub-module incorporates an endogenous learning-cost element, with hydrogen prices calculated endogenously within the HMM.

Hydrogen program managers emphasize the importance of the deployment component of the programs; however, no method is available to assign a specific value to these activities currently. To address some of the deployment-benefit issues, two major efforts may be used-a customer choice model and an agentbased model- to address specific policy questions, including issues related to deployment benefits.

\section{Biomass Technologies}

The Biomass Program does not currently model deployment activities explicitly and distinctly from its R\&D activities, but assumes these benefits are tacitly captured in its overall benefits estimates. The program provides cost and supply curves based on outputs from other models, in which cost and year of deployment are incorporated.

A scenario model has been created in the program to assist in the assessment of the impacts the program might encounter from demonstration activities. By modifying assumptions about investment risk within the model, the program can reveal the impact of a demonstration project, under the assumption that this type 
of deployment activity would reduce the risk involved. The Biomass Program develops three alternative returns on investment (ROI) estimates, one with conservative investment assumptions, one with moderate assumptions, and one assuming an aggressive investment strategy. The ROI is modeled to be high initially and declines as the cellulosic industry develops. An average-risk premium is developed as a function of cellulosic production capacity for each of the scenarios.

Additionally, the program is investigating farmer and investor behavior in an attempt to understand the reasons a farmer may switch crops, along with how investors behave.

\section{FreedomCAR and Vehicle Technologies}

To capture savings from FreedomCAR technologies in the integrated-modeling process, cost and performance parameters for vehicle subgroups are developed for future products and modeled within NEMS. This process is similar to how the hydrogen benefits are estimated within the transportation module.

For the GPRA modeling, the working assumption is that the "average" buyer will likely desire a three-year payback for a non-conventional, advanced-technology vehicle that achieves higher fuel efficiency. As reported in the documentation for the FY2008 benefits estimate, this payback assumption was based on a 2002 study of CAFÉ standards by the National Academy of Sciences. For the purposes of the GPRA, program success was assumed to occur when a manufacturer could produce a vehicle that could be sold for an incremental price equal to the fuel-cost savings in the first three years of the vehicle's use. The rate of improvement over time in cost and performance varies by type of vehicle and technology. In terms of the NEMS modeling, this assumption leads to different year that certain technologies and vehicle types would be introduced into the market (the actual year of introduction occurs when the incremental vehicle cost is $50 \%$ above the three-year fuel cost reduction).

Within the vehicle choice model in NEMS, the logit functions contain a number of terms to represent various attributes of vehicles (e.g., size, acceleration, fuel economy). As these functions were calibrated to historical market shares, a "constant" term ${ }^{13}$ represented all other attributes of a vehicle not categorically included by the specific variables. For most "alternative" vehicle types (the focus of EERE's FreedomCAR program), these constant terms are negative. The negative values indicate that even in the presence of many favorable attributes, (high efficiency or acceptable acceleration), the market shares predicted by the model will be low.

\footnotetext{
${ }^{13}$ Note that there is no equivalent constant term in MARKAL.
} 
For the GPRA case representing deployment efforts focused on end-users, the constant terms are reduced in absolute value. These adjustments spur the increase in the alternative vehicle market share. The rationale for these adjustments is that future improvements in alternative-fuel vehicles will begin to offset the negative bias currently existing in the market for these technologies. In part, the reduction of this negative bias would be accomplished by efforts to promote alternative-fuel vehicles in fleets maintained by federal and other governmental units (e.g., through the Clean Cities activities).

The primary assumption was that informative advertising of the fuel-economy benefits would be undertaken by the manufacturers. Implicit in the logit framework used in the NEMS transportation module is a measure that can be interpreted as an average discount rate (i.e., trade-off between vehicle cost and fuel economy, when adjusted for average miles driven and the price per gallon of fuel). This measure can be inferred from the ratio of the model coefficients on the vehicle cost and fuel economy. Apart from manufacturer advertising, the impact of any future governmental informational activities to increase the market sensitivity to fuel-economy benefits could be modeled by adjusting the coefficient on fuel economy. Unfortunately, however, no clear empirical foundation exists that could be exploited to link dollars spent (or any other measure of "information") and this coefficient.

At one time, the Clean Cities deployment activity was defined separately in the modeling framework (when EERE deployment activities were concentrated within the Weatherization and Intergovernmental Program), and the modelers have experimented with various options to separately represent the Clean Cities activity. One method employed was to increase the shares of alternative-fuel vehicles (AFVs) for the fleet vehicles based on estimated Clean Cities' impact, as provided by program analysts. The modelers also experimented with other deployment representations, including increasing the share of E85 ${ }^{14}$ used in flexfuel vehicles, changing the discount rate and evaluation period used for energyefficient vehicle technologies, and reducing the prices of hybrid vehicles to reflect purchase incentives provided by Clean Cities. The primary difficulty faced by the analysts was the determination of the expected impact of the program when its relatively small budget was taken into account. The analysts also did not fully address the issue of the method of attributing savings to DOE when Clean Cities' partners also have a substantial role in the implementation of the activity. At this time, the program is providing integrated (R\&D and deployment) modeling inputs. Consequently, the Clean Cities activity is not modeled separately.

\section{Modeling Deployment Activities within the NEMS Framework}

The second group of programs has deployment modeling built around the integrated NEMS-GPRA framework. These include Solar, Wind, and some of the

\footnotetext{
${ }^{14}$ Alcohol fuel mixture that typically contains a mixture of up to $85 \%$ denatured fuel ethanol.
} 
Buildings activities. These programs have found or are in the process of developing methods to modify the NEMS modules to account for deployment impacts. However, all analysts report flaws with this methodology, including the lack of an empirical, and sometimes theoretical, basis for modifying certain parameters. The following briefly describes these modeling activities. The focus remains on the overall approach-rather than the specific numeric modeling inputs or outputs - or the empirical justification upon which modeling assumptions and adjustments are made. In many cases, the modeling assumptions and adjustments have not yet been developed. For the Buildings Technologies, further information on the basis for various modeling assumptions is available in EERE's FY 2008 GPRA Benefits Estimates report.

\section{Solar Energy Technologies}

The Solar Program provides modifications to the technology characteristics for the photovoltaic (PV, for distributed and central systems) and concentrating solar power (CSP) technologies. Additionally, the Solar Program provides extensive revisions to the Annual Energy Outlook (AEO) baseline, ${ }^{15}$ including; 1 ) revising the projected PV cost for residential and commercial PV systems, 2) increasing the average residential and commercial building PV system size, 3) increasing the maximum share of residential and commercial buildings with solar access, including a declining PV buy-down program in California, and 4) modifying the adoption rate of distributed generation technologies.

For the PV characteristics, a set of technology-cost projections was produced based on a range of technology-cost projections under different funding and policy assumptions developed by a multi-lab, multi-technology team and cost projections developed for the U.S. PV Industry Roadmap under various funding and policy assumptions. CSP technology characteristics were based on data from California, and then adjusted by region to account for variations in solar insulation, which changes the capacity and storage requirements.

Additionally, the Solar Program is funding activities outside the GPRA framework, developing a deployment-model series for different systems: wind, solar, and CSP. These models will allow for the analysis of the impact of different rate structures and policy changes. Other tools, such as PVFlex, are used to investigate questions, such as what happens if a large quantity of solar is introduced to the electricity grid.

For both NEMS and MARKAL, the R\&D elements of the Solar Energy Technologies Program are modeled with a declining-cost curve for solar technologies over time.

\footnotetext{
${ }^{15}$ The GPRA baseline case is designed to represent a world without DOE-Applied R\&D. For most programs, the most recent AEO reference case is used as a starting point for developing this baseline; however, programs sometimes modify the reference-case assumptions.
} 


\section{Wind Technologies}

As the Wind Technologies portfolio expands to include a greater percentage of deployment activities, the program is currently attempting to improve the modeling of these activities. Several options are being explored to allow for deployment activity impact measurement, including modifying assumptions related to inter- or intra-region transmission, modification of regional capacity cost-escalation curves, and the impact of/on state Renewable Portfolio Standards. The approaches under consideration are summarized below:

- Within NEMS, the expense of installing the next megawatt of wind is based on a regionally based cost multiplier and capacity curve, which is currently built, in part, on interconnection costs. One option is to modify the default resourcemultiplier curve to show the impact of program-deployment activities.

- To measure the impact of state-based Renewable Portfolio Standards (RPS), one option may be to apply a percentage of the RPS benefits that are already hard-wired within NEMS to program activities.

- Other options are also being explored to model the impact of Wind's deployment activities, including capturing potential impacts on grid reliability and capacity, possibly through the inter-regional transmission-flow algorithm.

Further detail on possible modeling approaches related to the Wind Technologies Program is included later in this report (see section, "Incorporating Deployment Programs into NEMS"). Currently, the R\&D elements of the Wind Technologies Program are modeled within NEMS and MARKAL by adjusting cost and capacity factors to reflect an expansion of wind-power generation. A trajectory for various classes of wind by region is also provided as a model input.

\section{Building Technologies}

Within the Building Technologies Program, a variety of methods are currently used to model the impact of deployment activities. Some of these activities are developed within the integrated modeling framework and the methods used are described below.

Residential R\&D: Building America

The Residential R\&D Building America Project contains both R\&D and deployment activities, which are modeled in combination. Currently, this activity is modeled within the NEMS residential module by altering the cost and performance parameters of the two highest-efficiency residential-shell packages, which represent the R\&D activity. The market penetration of the deployment activities are modeled by altering the choice parameters (Beta1 coefficients), which increases the market penetration of the supported technologies.

\section{ENERGY STAR}

The modeling of ENERGY STAR technologies depends in part on technology. For Compact Fluorescents (CFL), Windows, and Home Performance with ENERGY 
STAR, technology characteristics-including performance parameters and cost estimates-are provided to the integrated modeling process. Estimated penetration curves and energy savings are also included. For the ENERGY STAR appliances, the Beta1 parameters are adjusted to yield increased market share of the ENERGY STAR-rated appliances within the residential module. Modifying the Beta1 parameter implicitly lowers the average discount rate.

\section{Off-Line (Non-Integrated) Modeling Approaches}

The third group of programs includes deployment activities that the program modelers were not able to model with conventional cost and performance inputs required for the integrated modeling process (i.e., not modeled within NEMS or MARKAL). Many of these programs (Industrial, FEMP, WIP, and some of Buildings) model the programs off-line and then submit cost, market penetration, performance, and sometimes savings estimates into the integrated process.

These off-line estimates will eventually receive what is commonly referred to as a "hair-cut" (percentage reduction to savings) in an attempt to account for overlap and integration with other programs after the fact. The following section briefly summarizes the modeling approaches taken by these programs. The specific details involved in developing inputs and energy savings for the various deployment activities, which are modeled off-line, are available in EERE's $F Y$ 2008 GPRA Benefits Estimates report, which documents modeling assumptions for each program.

\section{Building Technologies}

Within the Builting Technology program, a variety of methods are currently used to model the impact of deployment activities. Most of the efforts are developed outside the integrated-modeling framework. The methods used are described below.

\section{Commercial R\&D}

The Commercial R\&D Project contains both R\&D and deployment-like activities, which are modeled together. Although this program is similar to the Residential R\&D Program - targeting whole-building energy systems and designs in the commercial sector-it cannot be modeled within NEMS in an analogous manner to the residential program. A method to alter the cost and performance parameters of building shell packages within the commercial module is not currently available. Thus, inputs related to potential commercial-building load reductions impacted by this program, and market-penetration curves, are provided to the integrated-modeling process as "off-line" estimates.

\section{Equipment Standards and Analysis}

For the Equipment Standards Subprogram, estimates of energy savings are produced in a spreadsheet based on preliminary estimates of energy savings that were developed as part of the FY 2005 priority-setting process. Rather than 
estimated, savings from each product, an estimate of the total savings from all products is reported. Prior to the actual detailed analysis of a specific product, no definitive method is available to select the most appropriate level of the standard from which to estimate energy savings. Furthermore, publishing initial assumptions for specific products in this analysis may inappropriately suggest final rulemakings that appear to be endorsed by DOE. Avoiding such an outcome is important. Therefore, a reasonable method of generating and presenting the estimated energy savings from this project involves the use of preliminary analyses done for the 2005 priority-setting process, and subsequently aggregating the savings across all products. Products considered within the analysis include those for which rulemaking activities are expected from 2008 through 2011.

As part of the development of the spreadsheets used in the FY 2005 prioritysetting process, the energy-savings spreadsheets often contain several potential efficiency levels that may be considered for a standard. For the GPRA process, the standard level chosen generally tends to the mid to lower range of these potential levels (i.e., to generate a conservative level of savings). When the product is covered by the ENERGY STAR program, the ENERGY STAR efficiency level is typically selected. These estimates are adjusted to account for modeling integration, and then subtracted from the base-consumption levels within the modeling framework.

\section{Building Energy Codes}

GPRA estimates for this activity are based on the future development and adoption of more-stringent building-energy codes for both the residential and commercial sectors. The estimates are built up from the state level to better link changes in the codes with variations in climates and differences among states in the adoption and enforcement of building codes.

The building energy-codes deployment activities impact both adoption and compliance with national model codes (e.g., IECC 2006 Standard 90.1, ASHRAE Standard 90.1). The availability of compliance software and other training assistance is assumed to accelerate the adoption of standards by states and local jurisdictions. Based on the historical experience of the 1990's, states are expected to adopt standards from 3 to 10 years earlier than without the existence of the DOE training and assistance activities. These activities are also postulated to have a large impact on the compliance with changes in the code, measured by the percentage of potential savings attainable from one edition of the code to the next.

Rebuild America

In the past two years (FY07 and FY08 GPRA), Rebuild America has been modeled as an acceleration of the Commercial R\&D project. For the FY09 GPRA, the new initiatives under this activity are modeled as follows: 
- EnergySmart Schools and EnergySmart Hospitals: Inputs to the modeling effort include estimated load reductions and penetration rates, which assume an acceleration of the Commercial R\&D activities for the education and healthcare buildings.

- Building Application Centers: Inputs to the modeling effort include estimated load reductions and penetration rates, which assume an increase of $1 \%$ over the expected penetration of Commercial R\&D in building types other than education and healthcare.

- Advanced Code Initiative: Inputs were modeled jointly with the other codes activities.

- National Builders Challenge: Inputs to the modeling effort assumed that this activity assisted in the acceleration of the deployment of Residential R\&D: Building America.

- Commercial Lighting Challenge: Inputs to the modeling effort included estimated lighting savings and a forecast of penetration rates for the applicable building types.

- A number of ENERGY STAR products cannot be easily modeled within NEMS, and are modeled using off-line estimated load reductions and market-penetration estimates. These include ENERGY STAR Windows, CFLs, Solid-State Lighting, and Home Performance with ENERGY STAR.

\section{Industrial Technologies}

As the adoption process of new technologies is not explicitly modeled within the industrial module of NEMS, the Industrial Technologies Program (ITP) is currently unable to model its deployment programs in the NEMS/MARKAL integrated framework. ITP does, however, provide penetration and performance curves for the integrated-modeling process, which are estimated outside the NEMS framework, or "off-line," for the specific technologies impacted. These off-line estimates are based on information obtained from the annual (with two-year lag) evaluation of technology commercialization-tracking impacts-outcome assessment of the technology delivery efforts. ITP analyses by sector have focused on assessing the industrial processes where energy is actually consumed, in addition to understanding the current and best practices for each proposed technology. The participation of industry experts in this process is critical to refining the estimates.

ITP has an extensive evaluation system in place that continually assesses the progress or performance metrics of its deployment programs in terms of quantifiable measures. These measures include numbers of audits performed, the number of attendees at a training workshop, number of new firms participating in program, etc. The metrics are summarized quarterly, and a report is published annually that includes measurements, which are translated into energy metrics that form the basis of annual budget benefits estimates. 
Because this program has been unable to directly model its programs in NEMS, it has invested in a new integrated-modeling approach based on the Consolidated Impacts Modeling System (CIMS). The current plan is to adapt CIMS to accommodate U.S. industrial technologies that would explicitly account for energy usage in a more dynamic framework.

\section{Federal Energy Management Program (FEMP)}

FEMP's benefits estimates are produced outside the NEMS/MARKAL modeling framework. FEMP uses historical data from the previous five years to develop an estimate of energy savings per program dollar for the Project Financing, Technical Assistance, and DOE Specific Investments activities. The historical figures are then multiplied by the corresponding budget request to determine the potential forecasted benefits stream. This figure is then adjusted to $80 \%$ of the estimate based on the average performance of the fiscal years 2002 through 2005 , which ensures the projected savings estimates are conservative and attainable. However, the private investment stemming from shared energysavings programs is not incorporated, which is one of the reasons for significant variation from year to year in terms of the energy savings per program dollar. Federal fleet-vehicle use and the influence on accelerating market introduction of alternative-fuel vehicles are currently not modeled.

\section{Weatherization and Intergovernmental Program}

Within the GPRA framework, WIP's benefits estimates are produced outside the NEMS/MARKAL modeling framework. These "offline" estimates are developed as described below.

\section{Weatherization Assistance Program (WAP)}

WAP was characterized based on an estimated level of savings per household, cost to weatherize each household, budget request, leveraged funds, and an assumed life expectancy of 15 years for weatherization measures.

The figures representing savings per household were calculated from information provided in the1997 ORNL meta-evaluation report (Berry et al 1997), the ORNL Meeting the Challenge report (Schweitzer and Eisenberg 2000), and special tabulations from the 1997 "Residential Energy Consumption Survey" (Eisenberg 2001b). These analyses provided two levels of weatherization: regular measures and Plus measures. Of the units estimated to be weatherized, WIP speculated that $50 \%$ would have the higher savings rates associated with Weatherization Plus (Schweitzer and Eisenberg 2000).

To develop energy savings by building type, WIP evaluated historical Weatherization Project data (Berry et al 1997) concerning the types of households weatherized. 


\section{State Energy Program (SEP)}

An evaluation of the activities funded by SEP during the 2002 program year (Schweitzer and Tonn 2005) and on technical potential calculations that were developed as part of a market analysis funded by WIP (Arent et al 2006) provided the foundation for the SEP's GPRA estimates. For the SEP Formula Grants Program, 12 activities (referred to in Schweitzer and Tonn [2005] as project areas) supported by SEP were selected to represent the traditional grant programs. The following activities account for approximately $94.8 \%$ of the total estimated energy savings as reported in Schweitzer and Tonn (2005): Codes and Standards, Energy Audits, Rating and Labeling, Workshops/Training, Incentives, Retrofits, Loans and Grants, Technical Assistance, Traffic Signals, Tax Credits, Procurement, and Renewable Energy. The evaluation authors developed a series of indicator measurements for a number of activities traditionally funded by SEP's formula grants, which were applied to future expectations of the grant program.

For the competitive grants, energy-savings metrics were developed for each sector, based on the technical potential calculations developed in Arent et al. (2006). For the SEP competitive grants, the energy savings per dollar invested developed by sector within the WIP market analysis were used to represent that activity's energy savings.

\section{Tribal Energy Program}

For the GPRA modeling effort, a forecast of the megawatt capacity added each year, along with the capacity factor and percentage wind versus biomass, is provided to the modeling effort.

\section{Asia Pacific Partnership}

The Asia Pacific Partnership's energy savings are not currently modled because these savings are expected to accrue outside the U.S. 
Incorporating Deployment Programs into NEMS

In general, the process of modeling deployment activities in the NEMS integrated framework involves identifying the targeted audience of the program and which sector module will be impacted within NEMS. Each module is structured differently, but most will include some form of cost and financing sub-module as well as an equipment choice sub-module (where choices are made based on criteria, such as cost and performance). Frequently, one can point to a theoretical basis to justify modifying various parameters within these sub-modules to reflect deployment activities. However, modelers often lack the empirical basis to determine exactly the manner or degree these parameters should be modified. Figure 5 provides a comprehensive view of the NEMS modules impacted by EERE deployment activities and some of the corresponding parameters (generically described). Figure 5 also provides a list of approaches some programs have taken or could take to obtain an empirical basis for modifying these parameters.

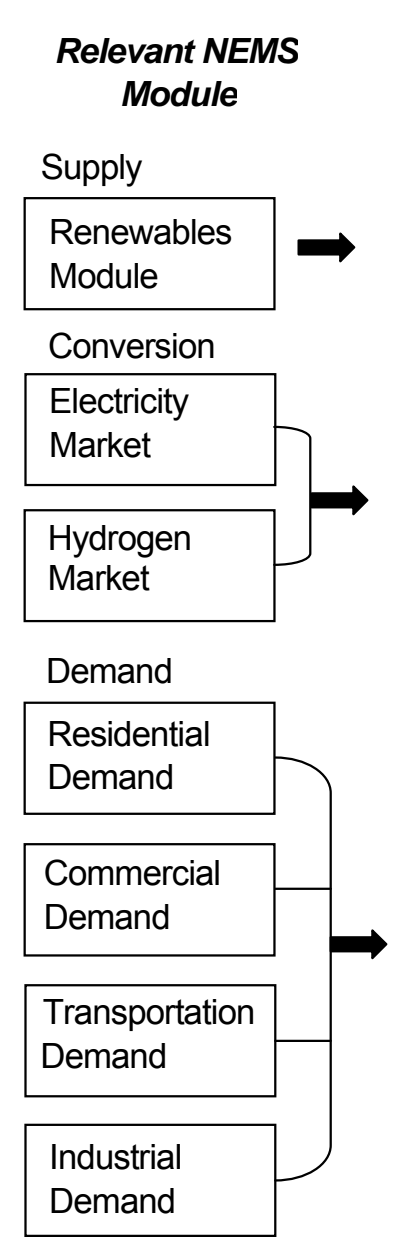

\section{Parameters Impacted by Deployment Activities}

\section{Capital Costs; Rate of Return; Input (fuel) Costs}

Finance factors; Costs; Multipliers

Costs of technologies;

Discount rates/ Hurdle rates; Risk premium factors/consumer time preference distribution;

Penetration/ Diffusion Curves; Multipliers

\section{Empirical Foundation}

Evaluation studies; Mark et/consumer surveys; Participant surveys; Literature reviews; Econometric studies;

Data tracking;

Focus groups; "Expert" opinions

Figure 5. Incorporating Deployment Activities into NEMS 
To illustrate the process of integrating various deployment activities into NEMS, this report examines three programs' activities targeting three separate sectors. These programs include deployment activities taking place in the Wind Program, the Biomass Program, and the Building Technologies Program.

\section{Wind Technologies Example}

The Wind Program is concentrated on reducing risks that undermine the growth potential of wind energy in the United States by 1) focusing on improving cost, performance, and reliability of large-scale land-based technologies, 2) facilitating wind energy's rapid market expansion by anticipating and addressing potential barriers (e.g., integration into the electric grid, siting, permitting, environmental issues), and 3) investigating wind energy's application to other areas from offshore wind technology to distributed and community-owned wind projects.

\section{Identifying the Relevant NEMS Module}

Within NEMS, the modeling of wind-electricity generation is contained in two modules: 1) the renewable fuels module (RFM), and 2) the Electricity Market Module (EMM). Within the RFM, the Wind Energy Sub-module (WES) contains information on U.S. regional wind-energy resources and provides estimates of wind supplies by region and cost. The WES sub-module quantifies regional wind supplies by differences in 1) average wind speed, and 2) distances from existing transmission lines.

The common technology values that determine how wind competes with other electricity-supply technologies are contained in the EMM. These values include: 1) overnight capital cost, 2) fixed operations and maintenance costs, 3) generation subsidies, 4) construction profiles, and 5) optimism and learning characteristics. This information, along with the data supplied by the WES, is used in the Electricity Capacity Planning (ECP) component of the Electricity Market Module to develop estimates of future wind-generation capacity.

\section{Identifying the Key Parameters}

The key supply and cost parameters in the WES are categorized into three separate cost elements in the RFM/WES elements of NEMS:

\section{1) General Transmission and Distribution (T\&D) Costs}

The costs for all electric-generating technologies (both fossil and renewable) are assigned a constant cost additive to cover transmission and distribution costs. These costs are based upon the historical ratios of construction costs for T\&D, as compared to new generating capacity (as reported to FERC). The costs will vary 
by NERC region. Expressed in 1987 dollars, the costs per kW vary from $\$ 132$ per kW (Northeast) to $\$ 350$ in California.

2) Interconnection Costs

The interconnection costs used in NEMS for wind generation are dependent upon the distance from an existing transmission line. According to EIA, these costs involve the permitting and construction costs of building feeder lines and associated connection equipment from the wind facility to the transmission line. ${ }^{16}$ These costs also were taken from utility reports to FERC and vary slightly by NERC region. Based upon the NEMS documentation for the 2006 AEO, these costs were about $\$ 5 / \mathrm{kW}$ for distances less than 5 miles and about $\$ 10 / \mathrm{kW}$ for distances between 10 and 20 miles.

3) Resource Cost Adjustment Factors

A third type of cost in the NEMS model includes more than transmission costs, but transmission cost is likely the single largest component. Capital costs for generating technologies using wind resources are assumed to increase as a function of exhaustion of most favorable resources.

These increasing costs are modeled as step-function supply curve. The supply curve is represented by a set of "resource cost multipliers" that adjust the costs upward for discrete ranges of increased generation capacity. The size of the ranges and the associated cost increases are judged to vary by region. ${ }^{17}$ The number and combinations of interregional and international trade opportunities in the Electricity Capacity Planning (ECP) are restricted to those areas of the country where bulk-power transfers currently exist.

EIA has recently funded work to update and more rigorously estimate the transmission-related elements that underlie the resource-cost multipliers. The purpose of the work was to "develop a methodology to estimate incremental costs as a function of regional resource utilization." ${ }^{18}$ More specifically, the estimates are designed to indicate, to the extent possible, the incremental transmissionsystem investment required to accommodate additional wind generation from the U.S. resource base in different regions of the country.

This project was conducted through cooperation between Princeton Energy Resource International (PERI) and National Renewable Energy Laboratory (NREL). NREL used Geographic Information System (GIS) modeling of the transmission-related costs of wind development to produce regional-level cost curves for wind development that revise the current Long Term (LT) Multiplier framework employed in NEMS. PERI analyzed dozens of transmission studies

\footnotetext{
${ }^{16}$ Personal communication with Chris Namovicz, EIA, on May 11, 2007.

${ }^{17}$ EIA reports these factors were benchmarked by examination of the underlying factors using regional renewable-energy market and resource assessments of the Northwest Power Planning Council and the California Energy Commission.

${ }^{18}$ The draft report provided to EIA is entitled "Revising Long Term Multipliers in NEMS: Quantifying the Incremental

Transmission Costs Due to Wind Power."
} 
undertaken by utilities, federal power authorities, and various state organizations in its effort to correlate the transmission-upgrade costs and expansion of windelectricity generation. The new set of supply curves now incorporate the interconnection costs discussed in paragraph two above, so that separate treatment of these costs will no longer be a part of NEMS.

Figure 6 illustrates the nature of the supply curve, aggregated for the entire U.S. The report is still in draft form. Consequently, the magnitudes in the figure should be regarded as illustrative. The GIS results are shown as a smooth curve. The step functions show the amounts of wind capacity that could be obtained for the cost multipliers of 1.2, 1.5, and 2.0, compared to the base cost. In comparison to the curves in the current NEMS, the revised estimates show much larger potential wind capacity for costs $20 \%$ or higher above the base costs (representing the most favorable areas for wind).

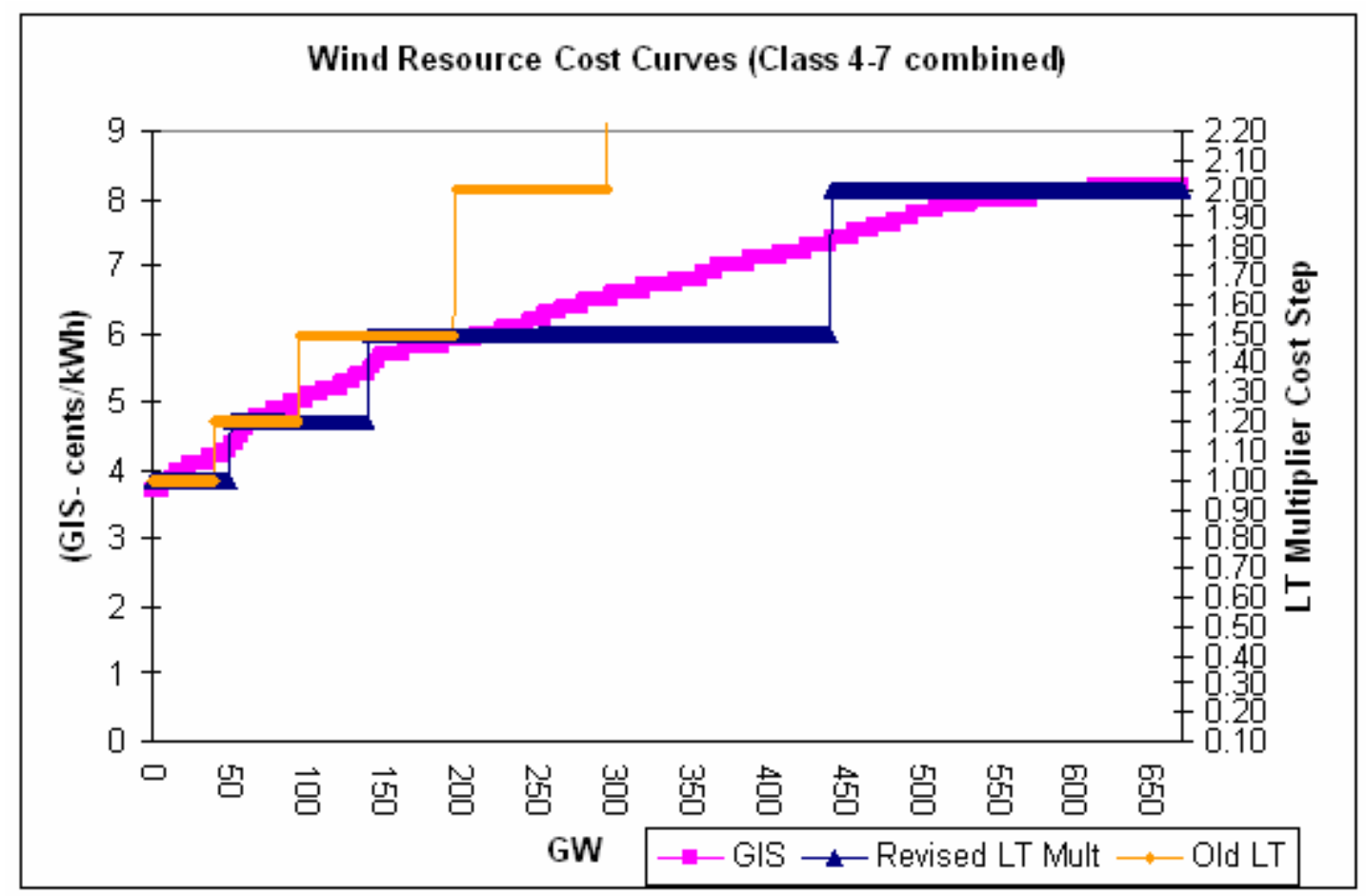

Figure 6. Comparison of GIS model results and revised 1.0-2.0 LT Multiplier Cost Steps $^{19}$

Finding the Empirical Basis

There are a variety of deployment activities currently being undertaken by the Wind Program to accelerate the use of wind-powered electricity generation in the U.S. These deployment activities are designed to reduce a number of market

${ }^{19}$ Source: Draft report by PERI to EIA, "Revising Long Term Multipliers in NEMS: Quantifying the Incremental." 
barriers that affect current and future investment in wind power. While imperfect, the NEMS (and MARKAL) model does contain sufficient detail to allow most of the benefits of these activities to be represented. Table 4 describes these topical areas related to deployment, the relevant portion of NEMS to address the topic, and the suggested analysis to support the parameter changes in NEMS.

Table 4. Summary of Deployment Linkages in NEMS for Wind Generation

\begin{tabular}{|c|c|c|c|c|}
\hline Topic Area & $\begin{array}{l}\text { NEMS } \\
\text { Module }\end{array}$ & $\begin{array}{l}\text { NEMS } \\
\text { Segment } \\
\text { (Parameter) }\end{array}$ & $\begin{array}{l}\text { Adjustment } \\
\text { Method }\end{array}$ & $\begin{array}{l}\text { Needed Supporting } \\
\text { Empirical Analysis }\end{array}$ \\
\hline $\begin{array}{l}\text { Technical// } \\
\text { Market } \\
\text { Risk }\end{array}$ & EMM & $\begin{array}{l}\text { Risk premium } \\
\text { (input file } \\
\text { ecpdat.txt) }\end{array}$ & $\begin{array}{l}\text { Adjust } \\
\text { downward over } \\
\text { time }\end{array}$ & $\begin{array}{l}\text { Recent case studies of } \\
\text { hurdle rates for IPP } \\
\text { wind firms. May now be } \\
\text { most relevant for off- } \\
\text { shore or smaller } \\
\text { projects. }\end{array}$ \\
\hline $\begin{array}{l}\text { Interconnection/ } \\
\text { transmission } \\
\text { costs/systems } \\
\text { integration }\end{array}$ & EMM & $\begin{array}{l}\text { Resource cost } \\
\text { multiplier curve } \\
\text { (5 segments) }\end{array}$ & $\begin{array}{l}\text { Produce flatter } \\
\text { curve for higher } \\
\text { generation } \\
\text { capacity }\end{array}$ & $\begin{array}{l}\text { Targeted studies of } \\
\text { transmission constraints } \\
\text { and estimated system } \\
\text { costs to integrate wind } \\
\text { into grid. Examine } \\
\text { historical studies for } \\
\text { impact. }\end{array}$ \\
\hline $\begin{array}{l}\text { Environmental } \\
\text { concerns and } \\
\text { costs }\end{array}$ & EMM & $\begin{array}{l}\text { Included in } \\
\text { resource cost } \\
\text { multiplier curve }\end{array}$ & $\begin{array}{l}\text { Assess permit } \\
\text { costs and risk of } \\
\text { environmental } \\
\text { damage }\end{array}$ & $\begin{array}{l}\text { Study environmental } \\
\text { (wildlife) permit costs by } \\
\text { state with attention to } \\
\text { the potential that these } \\
\text { may increase in the } \\
\text { future. A standardized } \\
\text { methodology to assess } \\
\text { environmental concerns } \\
\text { would lower planning } \\
\text { costs. Correlate to } \\
\text { planned NREL } \\
\text { activities. }\end{array}$ \\
\hline $\begin{array}{l}\text { Renewable } \\
\text { Portfolio } \\
\text { Standard (RPS) }\end{array}$ & EMM & $\begin{array}{l}\text { Embedded in } \\
\text { NEMS as } \\
\text { regional } \\
\text { constraints }\end{array}$ & $\begin{array}{l}\text { Adjust } \\
\text { standards } \\
\text { upward in } \\
\text { existing states; } \\
\text { project new } \\
\text { standards in } \\
\text { other states }\end{array}$ & $\begin{array}{l}\text { Identify past activities to } \\
\text { support state RPS } \\
\text { standards. Collect } \\
\text { state-level information } \\
\text { on progress toward } \\
\text { RPS goals, by } \\
\text { renewable technology. }\end{array}$ \\
\hline $\begin{array}{l}\text { Estimated } \\
\text { Potential Wind } \\
\text { Resource }\end{array}$ & $\begin{array}{l}\text { Renewable } \\
\text { Fuels } \\
\text { Market } \\
\text { (RFM) }\end{array}$ & $\begin{array}{l}\text { Exclusion zones } \\
\text { for wind }\end{array}$ & $\begin{array}{l}\text { Reduce } \\
\text { percentage of } \\
\text { excluded land }\end{array}$ & $\begin{array}{l}\text { Assess Federal- } \\
\text { controlled land on } \\
\text { detailed geographic } \\
\text { basis. }\end{array}$ \\
\hline $\begin{array}{l}\text { Information } \\
\text { (Validated wind } \\
\text { maps and state } \\
\text { working groups) }\end{array}$ & RFM & $\begin{array}{l}\text { Risk premium } \\
\text { (risk premium } \\
\text { might be } \\
\text { regionally } \\
\text { based), or } \\
\text { resource supply } \\
\text { cost (feasibility } \\
\text { studies) }\end{array}$ & & $\begin{array}{l}\text { Time series of } \\
\text { capacity/potential by } \\
\text { state. Correlate with } \\
\text { expenditures (activities } \\
\text { such as wind working } \\
\text { groups) by state. }\end{array}$ \\
\hline
\end{tabular}


The impact of several of these deployment activities may be linked to the existing model structure. For example, one of the key barriers to the widespread implementation of wind technologies relates to the acceptance of, and integration of, wind technologies into the regional-electric system. Future deployment activities may be directed toward expanding the number of wind-plant characterization, integration, and inter-connection studies. A number of these types of studies have been conducted in the past decade. A reexamination of these studies, along with targeted interviews of industry and utility professionals, could provide some measure of a particular study's impact. This type of analysis would seek to understand the planned adoptions of wind facilities prior to the study, and determine what role the study subsequently had on changing perceptions and actual adoptions. If a methodology can be established where the historical effect of a particular study (or related deployment activity) can be assessed, this methodology may be applicable to future efforts along these lines.

Renewable portfolio standards are now an important driver in promoting wind and other renewable technologies. Using interview and survey techniques, studies could be undertaken that identify the historical information flows from the winddeployment activities to key advocates of these standards in specific states. For example, to what extent were RPS advocates also members of the state windworking groups set up by the program? Some strategy would be required to develop attribution factors that link program activities to the probability that an RPS is established.

Efforts are also being undertaken within the wind program to mitigate site identification barriers associated with wind. One of the key siting issues involves environmental concerns, primarily concerning wildlife and avian impacts. One objective of the program in this area is to develop streamlined and consistent strategies to evaluate such impacts. The key to quantifying the benefits of this activity is the development of credible estimates of the costs of undertaking the necessary environmental studies. Thus, the cost savings due to the development of a consistent methodology must be converted to a savings per $\mathrm{kWh}$ of wind generation, and subsequently an adjustment to the long-term cost multiplier.

Many important deployment activities of the wind program are undertaken through the Wind Powering America (WPA) Program. WPA was established in the 1999-2000 time-frame with the goal of dramatically increasing the use of wind energy in the United States. From its inception, WPA has recognized the necessity of developing multi-stakeholder support of wind energy prior to the development of enabling policies. The U.S. Department of Energy has helped these state-stakeholder groups to organize wind-working groups to discuss the barriers and benefits of wind-energy development. As these groups have been in existence for different periods of time in various states (with some states not yet having established such groups), one empirical approach would be to develop a cross-section, time-series model by state that would attempt to correlate the amount of wind-energy generation to key explanatory variables. These variables 
would include qualitative or quantitative measures related to the wind-energy working groups. Other explanatory variables in such a model might consist of equipment cost, average efficiency of turbines, general electricity-market factors, and other historical DOE deployment-related activities that can be measured at the state level.

Historically, one particular barrier to the widespread use of wind, at least for smaller wind projects, has been high interconnection costs to the grid. With regard to interconnection costs, a 2000 study commissioned by NREL provides some perspective on interconnection costs that have been incurred by investors seeking to construct wind turbines (Alderfer 2000). As part of the survey information requested in this study, the customer or developer was asked to estimate the "barrier-related" costs associated with the project. These costs generally involved consulting, engineering, or legal fees.

Although, in this case, the sample of case studies in the Alderfer (2000) report was insufficient to develop any statistically valid measure of average interconnection costs for wind- or solar-renewable projects, an update of a study like this could help characterize the nature of these costs, and determine if specific activities could be undertaken to assist in the reduction of such costs. Table 5 shows the range of costs for eight renewable projects considered in the study.

Table 5. Interconnection Costs Derived from the Alderfer (2000) Study

\begin{tabular}{|l|r|}
\hline Project & $\begin{array}{l}\text { Interconnection } \\
\text { cost (\$/kW) }\end{array}$ \\
\hline Wind & $\$ 50$ \\
\hline $2100 \mathrm{~kW}$ Wind Turbines in CA & $\$ 200$ \\
\hline $90 \mathrm{~kW}$ Wind Turbine in IA & $\$ 350$ \\
\hline $20 \mathrm{~kW}$ Wind/PW system in Midwest & $\$ 600$ \\
\hline $10 \mathrm{~kW}$ Wind Turbine in TX & $\$ 1200$ \\
\hline $3.3 \mathrm{~kW}$ Wind/PV System in AZ & $\$ 100$ \\
\hline Solar (PV) & $\$ 200$ \\
\hline $2.4 \mathrm{~kW}$ PV System in NH & $\$ 800$ \\
\hline $132 \mathrm{~kW}$ PV System in CA & \\
\hline $43 \mathrm{~kW}$ PV System in PA & \\
\hline
\end{tabular}

Biomass Technologies Example

The Biomass Program focuses on promoting breakthrough technologies needed to make cellulosic ethanol cost-competitive with corn-based ethanol, enabling greater use of this alternative fuel to reduce future U.S. petroleum consumption. The program has an assortment of R\&D programs that contain deployment elements, in addition to independent deployment programs. 
Identifying the Relevant NEMS Module

In general, the key deployment objective is to encourage the development of a viable biofuels industry in the U.S. One gateway to achieve this objective is to reduce the investment uncertainty related to constructing ethanol plants that employ new, untested technologies. A measure of this risk is the required rate of return on equity required to prompt the building of new ethanol plants. The rate of return of renewable fuel plants is captured within the Renewable module of NEMS.

\section{Identifying Key Parameters}

For modeling in NEMS, activities that reduce the cost of capital can be represented in a straightforward manner. In NEMS, the specific parameter is the "Beta" parameter associated with equity financing. This parameter is a factor that is multiplied by the "market risk" (taken as the return on equity in the total stock market) to represent the specific risk associated with this investment.

The financial parameters used in the AEO 2007 version of NEMS for corn-based and cellulosic ethanol are shown in Tables 6 and 7 . As compared to existing corn-based ethanol plants, the parameters for cellulosic ethanol plants show both higher capital costs and a greater risk premium.

Table 6 NEMS Financial Inputs for Corn Ethanol Plants

\begin{tabular}{|l|r|r|r|r|r|}
\hline $\begin{array}{l}\text { Supply Curve } \\
\text { Point } \rightarrow\end{array}$ & $\mathbf{1}$ & $\mathbf{2}$ & $\mathbf{3}$ & $\mathbf{4}$ & $\mathbf{5}$ \\
\hline Parameter & & & & & \\
\hline $\begin{array}{l}\text { Capital cost, } \\
1987 \$ / \text { gallon }\end{array}$ & $\$ 0$ & $\$ 0$ & $\$ 0$ & $\$ 0.89$ & $\$ 0.89$ \\
\hline Asset life (yrs) & 20 & 20 & 20 & 20 & 20 \\
\hline Debt fraction & $40 \%$ & $40 \%$ & $40 \%$ & $40 \%$ & $20 \%$ \\
\hline Bond premium & $0.5 \%$ & $0.5 \%$ & $0.5 \%$ & $0.5 \%$ & $0.5 \%$ \\
\hline Equity premium & $6.75 \%$ & $6.75 \%$ & $6.75 \%$ & $6.75 \%$ & \multicolumn{1}{c|}{$6.75 \%$} \\
\hline Eq. premium Beta & 1.50 & 1.50 & 1.50 & 1.50 & 1.50 \\
\hline
\end{tabular}

Table 7 shows the financial inputs currently used in NEMS to represent the financial parameters associated with cellulosic ethanol plants.

Table 7. NEMS Financial Inputs for Cellulosic Ethanol Plants

\begin{tabular}{|l|c|c|c|c|c|}
\hline \multicolumn{1}{|c|}{$\begin{array}{c}\text { Supply Curve } \\
\text { Point } \rightarrow\end{array}$} & $\mathbf{1}$ & $\mathbf{2}$ & $\mathbf{3}$ & $\mathbf{4}$ & $\mathbf{5}$ \\
\hline Parameter & & & & & \\
\hline $\begin{array}{l}\text { Capital cost, } \\
1987 \$ \text { /gallon }\end{array}$ & $\$ 5.025$ & $\$ 5.025$ & $\$ 5.025$ & $\$ 5.025$ & $\$ 5.025$ \\
\hline Asset life (yrs) & 20 & 20 & 20 & 20 & 20 \\
\hline Debt fraction & $20 \%$ & $20 \%$ & $20 \%$ & $20 \%$ & $20 \%$ \\
\hline Bond premium & $0.5 \%$ & $0.5 \%$ & $0.5 \%$ & $0.5 \%$ & $0.5 \%$ \\
\hline Equity premium & $6.75 \%$ & $6.75 \%$ & $6.75 \%$ & $6.75 \%$ & $6.75 \%$ \\
\hline Eq. premium Beta & 1.75 & 1.75 & 1.75 & 1.75 & 1.75 \\
\hline
\end{tabular}


The Capital Asset Pricing Model (CAPM) can be used to compute a cost of equity, which is an implied investor's opportunity cost or the required rate of return of any risky investment. Based upon these parameters and an assumed "riskfree" rate of return of $4 \%$, the CAPM implies that the required rates of return on equity for corn-based and cellulosic ethanol plants to be:

$$
\begin{aligned}
& 0.04+1.50 *(6.75)=14.1 \% . \quad(\text { corn-based }) \\
& 0.04+1.75 *(6.75)=15.8 \% . \quad \text { (cellulosic) }
\end{aligned}
$$

Two issues can be raised regarding the parameters used in the NEMS model. First, as shown in Table 7, there is no variation in the equity premium with regard to the amount of ethanol capacity constructed. One would expect that the risk premium would fall as more capacity is brought on line. Second, for the initial plants, the risk premium appears to be somewhat lower than expected. For a relatively new technology, using cellulose rather than sugar (corn) as a feedstock, a considerable amount of financial and technical risk associated with a commercial plant are likely. As currently modeled in NEMS, the equity risk premium on the order of $20 \%$ to $25 \%$ would not be unreasonable. ${ }^{20}$

These observations suggest an approach for modeling a portion of the deployment activities related to the biomass (ethanol) program is to adjust the equity premium Beta to reflect these activities. One such activity is the promotion of public/private partnerships to develop new cellulose-based ethanol production. Public/private partnerships are one way to reduce the risk premium faced by the private sector in undertaking an untested-production technology. Recently, the Biomass Program selected six projects for the construction of demonstrationscale cellulosic ethanol plants, with a government cost share of $40 \%$.

\section{Finding the Empirical Basis}

As indicated in the discussion of biomass technologies, a key financial parameter in the modeling of future market growth relates to the risk-premium component of the cost of capital. This aspect, of course, is relevant to all renewable-energy technologies, and even more generally, to all energy-related investments.

Several studies were identified that develop quantitative estimates of the risk premium or required rate of return associated with renewable-energy (supply) projects.

\footnotetext{
${ }^{20}$ Appendix C of the FY 2008 GPRA Documentation states that "a real capital cost recovery factor of $15 \%$ is used in NEMS and MARKAL to calculate the per-gallon capital costs in each year." More explicit recognition of deployment activities thus might begin with a higher cost recovery factor in the early years and then would lower that factor in later year to reflect lower risk. Apparently, in NREL's Biomass Scenario Model, not yet used to support GPRA, the initial required rate of return for cellulosic ethanol plants is assumed to be $30 \%$. Over time, this rate of return declines to $10 \%$. (Personal communication with Debra Sandor, September 26, 2007). While the rate of return is not exactly equivalent to the capital recovery factor, the point is that this financial parameter is lowered over time to reflecting decreasing risk.
} 
An early relevant study is the report prepared by Edward Kahn at Lawrence Berkeley National Laboratory (LBNL) in 1995. In Comparison of Financing Cost for Wind Turbine and Fossil Power Plants, Kahn lays out the conventional framework for considering financing cost that includes debt versus equity financing, tax considerations, and risk (Kahn 1995). He employs information from a wind-power investment made by Kenetech Corporation in 1993. Using other information and assumptions, Kahn concludes that "the risk associated with equity investment in wind turbine projects requires at least a $600(17.36 \%$ $11.14 \%=6.22 \%$ ) basis point greater return than what is required by conventional (fossil-fuel) technology" (Kahn 1995).

Two more-recent studies of the role of renewable energy in Europe also shed some light on the risk premium for renewable-energy projects. The first of these studies was funded by the European Commission. The KEMA consulting firm in the Netherlands conducted an extensive study, entitled Modeling Risks of Renewable Energy Investments. (European Commission 2004). This two-year study, completed in 2004, made use of both surveys and interviews to gain a better understanding of the key factors contributing to risk in these types of projects. On the basis of this work, the study concluded that the internal rates of return (IRR) required by the investment community for renewable energy projects can be summarized as follows:

- the IRRs required for onshore wind farms were in the range of $12 \%-15 \%$

- typical IRRs for new biomass (ethanol) plants were in the range of $20 \%-$ $25 \%$

- too little experience with off-shore wind had been gained by 2004 to make any quantitative assessment of the IRR.

In a 2005 study for the United Kingdom's Department of Trade and Industry, Oxera Consulting compiled several estimates of the cost of equity for renewableenergy-generation projects. Oxera's particular interest was in deriving estimates for the asset Betas, implied by the published estimates of the cost of equity. Table 8 reproduces the table in the Oxera report, which shows the likely value of the asset Beta consistent with both the value of the cost of equity and a value for the percentage of the project financed by equity. Unfortunately, the Oxera report does not indicate the value of the market equity rate of return (measured by a broad index of stock market returns) by which the asset Betas were derived. Nevertheless, the cited estimates for the cost of equity have value in their own right in helping to inform current modeling efforts by EERE. Three of the four estimates pertain to renewable projects in the U.S. 
Table 8. Asset Beta values implied by various estimates of the cost of equity for renewable generation projects.

\begin{tabular}{|l|c|c|c|}
\hline & $\begin{array}{c}\text { Estimated cost of } \\
\text { equity (18\%) }\end{array}$ & Equity ratio & $\begin{array}{c}\text { Implied asset } \\
\text { Beta range }\end{array}$ \\
\hline Enviros (2005) & 18 & 75 & $0.81-0.97$ \\
\hline $\begin{array}{l}\text { Black and Veatch } \\
(2005)^{22}\end{array}$ & 16 & 60 & $1.10-1.35$ \\
\hline $\begin{array}{l}\text { Previsic, Siddiqui } \\
\text { and Bedard }\end{array}$ & 17 & 70 & $0.90-1.09$ \\
\hline $\begin{array}{l}\text { Energy Trust } \\
(2005)^{24}\end{array}$ & 12 & 50 & $0.88-1.19$ \\
\hline
\end{tabular}

\section{Building Technologies Example}

The Building Technologies (BT) Program supports a wide range of activities designed to facilitate widespread adoption and use of energy-saving technologies and practices. Through building project profiles, technical assistance, regulatory activities, and awards and recognition, the program provides the information and assistance needed for home and business owners, architects and engineers, community planners and consumers to make informative choices about energy.

One of the BT program's deployment activities having achieved widespread success is the ENERGY STAR program, which is a voluntary labeling program run jointly by DOE and the Environmental Protection Agency (EPA), which helps businesses and consumers easily identify high-efficiency products, homes, and buildings that will provide energy and money savings. ENERGY STAR promotes energy efficiency through more than 20,000 retail partners, 1200 product manufacturers, 400 utility partners, and others.

\section{Identifying the Relevant NEMS Module}

Market transformation and information-dissemination projects, such as ENERGY STAR, attempt to accelerate market penetration of existing high-efficiency technologies. The information provided by these programs is designed to influence consumers' awareness of future energy-cost savings as compared to the initial cost of the technology. Depending on the specific product targeted, ENERGY-STAR-supported technologies will either be contained within the Residential or Commercial Buildings modules of NEMS, or both. To illustrate the process of modeling this type of activity in NEMS, this report focuses on a singular ENERGY STAR product-the high-efficiency refrigerators promoted with

\footnotetext{
${ }^{21}$ Oxera Consulting analysis of the figures presented in Enviros (2005)

${ }^{22}$ Black and Veatch (2005), Kauai Island Utility Cooperative Renewable Energy Technology Assessments, (March 2005)

${ }^{23}$ Previsic, M., Siddiqui, O., and Bedard, R. Electricity Innovation Institute and Electric Power Research Institute (undated), Economic Assessment Methodology for Offshore Wave Power Plants.

24 Energy Trust of Oregon, CH2MHill (2005), Phase II Biopower Market Assessment: Sizing and Characterizing the Market for Oregon Biopower Projects. (April 2005)
} 
the ENERGY STAR label. This activity is modeled within the residential module of NEMS.

\section{Identifying Key Parameters}

From a modeling standpoint, these efforts are believed to be represented by a reduction in the consumers' implicit discount rate or hurdle rate. The implicit discount rate for a technology significantly impacts how a consumer determines the present value of the benefits and costs associated with this technology, as it is assumed to capture the perceived risk in the purchase of new products. Therefore, to facilitate the modeling of this deployment activity, a goal of the ENERGY STAR project is to reduce implicit discount rates by providing additional information about the potential benefits to the consumer.

Within NEMS, the two modeling parameters determining the implicit discount rate are labeled Beta1 and Beta2. Beta1 is used as multiplicative factor with the initial cost of the appliance, and Beta2 is used to multiply the annual energy cost. The sum of the two products (i.e., Beta1 * initial cost + Beta2 * operating cost) is used in the logit specification to yield market shares for each technology. As a rough approximation, the ratio of Beta1/Beta2 can be interpreted as the consumer discount rate for a specific technology. In the residential NEMS module, the Beta1 and Beta2 coefficients vary among technologies, as do the resulting discount rates. For example, the implied discount rate for refrigerators is $16 \%$, while the discount rate is estimated to be $>80 \%$ for electric water heaters.

Within the residential module of NEMS, several models of refrigerators are included in the technology database, one of which represents the class of refrigerators meeting the ENERGY STAR criteria. With the current set of parameters representing the discount rate consumers (implicitly) employ in choosing refrigerators, together with the current equipment and electricity prices, the NEMS model projects an approximately $20 \%$ share for ENERGY STAR refrigerators. The discount rate serves as the mechanism in the model by which the ENERGY STAR promotional activities influence consumers to purchase moreefficient appliances.

A key parameter affecting the average consumer-discount rate could be adjusted to yield an approximation of the targeted percentage point increase in the share of ENERGY STAR refrigerators. To do this, the Beta1 parameter is adjusted to reflect a change in the discount rate.

\section{Finding the Empirical Basis}

Although an approach that involves adjusting discount rates may have some theoretical merit, the degree this adjustment should take place is not clear. According to the most recent information from the EPA ENERGY STAR website, approximately $33 \%$ of refrigerator sales in 2004 met ENERGY STAR criteria. For the GPRA analysis, BT did not "calibrate" NEMS to yield the current ENERGY STAR 
sales, but rather adjusted a key parameter affecting the average consumerdiscount rate to yield a roughly 10-percentage point increase in the share of ENERGY STAR refrigerators (thus, raising the share from $20 \%$ to $30 \%$ ). ${ }^{25}$ Although ENERGY STAR programs have historical sales data upon which to base potential adjustments to Beta factors, the relationship between deployment and discount rates are not necessarily clear. Further empirical research is required to strengthen the basis of determining exactly how much the sales of a particular product have been influenced by the labeling program, such that one could conclude that " $X$ " dollars of deployment, for example, results in " $Y$ " change in the discount rate.

In the case of ENERGY STAR, a great number of evaluation studies, data tracking efforts, and analyses are available to the process. Annual status reports produced by Lawrence Berkeley National Laboratory (LBNL) estimate the marginal sales of various ENERGY STAR units that are attributable to the labeling program. ${ }^{26}$ Numerous regional studies also exist. In the case of ENERGY STAR, the empirical challenge is finding the data that are suitable for the specific product and determining how these relationships (e.g., labels influence on sales) may change over time.

\section{Identifying the Relevant NEMS Module}

In the three example cases examined-Wind, Biomass, and Buildings-the deployment activities targeted three distinct audiences: electric utilities, fuels producers, and residential consumers, respectively. The responses of these target audiences were revealed in three categories of NEMS sectors: the Conversion sector, Supply sector, and Demand sector, respectively. These were then modeled within three distinct sector modules: Electricity Market Module, Renewable Fuels Module, and the Residential Demand Module, respectively. As each NEMS module is structured differently, it is apparent that there is no individual prescriptive method for integrating deployment activities into the overall framework.

\section{Identifying Key Parameters Impacted by Deployment}

Each of the three example deployment cases examined, Wind, Biomass, and Buildings, targeted distinct sets of parameters for modification. Within the Renewable Fuels Module and the Electricity Market Module, the potentially impacted parameters include risk premiums, cost multipliers and technology cost curves, and rate-of-return factors. In the case of the Building Technologies

\footnotetext{
${ }^{25}$ The parameter value in the NEMS AEO 2006 baseline model is $0 .-0229$. That value is adjusted to -0.0055 to reflect the impact of Energy Star-related activities, and implicitly lowers the average discount rate.

${ }^{26}$ Marla Sanchez, Carrie A. Webber, Richard E. Brown, and Gregory K. Homan. 2007 Status Report Savings Estimates for the ENERGY STAR® Voluntary Labeling Program. March 23, 2007. Lawrence Berkeley National Laboratory LBNL-56380 (2007).
} 
example, the deployment activity indirectly impacted the discount rate within the technology choice sub-module of the residential module. Most of the EERE activities could potentially be modeled in one of the demand modules (residential, commercial, transportation, and selected technologies in industrial), and most of these demand modules contain some form of technology-choice sub-modules. ${ }^{27}$

Within these technology-choice sub-modules, equipment is chosen based on the economic criteria included within the sub-module-typically cost and performance characteristics - and parameters that represent time-preference assumptions (typically represented by one or more discount rates). R\&D programs will be typically characterized and modeled as adding a technology to the mix of technologies within the choice module, or reducing the cost and/or improving the performance of a given technology. Typically, a straight-forward path into NEMS to model these programs is already integrated. Deployment programs, on the other hand, will typically impact the behavioral parameters, often captured in some form of discount rate or risk premium. A more thorough examination of information-dissemination deployment activities illustrates this linkage to behavioral parameters.

\section{The Information Dissemination Example}

Information-dissemination activities are the most common types of deployment activities arising in EERE programs. Information dissemination, for the purpose of this report, is defined as the focused exchange of information to increase the probability of implementing energy-efficient or renewable-energy options by increasing the awareness of available options. This would include online resources (information, tools, databases, guidance), labeling, training and education, most technical assistance, and some software and tools specifically designed to better inform end users about the potential options. ${ }^{28}$

Information dissemination is intended to reduce information-related barriers that may prevent an end user from adopting easily implementable energy-efficient or renewable-energy options. While these options may be available in today's market, the information may be designed to prepare the market to ease future barriers associated with a lack of awareness. Additionally, information can be used to increase awareness of future technologies and practices to promote adoption. Information programs inform an end user of the best available options (e.g., more energy-efficient); however, the end-user is not obligated to implement the options.

As illustrated in Table 9, information-dissemination types of activities appear in all EERE programs.

\footnotetext{
${ }^{27}$ With the exception of discrete technology choice algorithms for electric motors, and CHP technologies, the industrial sector generally does not employ an economic choice framework.

${ }^{28}$ See draft report, Hostick, et. al., "EERE Information Dissemination Activity Analysis," July 31, 2007, for additional information on information dissemination activities.
} 
Table 9. Information Activities Matrix ${ }^{29}$

\begin{tabular}{|c|c|c|c|c|c|}
\hline \begin{tabular}{|l|} 
EERE \\
Program
\end{tabular} & $\begin{array}{l}\text { Online Information, } \\
\text { Tools, Databases, } \\
\text { Guidance }\end{array}$ & Labeling & $\begin{array}{l}\text { Education and } \\
\text { Training }\end{array}$ & $\begin{array}{c}\text { Software } \\
\text { (general } \\
\text { information } \\
\text { focus) }\end{array}$ & $\begin{array}{l}\text { Technical } \\
\text { Assistance }\end{array}$ \\
\hline Biomass & $\begin{array}{l}\text { Integration of Biorefinery } \\
\text { Technologies; Education } \\
\text { and Outreach }\end{array}$ & & $\begin{array}{l}\text { Education and } \\
\text { Outreach }\end{array}$ & & \\
\hline$\overline{B T}$ & $\begin{array}{l}\text { Commercial Lighting } \\
\text { Challenge; Residential } \\
\text { R\&D (Best Practices); } \\
\text { Commercial R\&D (High } \\
\text { Performance Buildings } \\
\text { Database); EnergySmart } \\
\text { Schools/Hospitals }\end{array}$ & ENERGY STAR & $\begin{array}{l}\text { Building Energy } \\
\text { Codes }\end{array}$ & $\begin{array}{l}\text { Building Energy } \\
\text { Codes }\end{array}$ & $\begin{array}{l}\text { EnergySmart } \\
\text { Schools and } \\
\text { Hospitals; Building } \\
\text { Application Centers }\end{array}$ \\
\hline FCVT & Clean Cities & & Clean Cities; GATE & & \\
\hline FEMP & $\begin{array}{l}\text { Project Financing; } \\
\text { Technical Assistance } \\
\text { and Guidance; Federal } \\
\text { Fleet; DOE Specific } \\
\text { Investments }\end{array}$ & & $\begin{array}{l}\text { Project Financing; } \\
\text { Technical } \\
\text { Assistance and } \\
\text { Guidance; DOE } \\
\text { Specific } \\
\text { Investments } \\
\end{array}$ & & $\begin{array}{l}\text { Technical } \\
\text { Assistance and } \\
\text { Guidance; DOE } \\
\text { Specific } \\
\text { Investments }\end{array}$ \\
\hline Hydrogen & $\begin{array}{l}\text { Codes and Standards; } \\
\text { Education and Outreach }\end{array}$ & & $\begin{array}{l}\text { Education and } \\
\text { Outreach }\end{array}$ & & \\
\hline ITP & $\begin{array}{l}\text { Best Practices; Industrial } \\
\text { Assessment Centers }\end{array}$ & & $\begin{array}{l}\text { Best Practices; } \\
\text { Industrial } \\
\text { Assessment } \\
\text { Centers }\end{array}$ & Best Practices & Best Practices \\
\hline Solar & Solar America Initiative & & & & $\begin{array}{l}\text { Solar America } \\
\text { Initiative }\end{array}$ \\
\hline Wind & $\begin{array}{l}\text { Technology Application; } \\
\text { Wind Powering America }\end{array}$ & & $\begin{array}{l}\text { Wind Powering } \\
\text { America }\end{array}$ & $\begin{array}{l}\text { Wind Powering } \\
\text { America }\end{array}$ & $\begin{array}{l}\text { Wind Powering } \\
\text { America }\end{array}$ \\
\hline WIP & $\begin{array}{l}\text { State Energy Program; } \\
\text { Tribal Energy Program }\end{array}$ & $\begin{array}{l}\text { State Energy } \\
\text { Program }\end{array}$ & $\begin{array}{l}\text { State Energy } \\
\text { Program; Tribal } \\
\text { Energy Program }\end{array}$ & & $\begin{array}{l}\text { State Energy } \\
\text { Program }\end{array}$ \\
\hline
\end{tabular}

Information-dissemination activities target a variety of audiences, from public policy makers and education institutions to businesses and consumer end-users. The undertakings would also eventually impact all demand sectors of the energyconsuming economy as well as certain supply sectors. The market barriers these activities address could include the following (previously defined) barriers:

- information awareness

- technical capacity

- risk aversion

- performance issues and system integration.

Components of these market barriers may be definitively modeled in NEMS (i.e., "performance issues" may appear explicitly as performance factors) or may be indirectly addressed in some form of discount/hurdle rate or risk premium. As was the case for the ENERGY STAR example presented above, for many of the technologies that are revealed in various demand modules of NEMS, some form of technology-choice sub-module or algorithm implicitly models the impact of information dissemination via the discount rate. For the supply modules and

${ }^{29}$ As previously noted, the FY08 budget request for Geothermal Technologies was $\$ 0$, and as that program is currently being phased out, it was not included within the scope of this analysis. 
electricity-market module, the impact of information dissemination would more likely be captured via some form of risk-premium factor. Thus, in general, the primary behavioral parameters within NEMS that are impacted by deployment activities include the "discount rate" (sometimes referred to generically as the hurdle rate), and the "risk premium."

\section{Characterizing the "Discount Rate"}

The implicit discount rate for a technology reflects how a consumer determines the present value of the benefits and costs associated with this technology. In the consumer-choice models, the discount rate can be expected to capture a number of different vaguely defined issues that factor into consumers' decision-making process and how benefits are weighed today versus tomorrow. This may include how risk is perceived regarding the purchase of new products, the consumer's level of "impatience," or even what could be described as consumer inertia. For many energy-efficient and renewable technologies, most of the costs are incurred at the time the technology is purchased, while most of the energy-saving benefits occur over time. If the implicit discount rate for a given technology is particularly high, the value a consumer places on these future energy-saving benefits will be low relative to the weight the consumer places on present costs-reflecting both the consumer's time preference and uncertainty about future benefits.

A significant amount of related literature contends that lack of information and technical capacity—barriers that are addressed with information-dissemination activities-are some of the reasons for these observed high implicit-discount rates. Thus, the discount rate is one of the most likely candidates for modification to reflect the impact of deployment programs. As the discount rates often apply to technology categories, it may be possible to modify these parameters to reflect the impact of generic deployment activities through the use of surveys.

\section{Commercial Sector Example}

Within the commercial module of NEMS, the implicit-discount rate is based on the model input, Consumer risk-adjusted time preference distribution data. The consumer-time preference is developed using a composite set of distributions of consumer payback-period requirements found in selected reports in the early 1990s. Due to data limitations, the same average distribution is typically applied across all technologies. These payback periods were converted to implied internal rates of return, and then the 10-year treasury rate was subtracted from each implied rate of return to estimate the consumer risk-adjusted timepreference premium distribution.

For the forecasting application in NEMS, the projected 10-year treasury rate is added to the time-preference premiums to yield the discount rates used in the choice algorithm. This treatment allows any change in the macroeconomic 
environment that affects long-term "risk-free" rates to have some influence on energy efficiency. ${ }^{30}$

Ideally, payback distributions for each general end-use class of equipment would be identified and used within the module to better reflect the proposed EERE technologies. At present, EIA does make a slight adjustment of the distribution of time premiums for lighting equipment, principally to reflect the impact of the EPA Green Lights Program. However, this framework is not currently designed to handle any special measure of additional risk that one could expect to be associated with new (i.e., EERE-funded) individual technology. In this case, modification of the present model structure needs to be explored, which would, in essence, incorporate a "risk premium" for a specific product. This topic is discussed further below.

Of note, the commercial market within NEMS is segmented by risk preference as well as cost (least cost), fuel type, and technology type. These categories tend toward a form of inertia within the model, where the consumer has a tendency to be loyal to similar types of equipment. These factors could potentially be adjusted; however, considering all the various factors at play, determining how much of an adjustment is appropriate relative to the changing discount rate would be extremely difficult.

\section{Residential Sector Example}

Within the residential module of NEMS, the choice sub-model for each end-use technology employs two key modeling parameters, labeled by EIA as Beta1 and Beta2. Beta1 is used as a multiplicative factor with the initial cost of the appliance, and Beta2 is used to multiply the annual energy cost. The sum of the two products (i.e., Beta $1{ }^{*}$ initial cost + Beta2 * operating cost) is used in a logit specification to yield market shares for each technology. These coefficients are specific to each equipment fuel type. As a rough approximation, the ratio of Beta1/Beta2 can be interpreted as an average consumer discount rate for the specific appliance. The Beta1 and Beta2 coefficients are included with the cost and efficiency data inputs in the file RTEKTY.

As the Beta1 and Beta2 coefficients vary among technologies, so do the implied discount rates. The logit framework yields non-zero market shares for each specific technology. However, the framework does not display "knife-edge" or "winner-take-all" solutions that are characteristic of an economic-optimization model. Because of the logit framework used to develop the Beta parameters, transforming an explicit discount rate distribution into the logit model— which implicitly represents a distribution-is not an easy task.

\footnotetext{
${ }^{30}$ In essence, this treatment allows interest rates to affect the capital intensiveness of the energy sector (by substituting capital for energy), as would be predicted by economic theory.
} 
Alternatively, as discussed in the previous section, the choice model underlying the NEMS commercial model relies upon the market segmentation approach, where a discrete distribution of discount rates is used. For each segment with a specific discount rate, the technology with the lowest levelized (life-cycle) cost is chosen. If the residential choice function were reconfigured to be more similar to the commercial module, generic payback distributions could be used to inform the choice model. More research or surveys could be performed to provide technology-specific results that will further refine the choice distributions. ${ }^{31}$

\section{Characterizing the "Risk Premium"}

Depending on the model/module, a discount-rate parameter may include a risk adjustment in addition to the expected consumer time-preference premium. In addition to the complexity involved in attempting to "decouple" that portion due to risk, another issue is that implicit discount rates are often applied to technology groups with similar characteristics, as opposed to individual technologies. For example, an adjustment in the implicit discount rate for air conditioners within the commercial NEMS module increases not only the share for the targeted EERE technology, but also the share of other higher-efficiency air conditioners. While this might be a valid approach to measuring the impact of general informationdissemination deployment activities, the method may not be the best manner of measuring the targeted deployment efforts for a specific technology. In cases where the deployment activity is specifically attempting to reduce the perceived risk of a new technology, exploring methods by which risk can be more fully incorporated within the choice algorithm may be worthwhile.

For renewable-energy supply technologies, a risk premium is already specifically included in the NEMS modules. For example, as pointed out in the previous discussion of biomass fuels, the equity premium "Beta" used in NEMS (2007 AEO reference case) was 1.75 , implying a risk premium of approximately $12 \%$.

For the FY09 GPRA case, NREL worked with OnLocation, Inc. to better characterize the risk premium, and link the premium to the increase in cellulosic ethanol capacity. Based upon NREL's biomass-scenario model, ROI estimates were developed for conservative, moderate, and aggressive investors. For each of these investor classes, a curve was generated showing a high initial ROI, but for which the ROI declines as the cellulosic ethanol industry develops. These

\footnotetext{
${ }^{31}$ As pointed out by Frances Wood of OnLocation, Inc., if the goal or expected impact of a deployment activity is expressed in terms of future market shares, then the exact characterization of the choice model is not an important issue. As is currently done for many residential ENERGY STAR appliances, the NEMS model parameters are adjusted to yield the approximate adoption goal of the program. Using the current logit framework in the residential model, the introduction of a new energyefficient technology reduces the market shares of all existing products by the same proportion. This attribute of the model thus may tend to overestimate the impact of a new technology. An explicit representation of a distribution of discount rates would overcome this behavior. The more desirable approach is to re-estimate some of the residential choice models, perhaps by the use of a "mixed" logit framework that would explicitly recognize a differences in discount rates across consumers.
} 
three curves were collapsed into a single curve, which was programmed into the GPRA version of NEMS.

The most recent EIA version of NEMS contains a provision to (exogenously) add new capacity for cellulosic ethanol. This feature can be used to represent the new capacity that stems from the public/private partnerships currently being initiated by the biomass program. Given the revised treatment of the risk premium in NEMS, the new capacity from these planned public/private partnerships will decrease the risk premium, thus spurring further investment in cellulosic ethanol production. As will be discussed in the next section, some corroboration of the parameterization now used to link the risk premium and industry capacity would be very useful. 
Gaps in knowledge that present significant challenges to modeling deployment generally fall into two categories: the empirical knowledge gap and modelingstructure issues (in which the current structure of the model is insufficient to capture impacts of deployment).

\section{Empirical Linkages}

Although a number of avenues are available into NEMS via the sub-modules that incorporate market behaviors targeted by deployment, simply being aware of which parameter is impacted by the deployment activity and direction of change does not make a complete model. As discussed in the sections characterizing discount rates and risk premiums, an empirical basis is needed to rationalize specific changes to the relevant parameters.

For the programs that consider the relatively long-term R\&D and futuretechnology development as the basis of the programs (e.g., Hydrogen, Biomass, FreedomCAR), the process of modeling deployment and R\&D together by adjusting price and performance (or adding a new technology to the mix of choices) in NEMS is a relatively straightforward process. If one were to attempt to extract the impacts from the deployment portion of the program, however, the process would become more complicated. As previously discussed, the process of delineating what portion of the "benefit" is attributable to R\&D versus deployment is difficult to estimate, provided the limited empirical data to drive the process.

Additionally, for those programs currently modeled completely "off-line," the amount by which off-line estimates should be decremented to account for integration impacts (as has been termed the "hair-cut") remains an issue. Originally, the amount of the "hair-cut" was determined by the difference between the overall savings levels when programs were run independent of each other compared to the savings that resulted when the integrated NEMS run was made, including all programs and modules. This has been modified in recent years to take into account the specific attributes of the activity in question-are there similar activities competing for market share in other programs, for example, or is activity unique? However; the ultimate rates used are based on the judgment of the analysts and modelers, and not necessarily on empirical studies.

For wind and biomass projects, the risk-premium component of the cost of capital was identified as a key model parameter. The three empirical studies cited in the discussion of the biomass program all focused upon the development of an approximate measure of the cost of capital associated with various types of renewable-energy projects. While useful, the results from the studies can best be interpreted as providing snapshots of the perceived riskiness of various types of 
projects during a specific time and place. Clearly, for example, the risk premium for large on-shore wind projects is lower today than a decade ago, or even five years ago. As snapshots, these studies provide no information on how risk premiums may have changed over the past 10 or more years. Accordingly, the studies provide no clues to indicate which factors may have influenced changes in the premiums over time.

The extensive study undertaken by the European Commission (EC) in 2004 provides some guidance on how to develop the information needed to link changes in the risk or equity premiums to the various deployment activities and government policies. The study itself was very comprehensive, lasting nearly two years, and involving contributors from nine EC countries.

As part of the study, a survey of more than 650 stakeholders involved in renewable energy was conducted to obtain views on investment risks and barriers. The stakeholders included representatives in the electric-power industry, renewable-energy project developers and investors, manufacturers of renewable-energy equipment, banks, non-government organizations, and government agencies. The questionnaire queried responses to the following topics:

- Which risks (technological, market, and regulatory) are relevant to investments in renewables?

- Which sources are least and most subject to such risks?

- What are the most important barriers faced in project development?

The survey showed that regulatory and political risks of financial support (e.g., tax credits) were the most important type of risks encountered by actors seeking to develop renewable-energy projects. Technological risks related to operation and performance were cited as the next most important risk factor, followed by planning and permit risks during the early stages of project development.

The survey conducted by the EC appears to have provided a reasonable picture of conditions influencing the risk of renewable projects in Europe circa 2003. However, as in the other studies identified in this study, the EC work discussed in this report does not address the impact of any EC (or other publicly-funded) activities designed to promote renewable energy in Europe.

The EC study suggests that conducting a survey of a similar scope may be a starting point for evaluating the impact of EERE-deployment activities that influence the risk premium of renewable projects in the U.S. Such a survey would identify key risk factors from the viewpoint of various segments of the renewableenergy industry. The study would be designed to yield quantitative estimates of the risk premium associated with various types of renewable-energy projects (primarily in the wind, biomass, and solar programs). 
The design of the survey, however, must go beyond that evident in prior studies. This would be accomplished by focusing on particular risk factors EERE is attempting to address in its deployment activities. Thus, for instance, if interconnection cost and availability are particularly important factors, some means of quantifying the effect of those factors would be desirable. For biomass, a key factor will likely be the performance of the cellulosic demonstration plants to be constructed over the next several years (as public/private partnerships). Moreover, survey respondents would be asked to indicate awareness of EERE's activities pertaining to this particular risk factor. In an initial survey, the questions would be structured to ascertain the historical influence had by federal deployment activities.

As the technological, market, and regulatory environments affecting renewable energy are continually changing, the survey instrument would need to be developed in such a way to collect future information on a periodic basis. Thus, annual updates might be conducted, in which respondents are asked as how various factors affecting risk in renewable-energy projects has changed compared to the previous year. Again, the questions would need to be tailored to elicit opinions of whether the EERE-activities had any measurable impact upon the risk factors.

The EC study found that insights into types of particular risk factors could only be obtained by interviewing people directly associated with the financing and construction of specific renewable projects. These interviews involved staff in banks and other financial firms as well as project developers in the wind and biomass renewable sectors. These interviews provided key information of the criteria banks use to evaluate the credit worthiness of particular projects. As applied to the question of federal deployment activities in the U.S., a similar interview process may be necessary to identify and quantify the effects of EEREfunded deployment activities and the relationship to lending criteria used by financial institutions.

\section{Model Structure Limitations}

Although this report has focused on finding commonalities between programmodeling processes and approaches regarding the incorporation of deployment activities into the integrated framework, a number of exceptions to these generalizations exist. An important acknowledgement is that for some EERE programs, the NEMS modules' structure does not allow certain activities to be modeled. For example, the way in which the industrial module of NEMS is currently structured, the adoption process of new industrial technologies is not definitively represented (e.g., no technology choice sub-module is available). The model for the industrial sector is not an engineering economic model, but rather an econometric model. The technique used to account for technological change within this module relies on engineering estimates of the impacts of technology penetration on the efficiency of energy use. The overall efficiency factor improves over time, but is responsive to changes in fuel prices. However, no algorithms 
that account for the adoption of specific technologies in particular industries are available.

\section{The Choice Modules and Discount Rates}

Notable limitations to many of the technology choice sub-modules within NEMS are apparent. Consider, for example, the approach of adjusting the discount rate to account for ENERGY STAR labels on residential products. The adjustment of parameters that reflect the discount rate (i.e., Beta1 or Beta2, as explained above) will increase the market penetration of all "relatively" efficient products, not merely ENERGY STAR products. As an example, if one is targeting a new technology that is much higher in efficiency than the standard "energy-efficient" products on the market, a change in the implied discount rate will increase the market shares of all relatively efficient products. Thus, targeted deployment efforts may not be adequately captured with this modeling approach.

Another illustration of the technology sub-module deficiencies is revealed in the commercial sector. In the commercial module, the market is binned into different discount rates based on several utility surveys related to payback periods. These data, however, were collected in the 1980s, and the model has since been calibrated such that the empirical link to this initial study has been lost. Apart from the specific value for discount rates, when an attempt is made to model a particular (new) technology within these market bins, the assumption is that 1) total costs are represented by the market (first) cost and discounted future energy-operating costs of the technology, and 2) all market participants are fully aware of every alternative.

In some analyses of information and product adoption, the development of a qualitative choice model has employed the concept of a "perceptual threshold." Such a threshold indicates that the decision-maker is sufficiently aware of the new product to make a credible assessment. In an empirical study addressing the adoption of innovative medical technologies, Van de Bulte et al. (1998), express the probability that one adopts a new product at any point in time (t) to be the product of the probability that one is aware at time $t$ multiplied by the probability that, once aware, the evaluation of the new product leads to its adoption. In terms of the conceptual framework of this model, the first probability (awareness) is a function of how much information is circulating in general, the media habits, perceived source credibility, and random shocks. To capture this "pool of awareness," modeling market penetration with market diffusion types of curves may be more appropriate.

The consideration of "awareness" suggests one somewhat mechanistic means of representing the information-dissemination aspects of deployment activities related to new EERE-funded technologies. For many of the technology choice models in the NEMS demand modules, new technologies are introduced by simply expanding the existing choice set of technologies. The models implicitly assume that, immediately upon introduction of the new technology, all consumers 
are as aware of the costs and benefits of the new technology as they are of the existing technologies. Models of the type considered by Van de Bulte et al. (1998) do not make this assumption.

The recognition of this fact might lead to a market segmentation within some of the NEMS models into two groups of decision-makers: 1) percentage of the market aware of the new technology, and 2) percentage of the market unaware of the new technology. For the first group, the choice set would include the new technology, and market shares would be estimated as in the current choicemodel framework. $^{32}$ For the second group, the choice model would apply only to existing technologies. Over time, as a result of targeted-information activities (external sources) and "word-of-mouth" effects (internal sources), the percentage of the first group would increase. An S-curve could be used to represent the time path of the increase.

An advantage of this type of approach is that an attempt to adjust the discount rate or distribution of discount rates to overtly represent information-at least as that information pertains to the introduction of new energy-efficient technologiesneed not be made. The approach blends both elements of a static choice model (for any given year) and a diffusion process over future years.

Further justification to consider alternatives to discount-rate-choice algorithms comes from a 2003 study by Soren Anderson and Richard Newel. In this study, the authors performed an intensive econometric analysis of the DOE/EERE's Industrial Assessment Centers (IAC) program. The study focused on a series of energy audits performed on 9034 industrial plants over a nearly 20-year time span. The IAC program focuses on small and medium-size manufacturers, with gross annual sales of less than $\$ 100$ million.

Recognizing prior use of the modeling device of changing discount rates to represent information programs, Anderson and Newell (2003) tease the reader early in the paper by suggesting that their analysis can shed some specific light on this issue. They write:

We explore this issue (modeling information programs by adjusting discount rates) by examining the rates of return for potential projects faced by firms that participated in the IAC program, to determine whether the level of implicit discounting used by plants that received information assistance actually decreased to the levels that some studies suggest.

One of most important empirical results to come from the study is a distribution of required payback periods and corresponding implicit-discount rates. Here, Anderson and Newell (2003) looked at the approximately 5000 firms in the

\footnotetext{
${ }^{32}$ This still does not address of the issue of whether there is "risk premium" associated with the new technology. The framework provides a mechanism for restricting the number of adopters to only that portion of the market that is aware of the costs and benefits of the new technology.
} 
sample that adopted some, but not all, of the recommended energy-saving projects. Over $98 \%$ of the firms were estimated to have payback thresholds of less than five years, and $79 \%$ had thresholds less than two years. The mean payback was estimated to be 1.4 years, and the median payback was 1.2 years. For a 10 -year project lifetime, ${ }^{33}$ these payback periods correspond to implicitdiscount rates of approximately $70 \%$ and $80 \%$, respectively.

Regarding whether the IAC program actually decreased discount rates, Anderson and Newell (2003) provide no precise statistical evidence. In their opinion, however, the authors do not believe the program had any significant effect in that regard. With respect to the payback thresholds required by plant managers to undertake efficiency investments, Anderson and Newell (2003) indicate that such thresholds "are consistent with what surveys of plant managers suggest they use for these types of investments, and do not therefore represent a significant decline" (italics added). ${ }^{34}$

On a more positive note, Anderson and Newell (2003) do conclude that the program in its entirety can be viewed as a success in leading to significant energy savings. Over the period from 1981 to 2000, the authors estimate the program has led to annual energy-expenditure savings of $\$ 100$ million. These savings were achieved for a total investment cost of just over $\$ 100$ million. Thus, from the point of view of government benefit-cost criteria, the IAC program has been a success.

The overall strategy of the program has been to provide information, specifically promoting awareness of cost-effective energy options to the targeted firms. In that regard, the program has been successful. However, also relevant to the study here is whether the program can be viewed in terms of a more general market-transformation activity, where the decision behavior by firms was

\footnotetext{
${ }^{33}$ In the parlance of utility energy efficiency programs, the IAC program can be viewed as falling into a "resource acquisition" approach, rather than "market transformation" approach. As defined by Ken Keating (PG\&E 2001), resource acquisition uses "trackable (to individual program participant and measure), measurable, cost-effective investments in energy efficiency to replace generation energy, transmission, and distribution capacity." Market transformation, on the other hand, involves market interventions that cause "beneficial", lasting changes in the structure or function of the market leading to greater adoption of energy efficient products (PG\&E, op. cit.), One potential effect of a market transformation activity is to modify decision making behavior that may be reflected in changes in the payback or discount rates used by decision makers. To consider the IAC's impact as a market transformation activity, considerably more evaluation effort would have been required by DOE. Comprehensive survey information would have been required, prior to the initiation of the program, to characterize the types of energy efficiency investments typically undertaken by this category of manufacturers and the decision criteria underlying those investments. Follow-up surveys to participating firms would be required to determine if the decision-making criteria (e.g., payback periods) had changed as a result of program participation. The bottom line is that an intensive set of periodic or longitudinal surveys would be required to determine any long-term effect of the program on the market.

${ }^{34}$ To the question of how one could determine if the IAC program lowered discount rates in a statistically rigorous fashion, it seems that data would need to have been collected on the efficiency projects undertaken by these same firms in years prior to the audit. This would have required information on the available alternative measures known to these plant managers in these earlier periods. To make a valid comparison, only sets of alternative potential projects having investment costs of the same order of magnitude should be used to infer the threshold payback periods. Obviously, the development of empirical data to develop such estimates would require substantial planning and resources.
} 
permanently altered by the existence of the program. On this point, the evidence does not appear to support that conjecture. 


\section{Possible Modeling Approaches}

Because of the complexities involved in developing a "one-size-fits-all" type of solution to these specific modeling challenges, a number of approaches are highlighted below to be considered for future research.

\section{Assessing the Empirical Linkages}

To address the empirical gaps in knowledge, a number of unique approaches could be taken, including conducting retrospective impact studies, market/consumer surveys, participant surveys, literature reviews, econometric studies, data tracking, focus groups, and "expert" opinions. This report includes the questions, responses, and analyses for two surveys conducted by ORC, addressing market barriers to wind generation, solar, and high-efficiency building components. Appendix $\mathrm{D}$ provides the results and statistical analyses of these surveys.

\section{Survey Considerations}

If surveys are utilized in an attempt to better inform the empirical gaps, some consideration should be given to the appropriateness of the survey vehicle itself. For example, the ORC surveys target a limited audience by only surveying household occupants or limiting the potential usefulness of the data to the perspective of the residential end-user. Additionally, surveys represent a snapshot in time. Ideally, a time series would be used to identify trends. Asking the same questions over an extended period of time would accomplish this task. Another consideration is whether generic survey instruments would provide insight into the specific impact of DOE programs, as opposed to other deployment efforts by manufacturers, states, and other federal programs. Finally, surveys - such as the ORC_-present the respondents' opinions, so may not contain the rigor of a scientific study that attempts to determine values for the variables of discount rates, risk premiums, or payback periods.

A survey methodology for estimating willingness to pay is proposed by Duncan (2007). If applied in the current context, the idea is to present a respondent with a choice between two products different in their quality (improved technology/product vs. existing one) and cost.

First, the introductory part of the survey makes the respondents familiar with the definition of improvements and how it is related to the cost difference. This establishes the cognitive benchmark such that the choice between products can be reliably answered. The respondent is presented with questions that encourage thinking about the value of the particular improvement. Then the explanation of the cost increase is introduced, which is followed by the test question that checks comprehension of the concept. It should involve a simple choice between identical products, except that one is more costly. Then a 
respondent is introduced with criteria that define the improvement (existing product, efficient product, advanced product) with a detailed explanation and example for each category.

Once the survey foundation is established, the respondents are presented with iterative choice questions structured in a particular way. As the author suggests, the choices are iterated, each time degrading the desirable aspect of the last alternative until the selection reverses. For example, if in the initial question the respondent preferred the less expensive product, which is not as efficient as a new one, the next question would present the same pair of alternatives with a step-increase in the cost of the previously chosen less efficient and less expensive product. Continued preference for the lower cost good leads to a continued increase in the cost of that good until the products cost the same with the preserved difference in efficiency levels. Once the respondent reverses the choice or becomes indifferent to the alternatives, the iterative process ends. The next section of the survey takes an analogous iterative approach comparing two products and iterating using the efficiencies. A continued preference for the more efficient and more expensive product leads to continued reductions in the efficiency level, until the efficiency is identical and the products differ only in cost. The iterations stop if the choice reverses or the respondent is indifferent between two alternatives. Demographic questions conclude the survey.

Survey results are analyzed within the framework of the modified choice model described in detail by Duncan (2007). Estimation is conducted via the Simulated Method of Moments approach of McFadden (1989), and obtained estimates are used as a basis for deriving willingness to pay, defined as a change in cost arising by the change in quality/efficiency while utility is held constant. The simulated willingness to pay is treated as univariate random variable for further statistical analysis. The results can be included as parameter estimates in the diffusion models described in this report.

\section{Commercial Module}

Regarding the commercial building technology-choice algorithm, a possible area of empirical research could address the technology-specific payback distributions identified and utilized within the module. As such, researchers could better reflect the proposed EERE technologies. Johnson Controls recently conducted a survey of 1250 company energy-management decision-makers. ${ }^{35}$ Within this survey, payback information was gathered regarding energy-efficiency purchases. Potentially, this information could be used to update the "time-preference premium" distributions currently used within NEMS (see Table 10). Because Johnson Controls plans to repeat the survey on an annual basis, DOE may wish to partner with them to expand the survey to include the gathering of technology-

${ }^{35}$ Johnson Controls. May 17, 2007. Energy Efficiency Indicator Research Final Report. 
specific payback information (e.g., lighting projects versus heating and cooling projects).

Table 10. Comparison of Commercial Customer Payback Periods

\begin{tabular}{|c|c|c|c|}
\hline \multicolumn{2}{|c|}{$\begin{array}{l}\text { Table E-2, NEMS Model } \\
\text { Documentation 2007: Commercial } \\
\text { Sector Demand Module }\end{array}$} & \multicolumn{2}{|c|}{$\begin{array}{l}\text { Jonson Controls Survey: Tolerance for } \\
\text { ROI on Energy Efficiency Investment }\end{array}$} \\
\hline $\begin{array}{l}\text { Preferred Payback } \\
\text { Period }\end{array}$ & $\begin{array}{c}\text { Percent of } \\
\text { Respondents } \\
(\mathrm{N}=659)\end{array}$ & Payback Period & $\begin{array}{c}\text { Percent of } \\
\text { Respondents } \\
(\mathrm{N}=1249)\end{array}$ \\
\hline 1 & 17 & 1 year or less & 8 \\
\hline 2 & 17 & 2 to 3 years & 34 \\
\hline 3 & 18 & 4 to 5 years & 30 \\
\hline 4 & 6 & 6 to 9 years & 10 \\
\hline$>4 *$ & 10 & 10 to 15 years & 5 \\
\hline Unknown** & 33 & More than 15 years & 1 \\
\hline \multicolumn{2}{|c|}{$\begin{array}{l}\text { * assumes that }>4 \text { year payback periods } \\
\text { average } 5.5 \text { years } \\
\text { ** assumes that "Unknown" implies a zero- } \\
\text { year payback period criterion }\end{array}$} & $\begin{array}{l}\text { Would not require } \\
\text { ROI }\end{array}$ & 3 \\
\hline
\end{tabular}

\section{Residential Module}

Regarding the residential technology choice function, if revamped to be more similar to that used in the NEMS commercial module, generic payback distributions could be used to inform the choice model. More research or surveys might be conducted to provide technology-specific results that would further refine the choice distributions. Such payback information may be gleaned from an ORC or similar survey instrument conducted specifically for this task.

An initial effort to collect this type of information through an ORC survey was recently undertaken by EERE (and summarized in Appendix D). Within that survey, residential consumers were questioned about payback preferences regarding energy efficiency in general and solar technologies in particular. Table 12 summarizes the results from querying householders regarding the amount spent willingly to achieve annual energy savings of $\$ 100$. The resulting distribution shown in the table can be converted to discount rates, provided an assumption is made concerning the time horizon of investment.

Respondents were also asked specifically about active solar-technology installations and whether a three-year return on investment would encourage investment. Almost one-half of the respondents (47\%) indicated this to be unlikely, with $75 \%$ of those indicating very unlikely, to invest $\$ 1500$ to capture $\$ 500$ per year in savings. This result is in contrast to the values obtained for the generic question shown in Table 11, where $31 \%$ of respondents were willing to spend $\$ 300$ or more to capture $\$ 100$ annual savings (indicated by a payback period of more than three years). Specific to solar technology, respondents are much less likely to make an investment despite meeting an applicable payback period. This finding indicates that further surveys and/or research may be 
required to gather technology-specific information about payback periods to inform technology-specific distributions. While an economic retrofit model within NEMS may use these numbers, applying and calibrating the payback information within the existing NEMS residential framework is not possible at this time.

Table 11. Residential Payback for Generic Energy Efficiency Improvements

\begin{tabular}{|l|c|}
\hline Payback Period & $\begin{array}{c}\text { Percent of } \\
\text { Respondents }\end{array}$ \\
\hline 1 year or less & 5 \\
\hline 2 years & 8 \\
\hline 3 years & 5 \\
\hline 4 years & 3 \\
\hline 5 years & 1 \\
\hline 6-7.5 years & 6 \\
\hline 7.5-20 years & 9 \\
\hline $\begin{array}{l}\text { More than } 20 \\
\text { years }\end{array}$ & 11 \\
\hline Would not do this & 32 \\
\hline Don't Know & 19 \\
\hline
\end{tabular}

\section{Risk Premium Parameters}

One possibility regarding risk-premium parameters, in general, is to explore the incorporation of a certainty equivalent by converting a measure of risk (typically, some type of premium incorporated into a discount or hurdle rate) to a dollar amount, and then applying the figure to the specific technology in an attempt to capture the "implicit cost" associated with the new technology (e.g., an end user may anticipate more service calls or other unknown costs, and, in essence, applies a mental "contingency" fund to the actual cost, causing individual choice behavior to be based on a higher cost.) The use of this type of method may also allow for "decoupling" of benefits between R\&D and deployment activities. The R\&D effort would be credited with introducing a technology to market at this implicit cost level (e.g., $\$ 700$ for a very high-efficiency water heater). Then, the deployment efforts would reduce the implicit cost to the actual (market) cost over a period of time as a reflection of the reduction in perceived risk. One issue not addressed by this type of method is that of deployment activities designed to increase market penetration of technologies already in the marketplace.

Presumaby, those technologies are already entered into NEMS based on marketprice information. Regardless, an additional "implicit cost" may be added to the market prices for certain products as a means of calibrating the model to the observed market shares.

If deployment activities are developed in this manner, the question then becomes how to determine the amount of the contingency for each technology. Generic surveys regarding consumer behavior and risk may not be applicable to the specific technology in question; thus, the preparation of technology-specific surveys may be necessary. However, the generic surveys may provide data that 
better inform the question. For example, within the ORC survey on general EERE deployment, the section on product attributes provides an indication as to the product features considered most important by residential buyers. To illustrate, within the group of respondents having purchased ENERGY STAR appliances, product reputation was extremely important, particularly for buyers age 18-34. While this would not help to define the starting point in terms of the contingency necessary to define the "higher" cost, it does help to determine which types of deployment activities would assist in the reduction of risk reflected in the implicit cost. Therefore, if a program is attempting to increase sales through the use of demonstration projects or case studies touting the reliability of a product, this segment of buyers would become more likely to purchase the equipment at its advertised cost.

\section{Integration Effect}

To address the "hair-cut" issue, more research specific to each impacted activity needs to be conducted to determine the appropriate decrement amount for those activities that remain outside the NEMS/MARKAL modeling framework. If another model is chosen to represent all deployment programs, this issue expands, in that an appropriate amount will need to be determined for a larger subset of activities. While one analysis (Hostick et al. 2006), conducted for BTP to determine the technical potential of the BTP R\&D portfolio, provided some insight into the potential amount by which the BTP R\&D integrated and nonintegrated estimates differed, a number of underlying issues remained that make application to the BTP portfolio difficult in general, let alone the entire EERE portfolio. In that analysis, Pacific Northwest National Laboratory (PNNL) developed two sets of technical potential numbers. These included a line-item estimate (assuming all other facets of market and technology were "frozen") and an integrated technical potential (where the technical performance of some technologies bounded those of competing technologies, and which accounted for interactions between HVAC/envelope and HVAC/lighting).

The resulting difference between the two technical potentials was approximately $34 \%$. However, PNNL also concluded that the application of this "hair-cut" for general benefits seemed large because the technical potential exercise assumed $100 \%$ penetration, while the GPRA exercise does not. Therefore, the crowdingout effect is expected to be small at best if penetrations are modest (as is usually the case within GPRA). While an argument could be made that penetration for all of the technologies would occur in the same buildings, the opposite could also be argued. If homeowners install extremely efficient windows, the heating load become so miniscule that the consumer will not believe a high-efficiency heat pump is cost effective. Conversely, a new heat pump may make heating so inexpensive that the homeowner would not wish to install new windows.

While further analysis, including research and survey instruments, might be employed to address this issue, a number of theoretical and practical differences 
are present between the energy sectors, the respective target markets, and the EERE programs that attempt to impact those sectors. Because the "hair-cut" amount should ideally be developed at the activity level, delving further into this issue may not be cost-effective. This is particularly true when the level of savings for that activity is small relative to the program/portfolio total.

\section{Addressing Model Structure Limitations}

To address some of the limitations presented in the existing NEMS structure, the consideration of some "add-on" modeling tp be completed either outside the NEMS structure or tacked onto a module as some form of sub-module may be useful. The consideration of alternative integrating models altogether may prove advantageous. Several possible approaches for alternative models are discussed in the following two sections.

\section{A Framework for Estimating Market Transformation Impacts}

In 2001, the large California electric utility, Pacific Gas and Electric (PG\&E), sponsored a major study focusing on the assessment of publicly-funded energy efficiency efforts (Dickerson 2001). The major objective of the resulting report was to discuss various methods of evaluating the cost-effectiveness of markettransformation interventions. In that respect, many of the issues covered in the report have direct relevance to the deployment activities undertaken by DOE/EERE.

The overall study was managed by Chris Ann Dickerson of PG\&E, and was funded through California Public Goods Charge. The project team consisted of a number of professionals with much experience in the area of program evaluation for both utilities and government entities. ${ }^{36}$

The report addresses key questions relating specifically to market-transformation activities undertaken by utilities and public agencies. Some of significant questions addressed in the study were:

- What is the economic rationale for energy efficiency policy?

- What is the proper role of market transformation in energy-efficiency policy?

- How can we design market transformation initiatives most effectively?

- What role does evaluation play in market transformation?

\footnotetext{
${ }^{36}$ Among key contributors to the report were: Lisa Skumatz (Skumatz Economic Research Associates), Shel Feldman (Shel Feldman Management Consulting), Miriam Goldberg (Xenergy, Inc.), Ken Keating (formerly with Bonneville Power Administration), Jane Peters (Research into Action, Inc.), and Fred Sebold and Alan Fields (Regional Economic Research, Inc.).
} 
- How can we evaluate the market effects associated with market transformation initiatives?

- How can we capture the dynamics of market transformation in the assessment of market effects?

Of particular relevance to the current study is the response to the final question in this list, namely the recognition of market dynamics and a means of developing estimates of market effects. ${ }^{37}$ The report identifies awareness, willingness, and availability as the critical factors that determine the new-technology-adoption process. Within the report, a framework is developed that connects payback, discount rate, and the adoption rate.

This proposed framework investigates three separate factors that are assumed to directly impact the adoption of a (new) energy-efficiency technology: 1) awareness, 2) willingness, and 3) availability. These factors are combined in a multiplicative fashion to determine the number (or market share) of adoptions at any time, as shown in the following expression:

\section{Adoptions= Applicable Market Size * Awareness * Willingness * Availability}

The first term in the above expression, market size, reflects the number of opportunities for which the (energy-saving) measure is applicable. The characterization of applicable market size depends on the market event associated with adoptions. The approach identifies the following market events: new construction, replace-on-burnout, retrofit, and appliance acquisition. The process can also be represented in terms of the adoption rate or market share:

\section{Adoption rate $=$ Adoptions $/$ Applicable Market Size $=$ $=$ Awareness * Willingness * Availability}

Similar to model developed by Van de Bulte et al. (1999), awareness plays a critical role in the framework. For any measure to be adopted, the market should be aware of its existence and basic properties. Lack of information due to poor information dissemination and/or high information costs directly impact the level of awareness in the market, which in turn influences adoption rate. This model assumes that with zero awareness, no adoptions will occur, and interventions (research, outreach programs, training, demos, etc.) increase awareness. A realistic assumption is made that awareness will change over time with or without interventions, and that the market does not become immediately aware of the product or measure when it becomes available. This dynamic process of effects from direct intervention is represented by the following equation:

Awareness $_{t}=\left(\alpha_{0}+\alpha_{1} I N T_{t}\right)$ Awareness $_{t-1}+\left(\alpha_{2}+\alpha_{3} I N T_{t}\right)\left(\alpha_{4}\right.$ - Awareness Aw- $)$,

${ }^{37}$ This topic was the focus of Section 7 in the PG\&E report, written by Fred Sebold and Alan Fields. 
where $\alpha_{0}$ is the fraction of the market that remains aware without any interventions by the public entity, and determines sustainability of awareness after intervention is discontinued. The term, $\alpha_{1} I N T_{t}$, is the fraction remaining aware as the result of some intervention in period t. Thus, the combined terms, $\left(\alpha_{0}+\alpha_{1}\right.$ $I N T_{t}$ ), represents the fraction of decision-makers that were aware in the previous period and remain aware.

Several terms in the model are used to develop the impacts on decision-makers who were unaware in the prior period. The parameter, $\alpha_{2}$, reflects the proportion that becomes aware as a result of factors other than interventions. The term, $\alpha 3$ INTt, represents the impact of the intervention on those who were previously unaware. Finally, the $\alpha 4$ parameter is used to adjust the potential fraction of decision-makers that can be made aware. The overall specification implies that awareness in previous periods depends on past interventions (i.e., the impact of current intervention can be sustained into the future periods).

"Willingness" is an unconventional term to be applied in a model of this type. The willingness to adopt is measured by the proportion of aware customers who actually adopt the measure when it is available. In this proposed framework, willingness is generally linked to a rate of return, a payback, or some other indicator of financial efficacy. Other determinants of willingness are the availability of financing, perceptions of risk, and concerns about performance. The impact of direct interventions on the willingness to adopt any particular measure is modeled as follows:

Willingness $_{t}=\left(\beta_{0}+\beta_{1} I N T_{t}\right)$ Willingness $_{t-1}+\left(\beta_{2}+\beta_{3} I N T_{t}\right)\left(\beta_{4}-\right.$ Willingness $\left._{t-1}\right)$,

where parameters $\beta_{0}, \beta_{1}, \beta_{2}, \beta_{3}$, have similar interpretation as found in the context of awareness. Note that consumers' willingness to adopt any measure at time (t) does not depend singularly on the willingness in previous periods or direct intervention. The adoption decision is equivalent to the investment decision, in that it relies heavily on perceived benefit/cost or perceived risk/payback. Therefore, payback could be included in place of the intervention impact to reflect such dependence:

Willingness $_{t}=\left(\beta_{0}+\beta_{1}\right.$ Payback $\left._{t}\right)$ Willingness $_{t-1}+\left(\beta_{2}+\beta_{3}\right.$ Payback $\left._{t}\right)\left(\beta_{4}-\right.$ Willingness $\left.s_{t-1}\right)$,

where coefficients $\beta_{1}$ and $\beta_{3}$ are negative to reflect the inverse relationship between payback and measure attractiveness. The authors suggest that the impact of the intervention on the payback might be represented as:

Payback $_{t}=\beta_{5}+\beta_{6}$ Payback $_{t}+\beta_{7} I N T_{t}$, 
where $\beta 5$ is the assumed payback given no interventions, $\beta 7$ reflects the current period impact of an intervention on the payback, and $\beta 6$ reflects the sustainability from of this impact on the payback after the intervention is withdrawn.

Unfortunately, this study does not elaborate on how the relationship between payback and the intervention works in practice. Given the market orientation of the model, one would expect that the payback represents some measure related to the distribution of payback thresholds in the population of consumers (e.g., mean payback). The key point is that the public intervention is presumed to affect the payback criterion in some measurable fashion.

The authors suggest distinguishing different types of interventions in the following manner: 1) rebates can be expected to have very low sustainability $\left(\beta_{6}\right.$ will be low, perhaps even 0 ), and 2 ) others, such as initiatives designed to improve manufacturing processes, may have highly sustainable impacts (i.e., $\beta_{6}=1$ ).

The third factor in this conceptual framework, "availability," is important for some energy-efficiency measures, especially emerging technologies. Due to market inertia, the availability of new energy-efficient technologies may develop slowly over time in response to both intervention and non-intervention factors. The dynamic relationship presented is similar to that described in the context of awareness and willingness.

The major challenge to the implementation application of this model is the development of parameter estimates. The authors demonstrate the sensitivity of adoption rate over time to the changes in parameters by comparing curves with several sets of initial values. These examples emphasize the importance of having credible parameter estimates to allow accurate adoption estimation.

Some suggestions are made regarding potential methods to approach this issue. The recommended methods include decision-maker and decision-influencer surveys, pre/post promotion surveys, pre/post training tests, and Delphi techniques, such as expert group and sequential questionnaires. With regard to willingness, the authors suggest the use of survey data to estimate payback distributions to indicate the relationship between willingness and payback.

The authors note that initial (in the sense of assessing an intervention from its outset) parameter values can be projected based on the information obtained from other similar initiatives. The researchers also strongly suggest that the framework may need calibration to observed values for an initial time period. This can be done by carefully adjusting individual parameters or by simply introducing a multiplicative factor that will make the model's predicted adoption rate consistent with the observed values. Regardless of the approach taken, the model requires data on the original condition of the market prior to the intervention, in addition to the systematically collected data after the intervention, to appropriately adjust time-variant parameters to forecast future adoptions. 
Several aspects of the framework proposed in this study may have relevance for the limitations in the current NEMS model, particularly with regard to deployment programs targeting end users. The first is that the framework adds additional support to the notion that explicitly representing awareness as a separate factor in the adoption (i.e., technology choice) process may be useful. As suggested previously in this report, a market-segmentation approach may be appropriate in several of the NEMS demand modules when the segments are distinguished by a fraction of consumers aware of a new technology.

The formulation of the model segment dealing with willingness is very simple and does not appear to add anything over the existing choice frameworks in NEMS currently. However, optimism that the surveys or other empirical analyses could be used to develop distributions of payback (criteria) or presumably other financial decision criteria used by end-users of energy-related technologies is expressed. Unfortunately, this study does not offer historical examples of surveys having been conducted for this purpose.

The challenge for improving the empirical foundation for NEMS is to collect substantially more information relating to the payback or discount rates, which will better inform the technology-choice frameworks. The information on payback criteria collected by Johnson Controls (2007) may be a very good starting point for improving the basic commercial model in NEMS. The more daunting challenge is to detect changes in consumer decision-making behavior (with regard to these financial criteria) that stem from EERE-supported deployment efforts. At a minimum, a long-term project must define a methodology that can measure changes in decision-making behavior over a period of years. Such a project must also attempt to gather information on the aspect of the decision behavior itself as well as gain insight on the various influences upon that behavior (including those related to the EERE deployment efforts).

\section{Market Diffusion Modeling}

For activities not well characterized in the technology-choice sub-modules of NEMS, incorporating some external factors, such as diffusion curves and/or empirical statistics to improve the modeling, may be possible.

Since the 1960s, many market-penetration theories have been researched with the objective of projecting the impact of the market adoption of a new technology. Diffusion models assume that a product's market penetration will follow a characteristic time path. Diffusion models are most appropriately applied to analyses involving new technologies (Bernhardt and Mackenzie 1972, Heeler and Hustad 1980). Previous research shows that technology introductions usually follow an S-curve with slow adoption in the beginning, followed by exponential growth, and a later decline in the adoption rate (Rogers 1962). Historically, this diffusion process has been represented in several ways, with epidemic and 
qualitative choice (probit) models being the two primary modeling approaches for this problem.

The first approach, epidemic modeling, explains the introduction of new technology with the way knowledge propagates to potential users. A slight difference exists in assumptions of two basic epidemic models, commonly used in this context. One of these assumes a central source (i.e., media advertising), which transmits information to a constant fraction of users each year. Unfortunately, this particular model fails to produce an expected S-curve due to the large growth in the beginning. The second type of epidemic model relies on information being spread by word-of-mouth. This model produces the expected outcome, an S-curve, but fails to provide insight into how successful introduction of new technology can be explained without initial installations. The gap between the two basic models was resolved by using a mix of both information sources (Geroski 2000).

The second approach, probit models, focuses on the potential developer's characteristics to explain why some actors adopt new technologies before others. This modeling technique produces the expected S-curve. The shape is dependent on the assumptions of how profitability is distributed among potential adopters, how this profitability evolves over time, and the relationship between profitability and adoption.

Two diffusion models that could be used to model some EERE's deployment activities are briefly considered below. The first diffusion model is a combination of epidemic and probit modeling, developed by Maribu et al. (2007) in a study addressing the diffusion of distributed energy-resource technologies in buildings. In the epidemic approach, the mixed-information source is represented by two parameters. The first accounts for percentage of potential users being reached by the central source, which includes outreach programs and research. The second parameter represents the word-of-mouth information flow. This flow of information from the second source increases as the installed capacity grows. As such, the strength of the process is proportional to the fraction of buildings that have the distributed technology already installed. The probit approach is represented by direct modeling of individual building characteristics as well as the economic attractiveness of the distributed technology.

Basic assumptions are listed below:

1. Some technological solutions are more suitable for particular buildings, which are reflected in variability of energy-bill savings. Therefore, the assumption is made that buildings with a higher energy-bill savings are more likely to install the distributed technology.

2. Some buildings will never adopt a new technological solution, even with complete information. Hence, the potential floorspace available for the distributed-technology installation is lower than total commercial floorspace. 
The empirical analysis in the paper focuses on the distribution of the small-scale power-generating technologies for commercial buildings. Thus, commercial floorspace, both available for installation and with the capacities already installed, is an essential part of the model. Other types of inputs required by this model include data related to building type, building size, available floorspace, and floorspace with previously installed distributed technologies. Detailed data on cost and performance of the distributed technologies and energy rate schedules are also needed.

The actual model developed in the paper (DER-MaDiM ${ }^{38}$ ) relies on the results of two intermediate estimation steps. First, building-energy loads are estimated by the DOE-2 ${ }^{39}$ energy-simulation model, which is based on the climate data and building characterization. Energy loads, energy prices, and technology characterization are then fed into DER-CAM, which produces optimal capacity and cost savings. These results are subsequently used by DER-MaDiM, the newly-developed model, to generate installed capacity, energy consumption, and cost savings.

The prediction of market diffusion is done for two different scenarios, which are completely defined by the adoption parameters (parameters of the logistic adoption function) and information-dissemination parameter (fraction of the potential users obtaining information from the central information source and strength of the word-of-mouth process). Analysis results in the expected Scurve-the shape of which is sensitive to the chosen parameter values.

An explicit path dependence of the predicted technology diffusion is observed (i.e., both initial state and process flow determine the outcome). In addition, the model has a significant uncertainty stemming from estimating the investor's behavior, energy costs, and technology-cost developments. This, in combination with the path dependence, implies that one of these developments may drastically change the rates of diffusion and, as a consequence, the nature of the end results.

Notably, the paper explicitly states that finding correct parameters for the model is a challenge. Even if parameters can be estimated empirically from introduction of similar technology, the comparison across technologies that have unique features might not be appropriate.

One possible approach would involve estimating parameters based on surveys of building owners' knowledge of distributed technology and willingness to invest. ORC or other survey platforms may contribute to gathering the type of information needed to determine the appropriate values for the parameters that represent the

\footnotetext{
${ }^{38}$ Distributed Energy Resources Market Diffusion Model (DER-MaDiM)

${ }^{39} \mathrm{DOE}-2$ is a public domain computer simulation program for energy analysis of buildings, developed by the U.S. Department of Energy.
} 
fraction of the potential users obtaining information from the central information source as well as strength of the word-of-mouth process. For example, in the July 2007 EERE Deployment Survey (included in Appendix D of this report), the respondents were asked to list the information source or sources most relied upon for making the purchase of the product they invested in. The results are presented in Table 12 below.

Table 12. EERE Deployment Survey Sample Result (Complete survey results found in Appendix D)

\begin{tabular}{|c|c|c|c|c|c|}
\hline & $\begin{array}{l}\text { Heat/Cool } \\
\text { Equip }\end{array}$ & Insulation & Window & $\begin{array}{c}\text { E-Star } \\
\text { Appliance }\end{array}$ & $\begin{array}{l}\text { Solar } \\
\text { Panel } \\
\text { IWH }\end{array}$ \\
\hline $\begin{array}{l}\text { Consumer Reports or } \\
\text { other consumer } \\
\text { information publications }\end{array}$ & $17 \%$ & $11 \%$ & $11 \%$ & $24 \%$ & $4 \%$ \\
\hline Internet Searches & $8 \%$ & $4 \%$ & $10 \%$ & $13 \%$ & $31 \%$ \\
\hline $\begin{array}{l}\text { Contractor/Builder } \\
\text { recommendations }\end{array}$ & $26 \%$ & $29 \%$ & $21 \%$ & $5 \%$ & $5 \%$ \\
\hline $\begin{array}{l}\text { Word-of-mouth, from } \\
\text { people you consider } \\
\text { knowledgeable }\end{array}$ & $26 \%$ & $18 \%$ & $24 \%$ & $15 \%$ & $25 \%$ \\
\hline $\begin{array}{l}\text { Advertisements (TV, } \\
\text { radio, newspaper, } \\
\text { Internet) }\end{array}$ & $6 \%$ & $3 \%$ & $7 \%$ & $5 \%$ & $7 \%$ \\
\hline $\begin{array}{l}\text { Labels, such as "Energy } \\
\text { Star" }\end{array}$ & $4 \%$ & $4 \%$ & $6 \%$ & $15 \%$ & $0 \%$ \\
\hline Sales people in the store & $5 \%$ & $11 \%$ & $8 \%$ & $14 \%$ & $21 \%$ \\
\hline $\begin{array}{l}\text { Utility-sponsored } \\
\text { programs and information }\end{array}$ & $4 \%$ & $9 \%$ & $2 \%$ & $2 \%$ & $0 \%$ \\
\hline $\begin{array}{l}\text { Government-produced } \\
\text { informational brochures } \\
\text { and websites (e.g., } \\
\text { Department of Energy, } \\
\text { State and City } \\
\text { departments) }\end{array}$ & $1 \%$ & $5 \%$ & $4 \%$ & $3 \%$ & $0 \%$ \\
\hline Other: [Specify] & $1 \%$ & $2 \%$ & $2 \%$ & $1 \%$ & $0 \%$ \\
\hline None of these & $1 \%$ & $3 \%$ & $1 \%$ & $1 \%$ & $0 \%$ \\
\hline Don't know & $1 \%$ & $<1 \%$ & $2 \%$ & $1 \%$ & $8 \%$ \\
\hline
\end{tabular}

Should sources of information in this question be grouped such that one group includes information flows representing word-of-mouth process ( salespeople in the store, contractor recommendations, word-of mouth from people considered knowledgeable, etc) and another group incorporates the central source, which includes outreach programs and research (government-produced informational brochures and websites, advertising, consumer reports, utility-sponsored programs and information, labels like ENERGY STAR, internet sources, etc.), then the total percentage values for each group can be directly placed into the model for parameter values. Based on the results for the specified grouping, when 
investing in heating and cooling equipment, $40 \%$ of the sample relied on the central-source programs, while $57 \%$ gave primary consideration to word-of-mouth information. Therefore, the parameter estimates for the model described above are 0.4 and 0.57 , respectively. Similarly, the estimates for insulation are 0.36 and 0.6 for central programs and word-of-mouth process, respectively.

Note that out of five products listed in the table, each one has a distinct distribution of the percentage values across different information sources, which results in distinct parameter estimates ( 0.4 and 0.57 for heating and cooling equipment versus 0.36 and 0.6 for insulation). This emphasizes the difficulty in trying to model diffusion of one product based on the estimation results for another, especially if the former possesses unique attributes. Such a variation becomes even more critical if path dependence is observed. ${ }^{40}$

In addition, as previously mentioned, the willingness to invest and awareness of the distributed technology for targeted markets within the residential sector can be derived directly from the ORC survey results. For example, one of the survey questions asked the respondents how much they would be willing to pay in order to capture $\$ 100$ annual energy savings. Approximately one-half of the respondents indicated they would be willing to pay something (49\%), with the remainder indicating they either did not know (19\%), or would not be willing to spend at all (32\%). Particularly compelling, though, is that-as a percent of the total-as many respondents were willing to pay $\$ 2000$ or more $(11 \%)$ as those willing to spend only less than $\$ 200(14 \%)$. Subset analyses indicate that $14 \%$ were willing to pay from $\$ 1-\$ 200 ; 9 \%$ were willing to pay $\$ 200-\$ 500$; and a surprising $27 \%$ were willing to pay more than $\$ 500$. Such a variation in willingness to invest suggests the distribution of paybacks that could be used rather than an average payback.

The missing fragment is the formally defined structure of the sectors targeted by the current modeling effort. The adjustment of the market diffusion model of Maribu et al. (2007) may be possible to make the model applicable to the sectors of interest from the standpoint of accommodating each individual type of technology. To pursue this goal, first defining the variables of interest is essential. Second, the objective of the modeling must be clearly defined, namely identifying the particular aspects requiring modeling and the assumptions needing to be incorporated.

Another recent model capable of capturing the essence of the diffusion process was developed by Muller (2006). This model, which examines historical consumer electronic sales, also relies on the concept of the mixed-information source, where the external-influence coefficient represents the information flow

\footnotetext{
${ }^{40}$ Path dependency suggests there is no convergence to a single equilibrium. In other words the departure point and the route define the destination point. In the context of technology adoption, a single event during the adoption period can significantly alter the outcome.
} 
from the central source and the internal influence coefficient reflects the strength of the word-of mouth process.

The fundamental difference of this model is that it accounts for a "dual market" structure that encompasses two distinct stages of the diffusion process. Namely, these include a first stage (when the product is adopted by the early adopters) and a second stage (when the product penetrates the main market [late adopters]). A discontinuity is evident between the two stages because of the assumption that late adopters refuse to rely on the information of the early adopters. Such an assumption results in the model producing a two-peak adoption curve. The first peak represents the high sales point of the first stage (early market), and the second peak results from the product saturating the main market.

This approach slightly contradicts the assumption of the first model formulated by Maribu et al. (2007), specifically with respect to continuous growth of the strength of word-of-mouth process as being proportional to the installed base of new technologies. In addition, this second model explicitly demonstrates the concern expressed by Maribu (2007) regarding the usage of similar technologies to estimate the influence parameters, and then applying the estimates to model the diffusion of parallel technologies. Not all of the estimated datasets analyzed by Muller and Yogev (2006) produced the desired dual-market shape. Therefore, when carrying over the parameters from one model to another, an unexpected result may be produced, not due to the uniqueness of the particular technology as reflected by the data, but rather due to implicitly inherited assumptions. This may be of particularly high concern for models that produce path-dependent equilibriums and, thus, are very sensitive to uncertainty (such as that produced by Maribu et al. [2007]).

In general, the dual-market result is consistent with the idea that some of the adopters discount the future at higher rates than others. Also, different discount rates would apply depending on the technology considered. Thus, the average adoption time for each market might be dictated, to a large extent, by the discount rate. The investigation into whether discount rates can be included into either one of these models directly, and to what extent they might impact the shape of the adoption curve, would be instrumental. A further evaluation of the two modeling frameworks is also necessary to determine the overall relevance to the deployment of EERE-developed technologies. The empirical testing of the "dual market" model by Muller and Yogev (2006) focused primarily on consumerelectronic products.

\section{Alternative Models: CIMS and SEDS}

Where model-structure limitations prevent accurately modeling deployment, the consideration of other integrating models may be useful. For example, the Industrial Technologies Program is currently investing the further development of 
the $\mathrm{CIMS}^{41}$ model. CIMS is an integrated set of economic energy and materials models designed to provide information to policy makers on the likely response of firms and households to policies that influence their technology acquisition and use decisions. Therefore, CIMS is sometimes described as a technologysimulation model that seeks to reflect how people actually behave rather than how they ought to behave. CIMS models the industrial sector by clearly taking into account specific industrial technology and efficiency factors.

Alternative models may also provide solutions to some of the limitations inherent in the relatively rigid choice algorithms embedded in NEMS. An insight on the possible modeling approach might be provided by the current Stochastic Energy Deployment Systems (SEDS) framework. In this framework, a fairly generic layout can be adjusted to different sectors. In turn, the modeling within the sector requires detailed knowledge of the sector-specific technologies and the market. This is dictated by the fact that the flow of technologies in time through each sector has a set of very particular imposed structural assumptions.

In addition, within SEDS, new technologies are competed against the old technologies, proportional to cost share. An investigation into the readjustment potential of a portion of the technology competition module may be informative. This may include adjusting the module so that it accounts for the technology diffusion not only through a static market allocation mechanism, but also with consideration given to a dynamic S-curve characterization as exemplified by the model of Maribu et al. (2007) and/or dual-market approach of Muller (2006). Including the discount rate as a possible diffusion-impacting variable may also prove to be useful.

${ }^{41}$ CIMS originally stood for Canadian Integrated Modeling System but, as the model is now being applied to other countries, the acronym is now used as a proper name. In the U. S., this acronym stands for "Consolidated Impacts Modeling System." 


\section{Conclusions}

At the outset of this project, a comprehensive assessment of the extent and manner in which EERE deployment activities are modeled within the integrated framework was not available. Although it appears that modeling deployment activities certainly has its challenges, there are a number of programs that explicitly model deployment programs within the NEMS/MARKAL framework, while a number of other programs model the deployment activities implicitly within the NEMS/MARKAL framework as part of their overall R\&D portfolio. Some programs, such as Industrial Technologies, FEMP, and WIP are currently not able to model their deployment within the integrated framework.

Although the robust NEMS/MARKAL framework allows for integration across various energy supply-and-demand sectors, it is not flexible enough to account for the wide variety of deployment activities that are currently undertaken by EERE. In addition, some of the NEMS modules, such as the industrial module, are not structured in a way to allow for industrial deployment modeling. There are also a number of programs (Hydrogen, Biomass, and Freedom Car), that model $R \& D$ and deployment together, and there currently appears to be little incentive for these programs to expend the effort to model R\&D and deployment activities separately as part of the integrated modeling effort.

The integrated modeling process has been structured to primarily gather modeling inputs in the form of cost and performance parameters. While it is typically sufficient to characterize R\&D programs in terms of cost and performance, deployment programs are more appropriately characterized as impacting behavioral parameters within the model (typically consumer discount rates or investor risk premiums). While it may be possible to identify behavioral parameters that could be impacted by deployment, perhaps the most significant challenge facing programs relates to the lack of empirical data to determine how specific parameters should be changed.

There are also consistency issues regarding model structure and nuances, such that program managers cannot have full confidence in the accuracy of modeling results. To address some of these knowledge gaps and model shortcomings, some additional efforts could be expended on gathering empirical data and devising new or adopting existing external diffusion models; however, both of these efforts would require significant time and resources; thus, it may be useful to reassess the modeling needs of EERE before initiating action in this area.

Table 13 provides a summary of the deployment modeling issues by program. 
Table 13. Program Modeling Summary

\begin{tabular}{|c|c|c|c|c|}
\hline $\begin{array}{l}\text { EERE } \\
\text { Program }\end{array}$ & NEMS Module Impacted & Key Parameters & Primary Knowledge Gaps & Resources Required \\
\hline Hydrogen & $\begin{array}{l}\text { HMM; Commercial Demand } \\
\text { Module (CDM); } \\
\text { Transportation Demand } \\
\text { Module (TDM) }\end{array}$ & $\begin{array}{l}\text { cost, performance, learning } \\
\text { cost function, market } \\
\text { diffusion curves }\end{array}$ & $\begin{array}{l}\text { Empirical basis to delineate } \\
\text { R\&D from deployment } \\
\text { activities. }\end{array}$ & $\begin{array}{l}\text { Significant resources required to } \\
\text { extract impact of deployment from } \\
\text { total program impact. }\end{array}$ \\
\hline Biomass & RFM & $\begin{array}{l}\text { risk premium (i.e., equity beta } \\
\text { parameter or financing } \\
\text { structure, debt/equity), } \\
\text { learning functions }\end{array}$ & $\begin{array}{l}\text { Empirical basis measuring } \\
\text { impact of program activities on } \\
\text { risk premium and delineating } \\
\text { R\&D from deployment. }\end{array}$ & $\begin{array}{l}\text { Significant resources required to both } \\
\text { empirically link risk premium to } \\
\text { program activity and extract impact } \\
\text { of deployment from total program } \\
\text { impact. }\end{array}$ \\
\hline Solar Energy & $\begin{array}{l}\text { Residential Demand Module } \\
\text { (RDM); Commercial Demand } \\
\text { Module (CDM) }\end{array}$ & $\begin{array}{l}\text { cost, performance, electricity } \\
\text { rate structures. }\end{array}$ & $\begin{array}{l}\text { Modeling structure to account } \\
\text { for policy actions and factors } \\
\text { impacting cost of grid } \\
\text { connections and other market } \\
\text { barriers. Recent work by EIA to } \\
\text { model solar in niche markets } \\
\text { will be very useful. }\end{array}$ & $\begin{array}{l}\text { Unclear, but likely significant required } \\
\text { to fill both modeling structure and } \\
\text { empirical gaps. Requires baseline } \\
\text { assessment of of cost implications of } \\
\text { interconnection costs (utility fees, } \\
\text { codes/standards, permitting costs). } \\
\text { Develop methodology to permit } \\
\text { future assessment of "Solar America } \\
\text { Cities." }\end{array}$ \\
\hline Wind & EMM, RFM & $\begin{array}{l}\text { risk premium, resource cost, } \\
\text { cost multiplier, regional } \\
\text { constraint factors }\end{array}$ & $\begin{array}{l}\text { Historical impact of } \\
\text { information/outreach } \\
\text { programs-by state. Potential } \\
\text { cost reductions from consistent } \\
\text { environmental assessment } \\
\text { methods. }\end{array}$ & $\begin{array}{l}\text { Significant resources required to } \\
\text { complete comprehensive time-series } \\
\text { (multiple years) empirical study. } \\
\text { Gather information from } \\
\text { interviews/surveys on environmental } \\
\text { permitting costs (including future } \\
\text { trends) }\end{array}$ \\
\hline $\begin{array}{l}\text { Freedom } \\
\text { Car/Vehicles }\end{array}$ & TDM & $\begin{array}{l}\text { cost, performance, "constant" } \\
\text { term in logit model share } \\
\text { equations (roughly } \\
\text { interpreted as risk premium) }\end{array}$ & $\begin{array}{l}\text { Empirical link between risk } \\
\text { premium and program } \\
\text { activities. }\end{array}$ & $\begin{array}{l}\text { Significant resources to assess } \\
\text { consumer purchase behavior with } \\
\text { unproven vehicle technologies. Will } \\
\text { require surveys or focus groups.. }\end{array}$ \\
\hline $\begin{array}{l}\text { Building } \\
\text { Technologies }\end{array}$ & CDM; RDM & $\begin{array}{l}\text { discount rates, risk } \\
\text { premiums, learning cost } \\
\text { functions, performance }\end{array}$ & $\begin{array}{l}\text { Modeling structure lacking for } \\
\text { some activities (e.g., building } \\
\text { energy codes). Empirical link } \\
\text { between discount rate/risk } \\
\text { premium and program } \\
\text { activities. }\end{array}$ & $\begin{array}{l}\text { Significant modifications to CDM and } \\
\text { RDM required. Significant resources } \\
\text { required to empirically (with time- } \\
\text { series studies or targeted surveys) } \\
\text { link discount rate with program } \\
\text { activities. Initial step is to review } \\
\text { utility and international studies of } \\
\text { "market transformation" }\end{array}$ \\
\hline
\end{tabular}




\begin{tabular}{|l|l|l|l|l|}
\hline $\begin{array}{l}\text { EERE } \\
\text { Program }\end{array}$ & NEMS Module Impacted & Key Parameters & Primary Knowledge Gaps & Resources Required \\
\hline $\begin{array}{l}\text { Industrial } \\
\text { Technologies }\end{array}$ & $\begin{array}{l}\text { Industrial Demand Module } \\
\text { (IDM) }\end{array}$ & $\begin{array}{l}\text { No technology choice } \\
\text { module exists. }\end{array}$ & $\begin{array}{l}\text { No integrated model structure } \\
\text { exists. }\end{array}$ & $\begin{array}{l}\text { Developing new model structure } \\
\text { (CIMS) requires significant } \\
\text { resources. }\end{array}$ \\
\hline FEMP & CDM; RDM; TDM & $\begin{array}{l}\text { Unclear (savings currently } \\
\text { calculated outside of model) }\end{array}$ & $\begin{array}{l}\text { Unclear (level of savings likely } \\
\text { would not warrant further } \\
\text { modeling efforts). }\end{array}$ & $\begin{array}{l}\text { Significant modifications to CDM to } \\
\text { segment buildings into public } \\
\text { (federal) and privately-owned. }\end{array}$ \\
\hline WIP & RDM; CDM; RFM & $\begin{array}{l}\text { Unclear (savings currently } \\
\text { calculated outside of model) }\end{array}$ & Unclear. & $\begin{array}{l}\text { Savings driven by budget - } \\
\text { exogenous to buildings models. } \\
\text { Current procedure of adjusting model } \\
\text { results is adequate. }\end{array}$ \\
\hline
\end{tabular}


This report presents several examples of recent empirical sources related to discount rates or payback periods that could be used to improve the current empirical foundation of the choice models in NEMS. The most promising of these sources is the extensive survey conducted by Johnson Controls. However, the scope of the study was not designed to perform a comprehensive literature search on this particular topic. A future study that focuses upon the financial decision-making criteria employed by end users of energy-using technologies would be valuable. An important aspect of such a study is to determine whether there has ever been an explicit attempt to measure the effect of government interventions upon this aspect of decision-making behavior-either at the state level or in any other country.

In addition to exploring the possible approaches described in the report, it may also be worthwhile to expend some effort synthesizing all EERE evaluation and analysis efforts beyond just what was explored with relation to GPRA estimates, which was the focus of this report. Additionally, current and historical analyses undertaken by utilities deserve further exploration. Because of their experience with Integrated Resource Planning, utilities and utility commissions have developed advanced databases and modeling techniques in an effort to accurately estimate the impacts of various demand-side and supply-side programs; many of these programs are deployment-focused, utilizing various forms of information dissemination.

To facilitate further research in the area of deployment modeling, it is essential that program managers come to a consensus regarding the goals of the modeling effort. Some questions that should be addressed include the following:

1. Is the goal of the deployment modeling effort to estimate how much energy is being saved or is the goal to determine how much energy is saved relative to other programs?

2. Is there a uniform need to measure the impact of deployment relative to R\&D?

3. Is it the goal that the model (NEMS or MARKAL) would be used as a forecasting or predictive tool, or is the objective to have the model simply reflect EERE goals?

4. How important is it to stay within the NEMS/MARKAL framework? Should other paths be considered?

5. How will the modeling results be used? Will modeling results be used to examine whether or not internal goals are being met, or will they be used externally? 
6. Is the universal energy/carbon metric essential, or are there other benefits that should/could be considered?

If incorporating deployment activities is a priority to the integrated modeling process, then consideration should be given to restructuring the guidance regarding model inputs. The process now primarily focuses on gathering cost and performance information for a given technology. Although these inputs may be sufficient in characterizing R\&D programs, they do not adequately characterize deployment activities, which will typically impact consumer or investor decision behavior or ancillary installation costs not directly associated with the technology. Because deployment programs do not fit into the current modeling input structure, they are often left out of the integrated modeling process altogether or characterized with external market diffusion and energy savings estimates that do not directly link to parameter inputs within the integrated modeling framework. To avoid these broken links, the modeling input should directly relate to the behavioral parameters (e.g., program impact on market discount rate or investment risk premium) within the model. This would be a difficult task, both in terms of clearly being able to define the behavioral parameters within NEMS and then in empirically linking the program activity to the modifications made to parameters. However, it would improve the transparency of the process enabling the modeler to more efficiently identify where knowledge gaps exist.

Finally, some thought should be given to the goal-setting process utilized by the EERE programs. Ideally, all programs have goals with outputs and outcomes that are measurable. The question is whether these goals should be set using historical analysis of very similar programs, or whether goals should be written to reflect an outcome such as market share or a degree of change in market behavior (measured somehow as a change in payback periods or discount rates). How to (and to what extent) determine the empirical basis for such changes may be very difficult to formulate. If the goal of the program is to demonstrate some change in market behavior, more study (most likely at the activity level) would ideally be needed to demonstrate the empirical basis for modifying the modeling parameters. Because all activities have limited resources for such studies, the magnitude of effort becomes an issue of setting priorities. For those activities in which historical trends might be applicable, measurement can be made more easily by basing the benefits on an extrapolation of empirical evidence as to how consumers and investors have been impacted by very similar activities in the past. Goals of this type should only be applied when there is very little doubt that the activities and audience are similar (a prime example would be ongoing deployment evaluation efforts, such as those conducted by ITP). 
Alderfer, RB, TJ Starrs, and MM Eldridge. (2000). Making Connections: Case Studies of Interconnection Barriers and Their Impact on Distributed Power Projects. NREL/SR-200-28053, National Renewable Energy Laboratory, Golden, Colorado. .

Anderson, ST and RG Newell. (2002). Information Programs for Technology Adoption: The Case of Energy-Efficiency Audits. Resources for the Future. Washington, D.C.

Arent, D, R Benioff, G Mosey, L Bird, J Brown, E Brown, L Vimmerstedt, J Aabakken, K Parks, M Lapsa, S Davis, M Olszewski, D Cox, K McElhaney, S Hadley, D Hostick, A Nicholls, S McDonald, and B Holloman. (2006). Energy Sector Market Analysis. NREL Report No. TP-620-40541, National Renewable Energy Laboratory, Golden, Colorado.

Bass, F. (1969). "A New Product Growth Model for Consumer Durables." Institute for Operations Research and the Management Sciences, Linthicum, Maryland. Management Science 15(5). 215-227.

Bass, F. (1980). "The Relationship Between Diffusion Rates, Experience Curves, and Demand Elasticities for Consumer Durable Technological Innovations." Journal of Business 53(3.2). S51-S67.

Bernhardt, I. and K Mackenzie. (1972). "Some Problems in Using Diffusion Models for New Products." Management Science 19(2). 187-200.

Berry, LG, MA Brown, and LF Kinney. (1997). Progress Report of the National Weatherization Assistance Program. ORNL/CON-450, Oak Ridge National Laboratory, Oak Ridge, Tennessee.

Dickerson, CA. (2001). A Framework for Planning and Assessing Publicly Funded Energy Efficiency. Study ID PG\&E-SW040, Pacific Gas and Electric Company, San Francisco, California.

Duncan, Gregory M. (2007). "Estimating Willingness to Pay by Means of Adaptive, Sequential Conjoint Experiments" , Department of Economics, University of California, Berkeley, and The Huron Consulting Group.

Eisenberg, JF. Oak Ridge National Laboratory. (2001a). Projections for the Weatherization Assistance Program, provided to the WIP program in file "Projections02d230.xls." 
Eisenberg, JF. Oak Ridge National Laboratory. (2001b). Special tabulations for the Weatherization Population derived from the 1997 Residential Energy Consumption Survey.

Electric Power Research Institute (EPRI). (1982). Methods for Analyzing the Market Penetration of End-Use Technologies: A Guide for Utility Planners, EPRI EA-2702, EPRI, Palo Alto, California.

Electric Power Research Institute (EPRI). (1991). Market Penetration of New Technologies, Programs, and Services, EPRI CU-7011, EPRI, Palo Alto, California.

Energy Efficiency and Renewable Energy (EERE) Deployment Task Force. (2004). 2004 EERE Deployment Inventory Effort, a collection of data, spreadsheets, and presentations.

Energy Efficiency and Renewable Energy (EERE). (2007). Projected Benefits of Federal Energy Efficiency and Renewable Energy Programs FY 2008 Budget Request: Appendix. March 2007. NREL/TP-62039684, National Renewable Energy Laboratory, Golden, Colorado.

Energy Efficiency and Renewable Energy (EERE). (2007). FY 2008 GPRA Benefits Estimates. NREL/TP-640-41347, National Renewable Energy Laboratory, Golden, Colorado. Accessed on the Internet October 25, 2007 at: http://www1.eere.energy.gov/ba/pba/gpra_estimates_fy08.html.

Energy Information Administration (EIA). (2007a). NEMS Model Documentation 2007: Commercial Sector Demand Module. U.S. Department of Energy, Washington, D.C.

Energy Information Administration (EIA). (2007b). NEMS Model Documentation 2007: Residential Sector Demand Module. U.S. Department of Energy, Washington, D.C

European Commission. (2004). Modeling Risks of Renewable Energy Investments. Prepared by KEMA (The Netherlands) for the European Commission. Work Package 2 within the $5^{\text {th }}$ Framework Programme of the European Commission supported by DG Research. Website: greenx.at/downloads/WP2

FY 2008 Budget Request (2007). Projected Benefits of Federal Energy Efficiency and Renewable Energy Programs FY 2008 Budget Request. Prepared by National Renewable Energy Laboratory, Golden, Colorado.

Geroski, P.A. (2000). "Models of Technology Diffusion.” Research Policy 29. 603-625. 
Heeler, R. and T Hustad. (1980). "Problems in Predicting New Product Growth for Consumer Durables." Management Science 26(10). 1007-1020.

Hostick, DJ, JA Dirks, DB Belzer, and DB Elliott. (2006). Program and SubElement Potential Benefits. PNNL-SA-49951, Pacific Northwest National Laboratory, Richland, Washington.

Johnson Controls. (May 2007). Energy Efficiency Indicator Research Final Report. Available at http://johnsoncontrolseei.web180.com/research_report.asp

Kahn, E. (1995). Comparison of Financing Cost for Wind Turbine and Fossil Power Plants. LBNL-36122. Lawrence Berkeley National Laboratory, Berkeley, California.

Mahajan, $V$ and $Y$ Wind, eds. (1986). Innovation Diffusion Models of New Product Acceptance. Ballinger Publishing Company, Cambridge, Massachusetts.

Maribu, KM, R Firestone, C Marnay, and A Siddiqui. (2007). "Distributed Energy Resources Market Diffusion Model.” Energy Policy 35. 4471-4484.

Sanchez, M, CA Webber, RE Brown, and GK Homan. 2007 Status Report Savings Estimates for the ENERGY STAR® Voluntary Labeling Program. March 23, 2007. LBNL-56380, Lawrence Berkeley National Laboratory, Berkeley, California. Published by Elsevier.

Muller, E and G Yogev. (2006). "When Does the Majority Become a Majority? Empirical Analysis of the Time at Which Main Market Adopters Purchase the Bulk of our Sales." Technological Forecasting and Social Change 73. 1107-1120, Published by Elsevier.

Oxera Consulting. (2007). What is the Impact of Limiting ROC Eligibility for LowCost Renewable Generation Technologies? Prepared for the Department of Trade and Industry, United Kingdom (URN 07/949). Downloaded from: http://www.dti.gov.uk/files/file39039.pdf

Reed, JH, G Jordan, and E Vine. (2007). Impact Evaluation Framework for Deployment Programs. EERE U.S. Department of Energy, Office of Energy Efficiency and Renewable Energy, Washington, D.C.

Rogers, E. (1967). "Mass Communication and the Diffusion of Innovations: Conceptual Convergence of Two Research Traditions." Paper presented at the Association for Education in Journalism, Boulder, Colorado.

Ruegg, R and G Jordan. (2007). Overview of Evaluation Methods for $R \& D$ Programs. Prepared for the U.S. Department of Energy, Office of Energy 
Efficiency and Renewable Energy by TIA Consulting, Inc. and Sandia National Laboratories. U.S. Department of Energy, Washington, D.C.

Schweitzer, M and JF Eisenberg. (2000). Meeting The Challenge: The Prospect of Achieving 30 Percent Energy Savings Through the Weatherization Assistance Program. ORNL/CON 479, Oak Ridge National Laboratory, Oak Ridge, Tennessee.

Schweitzer, M and B Tonn. (2005). An Evaluation of State Energy Program Accomplishments: 2002 Program Year Prepared by Oak Ridge National Laboratory for the U.S. Department of Energy, Office of the Weatherization and Intergovernmental Program, ORNL/CON-492, Oak Ridge National Laboratory, Oak Ridge, Tennessee.

U.S. Department of Energy, Weatherization Assistance Program (DOE/WAP). (2004). Funding Survey for Program Year 2003. Prepared by National Association for State Community Services Programs, Washington, D.C.

U.S. Department of Energy. (2007). FY 2008 Congressional Budget Request: Volume 3: Energy Supply and Conservation. DOE/CF-016. U.S. Department of Energy, Washington, D.C.

Van den Bulte, C and G Lilien. (1999). A Two-Stage Model of Innovation Adoption with Partial Observability: Model Development and Application ISBM Report 20-1999, Institute for the Study of Business Markets, The Pennsylvania State University. University Park, Pennsylvania. 
Appendix A - EERE Contacts

MODELING EERE DEPLOYMENT ACTIVITIES 


\section{Appendix A: Deployment and Modeling EERE Contacts \& Reviewers}

The table below outlines the primary contacts made by PNNL to identify and characterize the current slate of EERE deployment activities. In addition to these contacts, a number of exchanges, both via phone and email, were held with the modeling contacts for the programs (All meetings held in 2007).

\begin{tabular}{|c|c|c|}
\hline Program & Date of Meeting & Contact \\
\hline Buildings & $\begin{array}{l}\text { e-mailed } \\
4 / 25 \text { teleconference } \\
4 / 30 \text { teleconference } \\
4 / 30 \text { teleconference } \\
4 / 27 \text { teleconference } \\
4 / 20 \text { teleconference } \\
\text { Attempted telecon } 5 / 14 \\
\text { Email exchanges }\end{array}$ & $\begin{array}{l}\text { Jim Rannels, main contact } \\
\text { Carol Jones, PNNL, Com. Lighting Challenge } \\
\text { Rich Karney, Com. Lighting Challenge } \\
\text { Judy Dyer, NETL, Building Application Centers } \\
\text { Ron Majette, Advanced Codes } \\
\text { Ed Pollock, National Builder's Challenge } \\
\text { Lani MacRae, Patricia LeDonne, EnergySmart } \\
\text { Hospitals and Schools }\end{array}$ \\
\hline WIP & $\begin{array}{l}2 / 15 \text { meeting in } \mathrm{DC} \\
2 / 15 \text { meeting in } \mathrm{DC}\end{array}$ & $\begin{array}{l}\text { Cathy Short, Planning and Business Analysis (PBA) } \\
\text { Mark Bailey, acting Program manager }\end{array}$ \\
\hline Solar & $\begin{array}{l}2 / 14 \text { meeting in } \mathrm{DC} \\
3 / 14 \text { teleconference } \\
2 / 14 \text { teleconference }\end{array}$ & $\begin{array}{l}\text { Sheila Dade, PBA } \\
\text { Tom Kimbis, main contact } \\
\text { Charlie Hemmeline, program contact } \\
\text { Robert Margolis, modeler, NREL } \\
\text { Cecile Warner, modeler, NREL }\end{array}$ \\
\hline Wind & $\begin{array}{l}\text { 2/15 meeting in DC } \\
2 / 15 \text { meeting in } D C \\
2 / 15 \text { meeting in DC } \\
\text { Also multiple telecons } \\
(10 / 29 / 2007) \\
2 / 15 \text { meeting in DC } \\
2 / 15 \text { meeting in DC } \\
2 / 15 \text { meeting in DC } \\
\end{array}$ & $\begin{array}{l}\text { Linda Silverman, PBA } \\
\text { Alejandro Moreno, program contac } \\
\text { Maureen Hand, modeler, NREL } \\
\text { lan Baring-Gould, modeler, NREL } \\
\text { Steve Lindenberg, team leader } \\
\text { Phil Dougherty, Program manager }\end{array}$ \\
\hline $\begin{array}{l}\text { FreedomCAR } \\
\text { and Vehicles }\end{array}$ & $2 / 14$ meeting in $\mathrm{DC}$ & $\begin{array}{l}\text { Phil Patterson, PBA } \\
\text { Dennis Smith, program contact } \\
\text { Marcy Rood }\end{array}$ \\
\hline Hydrogen & $\begin{array}{l}\text { 2/14 meeting in } D C \\
3 / 14 \text { teleconference } \\
2 / 14 \text { meeting in } D C \\
2 / 14 \text { meeting in } D C \\
2 / 14 \text { meeting in } D C \\
2 / 14 \text { meeting in DC }\end{array}$ & $\begin{array}{l}\text { Randy Steer (PBA) } \\
\text { Fred Joseck, modeler } \\
\text { Pete Devlin (market transformation) } \\
\text { Christy Cooper, outreach } \\
\text { Andrea Chu, filling in for Christy Cooper } \\
\text { Antonio Ruiz, Safety Codes \& Standards work } \\
\text { Jonathan Munetz, Assistant to Ruiz }\end{array}$ \\
\hline Biomass & $\begin{array}{l}2 / 27 \text { teleconference } \\
2 / 27 \text { teleconference } \\
2 / 27 \text { teleconference } \\
9 / 28 \text { teleconference } \\
\end{array}$ & $\begin{array}{l}\text { Tien Nguyen, PBA } \\
\text { Michael Gonzales, PBA } \\
\text { Zia Haq, key program contact } \\
\text { Debra Sandor, NREL Systems Integration Office }\end{array}$ \\
\hline FEMP & $3 / 9$ teleconference & $\begin{array}{l}\text { Brad Gustafson, key program contact (referred us to } \\
\text { Will Lintner in phone conversation) } \\
\text { Will Lintner, program contact }\end{array}$ \\
\hline Industrial & $\begin{array}{l}\text { 2/14 telecon from } D C \\
\text { 2/14 telecon from DC; } \\
5 / 14 \text { follow-up, telecon }\end{array}$ & $\begin{array}{l}\text { Peggy Podolak, PBA } \\
\text { Bob Gemmer, program specialist in Best Practices } \\
\text { Michaela Martin, modeler, ORNL }\end{array}$ \\
\hline All & & $\begin{array}{l}\text { Frances Wood, OnLocation } \\
\text { Chip Friley, Brookhaven National Laboratory }\end{array}$ \\
\hline
\end{tabular}


The authors would like to express their appreciation to the individuals who assisted in the preparation of this document by providing comments and suggestions on a draft version of the report.

\begin{tabular}{|l|l|}
\hline Reviewer & Date, Format (e.g. e-mail) \\
\hline Philip Patterson, DOE & $10 / 5 / 07$, e-mail \\
\hline Michael Leifman, DOE & $10 / 12 / 07$, e-mail \\
\hline Frances Wood, OnLocation & $10 / 19 / 07$, e-mail \\
\hline David Boomsma, DOE & $10 / 19 / 07$, e-mail \\
\hline Peggy Podolak, DOE & $10 / 23 / 07$, e-mail \\
\hline Jeff Dowd, DOE & $10 / 24 / 07$, fax via D. Boomsma \\
\hline Gian Porro, NREL & $10 / 24 / 07$, e-mail \\
\hline
\end{tabular}


Appendix B - Deployment Program Characterizations and Modeling

Approaches

MODELING EERE DEPLOYMENT ACTIVITIES 
Hydrogen Program

\section{Project Description:}

Education and Outreach activities will allow for the increase in understanding of hydrogen and fuel-cell technologies to facilitate early market transformation. The pursuits will also lay the foundation for future market adoption and acceptance, which are required to realize the long-term benefits of using hydrogen as an energy carrier. Activities include the development and distribution of educational materials and training for safety and code officials, state and local governments, and potential endusers. Public education and outreach activities, with an emphasis on understanding the facts about hydrogen safety, are also included, in addition to efforts to develop and expand the hydrogen and fuelcell programs at colleges and universities. Hands-on activities and teacher-training materials are also deployed at the middle and high school levels.

\section{Market Barriers:}

The lack of information and understanding about the technology, in general, is the primary challenge being addressed by this deployment program. This lack of understanding may result in fear regarding the technology in its entirety.

\section{Modeling GPRA Benefits with NEMS:}

The Hydrogen program does not model deployment activities distinctively from R\&D activities, but includes these benefits as an underlying foundation of its overall modeling effort. The integrated GPRA benefits for this program are estimated both in the Transportation and in the Distributed Generation and CHP Submodule (add-on component in the Commercial and Residential Building modules) of NEMS. Cost and performance parameters are developed for future hydrogen-powered vehicles and fuel cells, which are then modeled in competition with other technologies in NEMS. Outside of the NEMS framework, analysts model a form of cost-benefit trade-off between technological characteristics, such as hydrogen purity and degradation, with the cost of the specific technology. These results drive the cost and performance inputs for NEMS. Hydrogen prices are calculated endogenously within the Hydrogen Market Module, an addon conversion module within NEMS (as modified for GPRA).

\section{Education and Outreach}

Project Type/Stage:

Advanced Market Penetration and Infrastructure Development

Preliminary Audience:

State and local government officials, Code officials, Potential end-users (large commercial building owners), Middle schools and High schools

Target Sector:

Commercial Buildings and Transportation Sector

\section{End Uses:}

Auto fuel and commercial building energy use

R\&D Linkage:

Accelerating the development of hydrogen and fuel-cell technologies. Early deployment at R\&D stage.

FY08 Budget Request:

$\$ 3.9$ million

Program/Modeling Contact: Christy Cooper

Website:

http://www1.eere.energy.gov/hyd rogenandfuelcells/education/ 
Education and Outreach

Hydrogen Program

Sources:

(1) FY 2008 Budget Request (2007). Projected Benefits of Federal Energy Efficiency and Renewable Energy Programs FY 2008 Budget Request. March 2007. Prepared by National Renewable Energy Laboratory.

(2) Interviews with Randy Steer (PBA), Pete Devlin (Market Transformation), Andrea Chu (filling in for Christy Cooper), Antonio Ruiz (Safety Codes \& Standards work), and Jonathan Munetz on February 14, 2007. Additional phone interview with Fred Joseck on March 14, 2007.

(3) HFCIT Multi-Year Research, Development and Demonstration Plan: Planned Program Activities for 2005-2015, available online:

http://www1.eere.energy.gov/hydrogenandfuelcells/mypp/. 
Hydrogen Program

\section{Project Description:}

The Hydrogen Codes \& Standards Program facilitates the development of codes and standards for hydrogen applications. Successful commercialization of hydrogen technologies requires a comprehensive and defensible database on component reliability and safety, published performance-based domestic standards, and international standards or regulations that will allow the technologies to compete in a global market. Outreach activities include the publishing of an online "Best Practices Handbook," independent safety evaluations of ongoing hydrogen projects, and updating of the "H2Incidents" and hydrogen-safety bibliographic websites.

\section{Market Barriers:}

The primary challenge being addressed by this deployment program is the general lack of information and comprehension about the technology. This lack of understanding sometimes results in fear regarding the technology in its entirety. Also prevalent is a lack of existing infrastructure to easily facilitate widespread implementation of hydrogen-based technologies.

\section{Modeling GPRA Benefits with NEMS:}

The hydrogen program does not model deployment activities distinctively from R\&D activities, but includes these benefits implicitly as part of its overall modeling effort. The integrated GPRA benefits for this program are estimated both in the Transportation as well as the Distributed Generation and CHP Submodule (add-on component in the Commercial and Residential Building modules) of NEMS. Cost and performance parameters are developed for future hydrogen-powered vehicles and fuel cells, which are then modeled in competition with other technologies in NEMS. Outside the NEMS framework, analysts model a form of cost-benefit trade-off between technological characteristics—such as hydrogen purity and degradation-with the cost of the specific technology. These results drive the cost and performance inputs for NEMS. Hydrogen prices are calculated endogenously within the Hydrogen Market Module, an add-on conversion module within NEMS (as modified for GPRA).

\section{Codes \& Standards Program}

Project Type/Stage:

Advanced Market Preparation and Infrastructure Development

Preliminary Audience:

State and Local Government Officials and Code officials

Target Sector:

Transportation Sector

\section{End Uses:}

Automotive fuel

R\&D Linkage:

Accelerating the development of hydrogen and fuel-cell technologies. Early deployment at $R \& D$ stage.

FY08 Budget Request:

\$16 million

Program/Modeling Contact:

Antonio Ruiz

Website:

http://www1.eere.energy.gov/hyd rogenandfuelcells/codes/ 
Codes \& Standards Program

Hydrogen Program

\section{Sources:}

(1) FY 2008 Budget Request (2007). Projected Benefits of Federal Energy Efficiency and Renewable Energy Programs FY 2008 Budget Request. March 2007. Prepared by National Renewable Energy Laboratory.

(2) HFCIT Multi-Year Research, Development and Demonstration Plan: Planned Program Activities for 2005-2015, available online: http://www1.eere.energy.gov/hydrogenandfuelcells/mypp/.

(3) Interviews with Randy Steer (PBA), Pete Devlin (Market Transformation), Andrea Chu (filling in for Christy Cooper), Antonio Ruiz (Safety Codes \& Standards work), and Jonathan Munetz on February 14, 2007. Additional phone interview with Fred Joseck on March 14, 2007. 
Technology Validation

Hydrogen Program

\section{Project Description:}

Deployment activities within the Technology Validation Program include efforts to lay the foundation for broader public awareness and market transformation.

\section{Market Barriers:}

A general lack of information and awareness exists about hydrogen-based technologies and the potential associated benefits.

\section{Modeling GPRA Benefits with NEMS:}

The Hydrogen program does not model deployment activities distinctively from R\&D activities, but includes these benefits implicitly as part of its total modeling effort. The integrated GPRA benefits for this program are estimated both in the Transportation and in the Distributed Generation and CHP Submodule (add-on component in the Commercial and Residential Building modules) of NEMS. Cost and performance parameters are developed for future hydrogenpowered vehicles and fuel cells, which are then modeled in competition with other technologies in NEMS. Outside of the NEMS framework, analysts model a style of cost-benefit trade-off between technological characteristics, such as hydrogen purity and degradation, with the cost of the specific technology. These results drive the cost and performance inputs for NEMS. A lack of existing infrastructure to easily facilitate widespread implementation of hydrogen-based technologies also exists. Hydrogen prices are calculated endogenously within the Hydrogen Market Module, an add-on conversion module within NEMS (as modified for GPRA).

\section{Technology Validation}

Project Type/Stage:

Advanced Market Preparation and Infrastructure Development

Preliminary Audience:

Education community

Target Sector:

Potentially commercial, residential, industrial, and transportation.

\section{End Uses:}

Prospectively electricity and motor fuels/transport energy.

\section{R\&D Linkage:}

Accelerating the development of hydrogen and fuel-cell technologies. Early deployment at R\&D stage.

FY08 Budget Request:

$\$ 30$ million

\section{Program/Modeling Contact:} Pete Devlin

Website:

http://www1.eere.energy.gov/hydrog enandfuelcells/tech validation/

\section{Sources:}

(1) FY 2008 Budget Request (2007). Projected Benefits of Federal Energy Efficiency and Renewable Energy Programs FY 2008 Budget Request. March 2007. Prepared by National Renewable Energy Laboratory.

(2) Interviews with Randy Steer (PBA), Pete Devlin (Market Transformation), Andrea Chu (filling in for Christy Cooper), Antonio Ruiz (Safety Codes \& Standards work), and Jonathan Munetz on February 14, 2007. Additional phone interview with Fred Joseck on March 14, 2007.

(3) HFCIT Multi-Year Research, Development and Demonstration Plan: Planned Program Activities for 2005-2015, available online: http://www1.eere.energy.gov/hydrogenandfuelcells/mypp/. 
Hydrogen Program

\section{Project Description:}

The deployment activities of the Distributed Energy

Fuel Cell Program include stationary fuel-cell demonstration projects involving international and intergovernmental partnerships.

\section{Market Barriers:}

A lack of knowledge and technical capacity exists that may inhibit the end-user in efficiently implementing this hydrogen technology.

\section{Modeling GPRA Benefits with NEMS:}

The Hydrogen program does not model deployment activities distinctively from R\&D activities, but includes these benefits as an underlying portion of its overall modeling effort. The integrated GPRA benefits for this program are estimated both in the Transportation and in the Distributed Generation and CHP Submodule (add-on component in the Commercial and Residential Building modules) of NEMS. Cost and performance parameters are developed for future hydrogen-powered vehicles and fuel cells, which are then modeled in competition with other technologies in NEMS. Outside of the NEMS framework, analysts model a type of costbenefit trade-off between technological characteristics, such as hydrogen purity and degradation, with the cost of the specific technology. These results drive the cost and performance inputs for NEMS. Hydrogen prices are calculated endogenously within the Hydrogen Market Module, an add-on conversion module within NEMS (as modified for GPRA).

\section{Sources:}

(1) FY 2008 Budget Request (2007). Projected Benefits of Federal Energy Efficiency and Renewable Energy Programs FY 2008 Budget Request. March 2007. Prepared by National Renewable Energy Laboratory.

(2) Interviews with Randy Steer (PBA), Pete Devlin (Market Transformation), Andrea Chu (filling in for Christy Cooper), Antonio Ruiz (Safety Codes \& Standards work), and Jonathan Munetz on February 14, 2007. Additional phone interview with Fred Joseck on March 14, 2007.

(3) HFCIT Multi-Year Research, Development and Demonstration Plan: Planned Program Activities for 2005-2015, available online: http://www1.eere.energy.gov/hydrogenandfuelcells/mypp/.

\section{Hydrogen-Distributed Energy Fuel-Cell Systems}

Project Type/Stage:

Advanced Market Preparation and Infrastructure Development

Preliminary Audience:

National and international governmental bodies.

Target Sector:

Commercial, residential, and Industrial sectors.

\section{End Uses:}

Electricity usage in commercial, residential, and industrial sectors.

R\&D Linkage:

Accelerating the development of hydrogen and fuel-cell technologies. Early deployment at R\&D stage.

FY08 Budget Request:

$\$ 7.7$ million

Program/Modeling Contact:

Pete Devlin

Website:

http://www1.eere.energy.gov/hyd $\underline{\text { rogenandfuelcells/fuelcells/ }}$ 


\section{Project Description:}

The Integration of Biorefinery Technologies project supports industry's efforts to commercialize biorefineries for the production of transportation fuels and co-products. The Program takes a systemsintegration approach that translates the technical successes achieved in each of the other four core R\&D areas to an integrated market-ready biorefinery. The goal is to establish integrated biorefineries through partnerships with industry and academia. Outreach mechanisms include various publications (fact sheets and articles), websites, and databases.

\section{Market Barriers:}

This program targets a wide range of market barriers including: 1) lack of information awareness, 2) policy and regulation barriers, 3) cost and financing barriers, 4) technical capacity constraints, 5) risk aversion, 6) market fragmentation, and 7) misplaced incentives. An existing infrastructure to easily facilitate widespread implementation of biofuels is also lacking.

\section{Modeling GPRA Benefits within NEMS:}

Currently, the Biomass Program does not model deployment activities explicitly from its $R \& D$ activities, but assumes these benefits are wholly captured in its overall benefits estimates. The Program provides cost and supply curves based on outputs from other models that incorporate cost and year of deployment.

\section{Integration of BioRefinery Technologies}

Project Type/Stage:

Manufacturing and Business

Infrastructure

\section{Preliminary Audience:}

Industry and Academia

\section{Target Sector:}

Transportation Sector, Utilities, and Industry

\section{End Uses:}

Liquid Transportation Fuel, Commodity Chemical

R\&D Linkage:

Sugar Platform R\&D, Thermochemical Platform Biorefinories

\section{FY08 Budget Request:}

$\$ 92.103$ million

\section{Program/Modeling Contact:}

Zia Haq

Website:

http://www1.eere.energy.gov/bio mass/integrated biorefineries.ht $\underline{\mathrm{ml}}$

\section{Sources:}

(1) FY 2008 Budget Request (2007). Projected Benefits of Federal Energy Efficiency and Renewable Energy Programs FY 2008 Budget Request. March 2007. Prepared by National Renewable Energy Laboratory.

(2) Teleconferences with Tien Nguyen (PBA) and Zia Haq (key program contact) on February 27, 2007.

(3) Information gathered on the Internet from: [http://www1.eere.energy.gov/biomass/integrated_biorefineries.html] on September 2007.

(4) "EERE Deployment Inventory Survey Results." Survey results in Excel spreadsheet from survey conducted in 2004 to characterize and evaluate deployment programs in DOE's Energy Efficiency and Renewable Energy Program.

(5) Biomass Multi-Year Program Plan (2007). Available on the Internet from:

http://www1.eere.energy.gov/biomass/pdfs/biomass_program_mypp.pdf. October 2007. 
Products and Development

Project Type/Stage:

Manufacturing and Business

Infrastructure

Preliminary Audience:

Public and Business

Target Sector:

Transportation Sector, Utilities, and Industry

\section{End Uses:}

Transportation Fuel, Commodity Chemicals, and Combined Heat and Power Technologies

R\&D Linkage:

Bio-Based Products R\&D

FY08 Budget Request: $\$ 10$ million

Program/Modeling Contact: Zia Haq

Website:

http://www1.eere.energy.gov/bio mass/products rd.html

\section{Sources:}

(1) FY 2008 Budget Request (2007). Projected Benefits of Federal Energy Efficiency and Renewable Energy Programs FY 2008 Budget Request. March 2007. Prepared by National Renewable Energy Laboratory.

(2) Biomass Budget Brief Document (2007). "Biomass and Biorefinery Systems R\&D Program." Pdf document available on biomass website.

(3) Teleconferences with Tien Nguyen (PBA) and Zia Haq (key program contact) on February 27, 2007.

(4) Information gathered on the Internet from:

[http://www1.eere.energy.gov/biomass/products_rd.html] on September 2007.

(5) "EERE Deployment Inventory Survey Results." Survey results in Excel spreadsheet from survey conducted in 2004 to characterize and evaluate deployment programs in DOE's Energy Efficiency and Renewable Energy Program.

(6) (3) Biomass Multi-Year Program Plan (2007). Available on the Internet from: http://www1.eere.energy.gov/biomass/pdfs/biomass_program_mypp.pdf. October 2007. 


\section{Project Description:}

While Bioconversion Platform Research and Development (R\&D) is primarily focused on $R \& D$ to reduce the costs of producing mixed, dilute sugar streams from a wide range of biomass feedstocks, it does contain some deployment-type activities, including data collection and dissemination, and technical, market, economic, and other analyses.

\section{Market Barriers:}

There is a general lack of information and awareness about this technology. In addition, high "first" costs and/or insufficient available financing options to pay for projects may deter implementation. In addition, there is a lack of knowledge and technical capacity to enable the end-user to efficiently implement this technology. As a result, the externality costs (e.g., environmental damage) of market alternatives are not realized or internalized by the market and consumers.

\section{Modeling GPRA Benefits within NEMS:}

Currently, the Biomass Program does not model deployment activities explicitly from its $R \& D$ activities, but assumes these benefits are wholly captured in its overall benefits estimate. The Program provides cost and supply curves based on outputs from other models that incorporate cost and year of deployment.

\section{Sources:}

(1) FY 2008 Budget Request (2007). Projected Benefits of Federal Energy Efficiency and Renewable Energy Programs FY 2008 Budget Request. March 2007. Prepared by National Renewable Energy Laboratory.

(2) Teleconferences with Tien Nguyen (PBA) and Zia Haq (key program contact) on February 27, 2007.

(3) Biomass Multi-Year Program Plan (2007). Available on the Internet from: http://www1.eere.energy.gov/biomass/pdfs/biomass program mypp.pdf. October 2007.

(4) Information gathered on the Internet from: http://www1.eere.energy.gov/biomass/sugar platform.html.

\section{Bioconversion Platform R\&D}

Project Type/Stage:

Advanced Market Preparation and Infrastructure Development

Preliminary Audience:

Public and Industry

Target Sector:

Transportation Sector, Utilities, and Industry

End Uses:

Biofuels and Chemicals

R\&D Linkage:

Sugar Platform R\&D

FY08 Budget Request:

$\$ 38.3$ million

Program/Modeling Contact:

Zia Haq

Website:

http://www1.eere.energy.gov/bio mass/sugar platform.html 


\section{Project Description:}

While Thermochemical Platform R\&D is primarily focused on research and development efforts to reduce thermochemical conversion costs of biomass and process residues from biorefineries into clean SYNGAS or bio-oils, it does contain some deployment-type activities. These include data collection and dissemination, and technical, market, economic, and other analyses.

\section{Market Barriers:}

This program targets a wide range of market barriers including: 1) lack of information awareness, 2) policy and regulation barriers, 3 ) cost and financing barriers, 4) technical capacity constraints, 5) risk aversion, 6) market fragmentation, and 7) misplaced incentives. An existing infrastructure to easily facilitate widespread implementation of biofuels is also lacking.

\section{Modeling GPRA Benefits within NEMS:}

Currently, the Biomass Program does not model deployment activities explicitly from its R\&D activities, but assumes these benefits are wholly captured in its overall benefits estimates. The Program provides cost and supply curves based on outputs from other models that incorporate cost and year of deployment.

\section{Sources:}

(1) FY 2008 Budget Request (2007). Projected Benefits of Federal Energy Efficiency and Renewable Energy Programs FY 2008 Budget Request. March 2007. Prepared by National Renewable Energy Laboratory.

(2) Teleconferences with Tien Nguyen (PBA) and Zia Haq (key program contact) on February 27, 2007.

(3) Information gathered on the Internet from:

[http://www1.eere.energy.gov/biomass/thermochemical_platform.html] on September 2007.

(4) "EERE Deployment Inventory Survey Results." Survey results in Excel spreadsheet from survey conducted in 2004 to characterize and evaluate deployment programs in DOE's Energy Efficiency and Renewable Energy Program.

(5) Biomass Multi-Year Program Plan (2007). Available on the Internet from: http://www1.eere.energy.gov/biomass/pdfs/biomass program mypp.pdf. October 2007.
Thermochemical Platform

Project Type/Stage:

Advanced Market Preparation and Infrastructure Development

Preliminary Audience:

Target Sector:

End Uses:

Biofuels and Chemicals

R\&D Linkage:

FY08 Budget Request:

$\$ 19.437$ million

Program/Modeling Contact:

Zia Haq

Website:

http://www1.eere.energy.gov/bio mass/thermochemical platform.h $\underline{\mathrm{tml}}$ 


\section{Project Description:}

Five Regional Feedstock Partnerships will address regional infrastructure needs in conjunction with the U.S. Department of Agriculture (USDA) and landgrant universities. The program will also continue to partner with the genomics-research activity within the DOE Office of Science and at USDA to further promote feedstock efforts.

\section{Market Barriers:}

This program targets a wide range of market barriers including: 1) lack of information awareness, 2) technical capacity constraints, and 3) risk aversion. In addition, the externality costs (e.g., environmental damage) of market alternatives are not realized or internalized by the market and consumers. An existing infrastructure to easily facilitate widespread implementation of biofuels is also lacking.

\section{Modeling GPRA Benefits within NEMS:}

Currently, the Biomass Program does not model deployment activities explicitly from its R\&D activities, but assumes these benefits are wholly captured in its overall benefits estimates. The Program provides cost and supply curves based on outputs from other models that incorporate cost and year of deployment.

\section{Sources:}

(1) FY 2008 Budget Request (2007). Projected Benefits of Federal Energy Efficiency and Renewable Energy Programs FY 2008 Budget Request. March 2007. Prepared by National Renewable Energy Laboratory.

(2) Teleconferences with Tien Nguyen (PBA) and Zia Haq (key program contact) on February 27, 2007.

(3) Information gathered on the Internet from:

[http://www1.eere.energy.gov/biomass/biomass_feedstocks.html] on September 2007.

(4) Biomass Multi-Year Program Plan (2007). Available on the Internet from: http://www1.eere.energy.gov/biomass/pdfs/biomass_program_mypp.pdf. October 2007.

\section{Regional Feedstock \\ Partners Outreach}

Project Type/Stage:

Manufacturing and Business

Infrastructure

Preliminary Audience:

End-Users and Business

Target Sector:

Agriculture, Industry, and

Forestry

End Uses:

Biomass Conversion

R\&D Linkage:

Biomass Feedstocks R\&D

FY08 Budget Request:

$\$ 9.737$ million

Program/Modeling Contact:

Zia Haq

Website:

http://www1.eere.energy.gov/bio mass/biomass feedstocks.html 


\section{Education and Outreach}

Project Type/Stage:

Marketing and Outreach

Preliminary Audience:

End Users, Industry Partners, Researchers, and Policy Makers

Target Sector:

Transportation Sector, Utilities, and Industry

End Uses:

Biomass Usage

R\&D Linkage:

Biomass R\&D

FY08 Budget Request:

Not called out separately within budget request

Program/Modeling Contact: Zia Haq

Website:

http://www1.eere.energy.gov/bio mass/information resources.html

Program provides cost and supply curves based on outputs from other models that incorporate cost and year of deployment.

\section{Sources:}

(1) FY 2008 Budget Request (2007). Projected Benefits of Federal Energy Efficiency and Renewable Energy Programs FY 2008 Budget Request. March 2007. Prepared by National Renewable Energy Laboratory.

(2) Teleconferences with Tien Nguyen (PBA) and Zia Haq (key program contact) on February 27, 2007.

(3) Information gathered on the Internet from: [http://www1.eere.energy.gov/biomass/information_resources.html] on September 2007.

(4) "EERE Deployment Inventory Survey Results." Survey results in Excel spreadsheet from survey conducted in 2004 to characterize and evaluate deployment programs in DOE's Energy Efficiency and Renewable Energy Program.

(5) Biomass Multi-Year Program Plan (2007). Available on the Internet from: http://www1.eere.energy.gov/biomass/pdfs/biomass_program_mypp.pdf. October 2007. 


\section{Project Description:}

The President's Solar America Initiative (SAI) was launched in January 2006 as part of the Administration's Advanced Energy Initiative. The Solar America Initiative's objective is to accelerate the development of advanced photovoltaic (PV) materials that convert sunlight directly to electricity. The purpose of the SAI is to make PV costcompetitive with other forms of renewable electricity by 2015. Specific deployment activities include partnering with industry, universities, and state governments in an effort to transform the market by reducing market barriers impacting solar implementation, such as the inability to easily connect to the electric grid, the lack of net-metering regulations, and the forced purchasing of liability insurance by a utility. The outreach activities include various publications, websites, educational materials, partnerships, demonstration projects, and technical assistance.

\section{Market Barriers:}

A general lack of information and awareness about the solar technology is recognized. Technology deployment is hindered by the existence of an insufficient enabling infrastructure (e.g., ability to connect with grid). Finally, solar technologies face considerable risk aversion in the market due to fears regarding the reliability of solar technology and/or concerns regarding financial loss without a corresponding payback.

\section{Modeling GPRA Benefits with NEMS:}

The Solar Program provides modifications to the technology characteristics for the photovoltaic (PV, for distributed and central systems) and concentrating solar power (CSP) technologies. Additionally, the Solar Program provides extensive modifications to the AEO baseline, including revising the projected PV cost for residential and commercial $P V$ systems, increasing the average residential- and commercial-building PV-system size, increasing the maximum share of residential and commercial buildings with solar access, including a declining PV buy-down program in California, and modifying the adoption rate of distributed generation technologies.

For the PV characteristics, a set of technology-cost projections was produced, based on a range of technology-cost projections under different funding and policy assumptions developed by a multilab, multi-technology team, in addition to cost estimations developed for the U.S. PV Industry Roadmap under various funding and policy assumptions.

\section{Solar America Initiative}

Project Type/Stage:

Manufacturing and Business

Infrastructure and Technology

Adoption Supports

\section{Preliminary Audience:}

States, cities, utilities, the

Building industry, and the

Federal sector

\section{Target Sector:}

Commercial Buildings,

Residential Buildings, and

Utilities/Independent Power

Producers

\section{End Uses:}

Potentially heating, cooling, water heating, lighting, and plug loads

\section{R\&D Linkage:}

Relevant Solar R\&D

FY08 Budget Request:

$\$ 16.34$ million

\section{Program/Modeling Contact:}

Charlie Hemmeline

Website:

http://www1.eere.energy.gov/sol arl 


\section{Sources:}

(1) FY 2008 Budget Request (2007). Projected Benefits of Federal Energy Efficiency and Renewable Energy Programs FY 2008 Budget Request. March 2007. Prepared by National Renewable Energy Laboratory.

(2) Interviews with Charlie Hemmeline (backup) and Cecile Warner (NREL modeler) on February 14, 2007. Additional phone interview with Robert Margolis (NREL modeler) on March 14, 2007.

(3) "EERE Deployment Inventory Survey Results." Survey results in Excel spreadsheet from survey conducted in 2004 to characterize and evaluate deployment programs in DOE's Energy Efficiency and Renewable Energy Program.

(4) Information gathered on the Internet from: [http://www1.eere.energy.gov/solar] on September 2007.

(5) Solar Energy Technologies Program Multi-Year Program Plan, 2007-2011. Available on the Internet at: http://www1.eere.energy.gov/solar/pdfs/set myp 2007-2011 proof 1.pdf. 


\section{Project Description:}

The Solar Decathlon Competition charges students with designing, constructing, and operating an attractive and effective solar-powered house using the solar-energy systems connected to the house that will fulfill all of its power needs. The competition helps to demonstrate that market-ready technologies exist, which can meet the energy requirements of society's daily activities by tapping into the sun's power.

\section{Market Barriers:}

A general lack of information and awareness remains about solar technology. In addition, solar technologies encounter considerable risk aversion in the market due to trepidation regarding the reliability of solar technology and/or concerns regarding financial loss without a corresponding payback.

\section{Modeling GPRA Benefits with NEMS:}

The Solar Program provides modifications to the technology characteristics for the photovoltaic (PV, for distributed and central systems) and concentrating solar power (CSP) technologies. Additionally, the Solar Program provides extensive modifications to the AEO baseline, including increasing the average residential- and commercialbuilding PV system size, increasing the maximum share of residential and commercial buildings with solar access, including a declining PV buy-down program in California, and modifying the adoption rate of distributed generation technologies.

\section{Sources:}

(1) FY 2008 Budget Request (2007). Projected Benefits of Federal Energy Efficiency and Renewable Energy Programs FY 2008 Budget Request. March 2007. Prepared by National Renewable Energy Laboratory.

(2) Interviews with Charlie Hemmeline (backup) and Cecile Warner (NREL modeler) on February 14, 2007. Additional phone interview with Robert Margolis (NREL modeler) on March 14, 2007.

(3) "EERE Deployment Inventory Survey Results." Survey results in Excel spreadsheet from survey conducted in 2004 to characterize and evaluate deployment programs in DOE's Energy Efficiency and Renewable Energy Program.

(4) Information gathered on the Internet from: [http://www.solardecathlon.org/] on September 2007.

(5) Solar Energy Technologies Program Multi-Year Program Plan, 2007-2011. Available on the Internet at: http://www1.eere.energy.gov/solar/pdfs/set myp 2007-2011 proof 1.pdf. 


\section{Project Description:}

The Wind Resource Assessment promotes the deployment of wind energy by developing tools and processes to assist in the rapid identification of potentially windy areas that also possess other desirable qualities for wind-project development to facilitate a more efficient site-identification process. The program synthesizes data on existing wind patterns, topographic indicators, field surveys, accessibility, land use, obstructions, and available land area, and makes these resources available to potential investors. The project also addresses other potential barriers (e.g., integration into the electric grid, site identification, permitting, environmental issues), and investigates wind energy's application to other areas-from offshore wind technology to distributed and community-owned wind projects.

\section{Market Barriers:}

Information and awareness about wind technology continues to be deficient. Combined with this is a lack of technical capacity, which may inhibit potential investors from efficiently implementing the technology. Some policies and regulations related to power distribution presently inhibit the implementation of wind power. This technology also faces considerable risk aversion in the market because of concerns regarding the financial viability of the investment.

\section{Modeling GPRA Benefits with NEMS:}

As the Wind Technologies portfolio expands to include a greater percentage of deployment activities, the program is currently making an effort to improve the modeling of these activities. The

\section{Wind-Resources \\ Assessment}

Project Type/Stage:

Public Infrastructure and Policy

Regulation

Preliminary Audience:

National, State and Local Power Agencies, Education Community, and Trade Associations.

Target Sector:

Utilities/Independent Power

Producers

End Uses:

Electricity (residential, commercial, and industrial sectors)

R\&D Linkage:

Relevant Wind R\&D

FY08 Budget Request:

$\$ 12.869$ million

Program/Modeling Contact:

Maureen Hand

Website:

http://www1.eere.energy.gov/win dandhydro/wind research.html program is currently exploring several options to allow for the measurement of the impact of its deployment activities, including inter- or intra-region transmission and modification of regional-capacity cost-escalation curves. To measure the impact of changes in statebased standards related to renewable energy, one would have the ability to apply a percentage of the standard's benefits that are presently hard-wired within NEMS to program activities. 


\section{Sources:}

(1) FY 2008 Budget Request (2007). Projected Benefits of Federal Energy Efficiency and Renewable Energy Programs FY 2008 Budget Request. March 2007. Prepared by National Renewable Energy Laboratory.

(2) Interviews with Linda Silverman (PBA), Alejandro Moreno (Program Contact), Maureen Hand (NREL Modeler, Key Contact), lan Baring-Gould (NREL Modeler), Steve Lindenberg (Team Leader), and Phil Dougherty (Program Manager) on February 15, 2007.

(3) "EERE Deployment Inventory Survey Results." Survey results in Excel spreadsheet from survey conducted in 2004 to characterize and evaluate deployment programs in DOE's Energy Efficiency and Renewable Energy Program.

(4) Information found on the Internet:

http://www1.eere.energy.gov/windandhydro/wind research.html.

(5) Wind Energy Program Multiyear Program Plan 2007 - 2012.

http://www1.eere.energy.gov/windandhydro/pdfs/wind mypp 2007-2012.pdf 


\section{Project Description:}

The Wind Powering America Project develops innovative pilot projects, replicates successes, and develops and disseminates targeted information, analyses, and tools. The program augments the efforts of the Department of Energy's wind-research program, the American Wind Energy Association (AWEA), and other wind-related organizations to identify and address gaps in technical information and tools needed for its program areas. Examples include: 1) development and access to simplified spreadsheet tools for initial analyses of wind-project economics and economic-development impacts, 2) development and distribution of state-specific wind maps and small wind-application guidebooks, and 3) publication of a brochure that focuses on wind opportunities, case studies, and economics for rural electric co-ops.

\section{Market Barriers:}

The efficient implantation of this technology by potential investors may be inhibited by a general lack of information and awareness about wind technology, in addition to the deficiency of technical capacity to employ that technology. Considerable risk aversion is also prevalent in the market due to concerns about the financial viability of the investment.

\section{Modeling GPRA Benefits with NEMS:}

As the Wind Technologies portfolio expands to include a greater percentage of deployment activities, the program is currently attempting to improve the modeling of these activities. The program is exploring several options to allow for measurement of the impact of its deployment activities, including inter- or intra-region transmission, and modification of regional-capacity cost-escalation curves. One modeling option being considered within NEMS is to modify the default resource-multiplier curve to show the impact of programdeployment activities. Within NEMS, the expense of installing the next megawatt of wind is based on a regionally based cost multiplier and capacity curve, which is currently founded, in part, on interconnection costs.

\section{Wind Powering America}

Project Type/Stage:

Manufacturing and Business Infrastructure and Technology Adoption Supports

Preliminary Audience:

Knowledge Community and Associations; Electric Co-ops.

\section{Target Sector:}

Utilities/Independent Power

Producers

\section{End Uses: \\ Electricity}

R\&D Linkage:

Relevant Wind R\&D

FY08 Budget Request:

Not called out separately within budget.

\section{Program/Modeling Contact:} Maureen Hand

Website:

http://www.eere.energy.gov/wind andhydro/windpoweringamerica// 
Wind Powering America

Wind Program

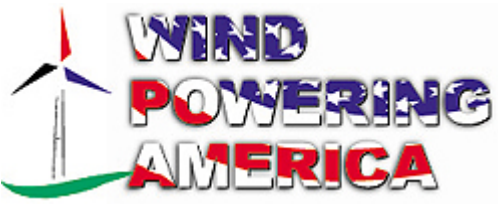

Sources:

(1) FY 2008 Budget Request (2007). Projected Benefits of Federal Energy Efficiency and Renewable Energy Programs FY 2008 Budget Request. March 2007. Prepared by National Renewable Energy Laboratory.

(2) Interviews with Linda Silverman (PBA), Alejandro Moreno (Program Contact), Maureen Hand (NREL Modeler, Key Contact), lan Baring-Gould (NREL Modeler), Steve Lindenberg (Team Leader), and Phil Dougherty (Program Manager) on February 15, 2007.

(3) "EERE Deployment Inventory Survey Results." Survey results in Excel spreadsheet from survey conducted in 2004 to characterize and evaluate deployment programs in DOE's Energy Efficiency and Renewable Energy Program.

(4) Information found on the Internet:

http://www.eere.energy.gov/windandhydro/windpoweringamerica//

(5) Wind Energy Program Multiyear Program Plan 2007 - 2012.

http://www1.eere.energy.gov/windandhydro/pdfs/wind mypp 2007-2012.pdf 


\section{Project Description:}

The Vehicle Technologies Deployment activity promotes the adoption and use of petroleum reduction technologies and practices by working with local Clean Cities coalitions and the respective stakeholders, industry partners, fuel providers, and end-users. The program provides technical assistance for early adopters and furnishes education, training, and workshops to coalitions, public-safety officials, and stakeholders. Activities include showcasing the technology focus areas, national and regional alliances to promote petroleum-reduction strategies as well as work to support the further expansion of ethanolinfrastructure deployment as part of the program's outreach efforts.

\section{Market Barriers:}

The overall fragmentation of the marketplace for many of these products and technologies does not lend itself to overall acceptance of a given technology. Consumers are left to invest considerable time and energy to gather information about the various choices of products, which increases "search costs" and investment uncertainty. Finally, externality costs (e.g., environmental damage) of market alternatives may not be realized or internalized by consumers of these products.

\section{Modeling GPRA Benefits with NEMS:}

To capture savings from FreedomCAR technologies in the integrated-modeling process, cost and performance parameters for vehicle subgroups are developed for future products and modeled within NEMS, similar to how hydrogen benefits are estimated. In addition, an adjustment is made to a "constant" term within NEMS, which represents various vehicle attributes (e.g., size, acceleration, fuel economy). Clean Cities is not currently modeled separately from the R\&D portfolio.

\section{Sources:}

(1) FY 2008 Budget Request (2007). Projected Benefits of Federal Energy Efficiency and Renewable Energy Programs FY 2008 Budget Request. March 2007. Prepared by National Renewable Energy Laboratory.

(2) Interview with Phil Patterson (PBA) on February 14, 2007.

\section{Clean Cities}

Project Type/Stage:

Public Infrastructure and Policy and Business Infrastructure; and Technology Adoption Supports

Preliminary Audience: Industry partners, fuel providers, and end-users (e.g., motorists).

Target Sector:

Transportation and Commercial Sectors.

End Uses:

Automotive fuel/petroleum.

R\&D Linkage:

Freedom Car/Vehicles R\&D

FY08 Budget Request:

$\$ 9.593$ million

Program/Modeling Contact:

Dennis Smith

Website:

http://www.eere.energy.gov/clea ncities/ and Regulation; Manufacturing 
Graduate Automotive Technology Education (GATE)

FreedomCAR/Vehicles Program

\section{Project Description:}

The Graduate Automotive Technology Education

(GATE) activity funds eight GATE Centers of Excellence to develop new curricula and provide research fellowships for approximately 25 students for research in advanced-automotive technologies.

\section{Market Barriers:}

There is a lack of technical capacity in the field of alternative-automotive technology to enable businesses to efficiently mass-manufacture various advanced products, designs, and technologies.

\section{Modeling GPRA Benefits with NEMS:}

To capture savings from FreedomCAR technologies in the integrated-modeling process, cost and performance parameters for vehicle subgroups are developed for future products and modeled within NEMS, similar to how the hydrogen benefits are estimated. In addition, an adjustment is made to a "constant" term within NEMS, which represents various vehicle attributes (e.g., size, acceleration, fuel economy).

\section{Sources:}

(1) FY 2008 Budget Request (2007). Projected Benefits of Federal Energy Efficiency and Renewable Energy Programs FY 2008 Budget Request. March 2007. Prepared by National Renewable Energy Laboratory.

(2) Interview with Phil Patterson (PBA) on February 14, 2007.

\section{GATE}

Project Type/Stage:

Technology Adoption Supports

Preliminary Audience:

Students and education

community

Target Sector:

Transportation Sector

\section{End Uses:}

Automotive Fuel

R\&D Linkage:

Freedom Car/Vehicles R\&D

FY08 Budget Request:

\$0.5 million

Program/Modeling Contact:

Dennis Smith

Website:

http://www1.eere.energy.gov/veh iclesandfuels/deployment/educati on/fcvt gate.html 


\section{Project Description:}

The Advanced Vehicle Competitions activity conducts the Challenge $X$ Competition in partnership with General Motors. Selected teams are challenged to integrate advanced-vehicle technologies and appropriate fuels to develop an approach that minimizes use of petroleum fuel.

\section{Market Barriers:}

A general lack of technical capacity in the field of alternative automotive technology exists that may inhibit businesses in efficiently mass-manufacturing various advanced products, designs, and technologies.

\section{Modeling GPRA Benefits with NEMS:}

To capture savings from FreedomCAR technologies in the integrated-modeling process, cost and performance parameters for vehicle subgroups are developed for future products, and modeled within NEMS, similar to the estimation process for hydrogen benefits. In addition, an adjustment is made to a "constant" term within NEMS, which represents various vehicle attributes (e.g., size, acceleration, fuel economy).

\section{Sources:}

(1) FY 2008 Budget Request (2007). Projected Benefits of Federal Energy Efficiency and Renewable Energy Programs FY 2008 Budget Request. March 2007. Prepared by National Renewable Energy Laboratory.

(2) Interview with Phil Patterson (PBA) on February 14, 2007.

\section{Advanced Vehicle Competitions}

Project Type/Stage:

Manufacturing and Business

Infrastructure

Preliminary Audience:

Business/Industry

Target Sector:

Transportation Sector

End Uses:

Automotive fuel

R\&D Linkage:

FreedomCAR/Vehicles R\&D

FY08 Budget Request:

$\$ 1.3$ million

Program/Modeling Contact:

Dennis Smith

Website:

http://www1.eere.energy.gov/veh iclesandfuels/index.html 
National Builders Challenge and Building America

Building Technologies Program

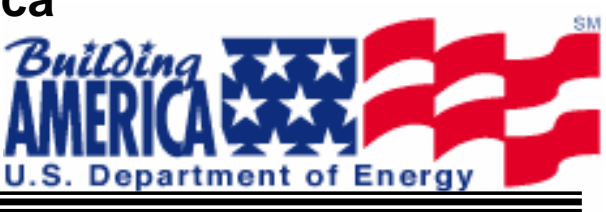

\section{Project Description:}

The National Builders Challenge will construct over

3.7 million homes between 2007 and 2020 .

Competitive solicitations will be issued to increase

the production of Building America homes at the $40 \%$ level, in addition to developing a design

competition that will challenge builders to design

affordable homes that are $70 \%$ better than code.

Awards will also be created to recognize the builders that employ exemplary building practices that lead to the creation of super-efficient homes.

\section{Market Barriers:}

High "first" costs and/or insufficient available financing options to pay for high-efficiency designs and building components often deter implementation. A lack of knowledge and technical capacity exists that may hinder the builders from efficiently implementing the higher-efficiency products, designs, or technologies. In particular, the ability to integrate systems to maximize the efficiency performance presents challenges to builders and designers. These products and designs are subject to considerable risk aversion in the building market because of concerns regarding reliability and financial loss by the builders. An overall fragmentation of the marketplace for some of the products promoted by the program is present. This does not promote overall acceptance of a given technology. Builders and homeowners are left to invest considerable time and energy to gather information about the various choices of products. In turn, this increases "search costs" and uncertainty related to implementing a given product, design, or technology. Finally, the externality costs (e.g., environmental damage) of market alternatives are not realized or internalized by the consumer, leaving the higher-efficiency components at a disadvantage.

\section{Modeling GPRA Benefits:}

The benefits of this program are calculated "off-line" (i.e., outside of NEMS), in coordination with the benefits estimated for Residential Building R\&D, accelerating the market penetration of the products and designs developed and promoted by the Residential R\&D Program. 
National Builders Challenge and Building America

Building Technologies Program

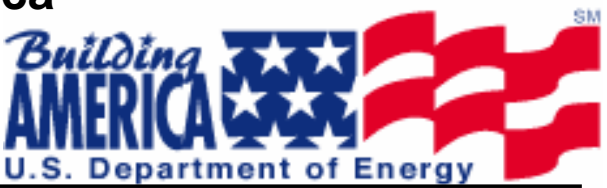

\section{Sources:}

(1) FY 2008 Budget Request (2007). Projected Benefits of Federal Energy Efficiency and Renewable Energy Programs FY 2008 Budget Request. March 2007. Prepared by National Renewable Energy Laboratory.

(2) Building Technologies Multi-Year Program Plan (2007)

http://www.eere.energy.gov/buildings/about/mypp.html, Updated January 2007. 


\section{Project Description:}

Commercial R\&D seeks to develop cost-effective technologies and building practices that will enable the design and construction of Net Zero Energy Buildingscommercial buildings that produce as much energy as is used on an annual basis-by 2025. Outreach activities include publications, a database, software tools, and a national green buildings challenge.

\section{Market Barriers:}

A general lack of information and awareness exists regarding highly efficient building-design techniques as well as a lack of technical capability on the part of the building industry to efficiently implement these designs and components. In particular, the ability to integrate systems to maximize the performance efficiency presents challenges to builders and designers. In addition, high "first" costs and/or insufficient available financing to pay for higher-efficiency building components often deter implementation. Finally, many of these design practices and products face considerable risk aversion in the market due to fears regarding reliability of products and/or concerns regarding financial payback.

\section{Modeling GPRA Benefits:}

The Commercial R\&D Project contains both R\&D and deployment-like activities, which are modeled together. Inputs to the modeling effort include estimated commercial building load reductions and penetration curves.

\section{Sources:}

(1) FY 2008 Budget Request (2007). Projected Benefits of Federal Energy Efficiency and Renewable Energy Programs FY 2008 Budget Request. March 2007. Prepared by National Renewable Energy Laboratory.

(2) Interviews with Ron Majette on February 20, 2007; Carol Jones (Commercial Lighting Challenge) on February 25, 2007; Judy Dyer on February 27, 2007; and Rich Karney and Carol Jones on February 30, 2007. Additional email conversations with Jim Rannels (Fed. Main Contact).

(3) "EERE Deployment Inventory Survey Results." Survey results in Excel spreadsheet from survey conducted in 2004 to characterize and evaluate deployment programs in DOE's Energy Efficiency and Renewable Energy Program.

(4) Information gathered on the Internet from: [http://www.eere.energy.gov/buildings/highperformance/] on September 2007.

(5) Building Technologies Multi-Year Program Plan (2007) http://www.eere.energy.gov/buildings/about/mypp.html, Updated January 2007.

\section{Commercial Buildings R\&D}

Project Type/Stage:

Identifying Promising

Technologies and Technology

Adoption Support

\section{Preliminary Audience:}

Commercial building owners, builders, architects, and education community.

Target Sector:

Commercial Buildings

\section{End Uses:}

Potentially heating, cooling, water heating, lighting, and plug loads

\section{R\&D Linkage:}

Building Technologies

Commercial R\&D

\section{FY08 Budget Request:}

$\$ 7$ million (only a small

percentage is for deployment)

\section{Program/Modeling Contact:} Dru Crawley

Website:

http://www.eere.energy.gov/build ings/highperformance/ 


\section{Project Description:}

The Equipment Standards and Analysis subprogram develops minimum energy-efficiency standards that are technologically feasible and economically justified, as required by law.

\section{Market Barriers:}

Market regulation can assist in overcoming issues with overall fragmentation of the market place, which does not lend itself to overall acceptance of a given technology. Consumers are left to invest considerable time and energy to gather information about the various choices of products. This increases "search costs" and uncertainty related to implementing a given product, design, or technology. An additional market barrier addressed with regulation is the externality cost (e.g., environmental damage) of some of the market alternatives to higher-efficiency products, in that these costs are not realized or internalized by consumer. Finally, some of the products addressed with regulation have elements of a "public good," indicating that no one can be excluded from using and benefiting from this program (non-excludable). This often leads to under-investment in the program, as no one entity can own the benefits.

\section{Modeling GPRA Benefits:}

For the Equipment Standards subprogram, estimates of energy savings are produced in a spreadsheet based on preliminary estimates of energy savings developed as part of the FY 2005 priority-setting process. Products considered within the analysis include those for which rulemaking activities are expected from 2008 through 2011. These estimates are adjusted to account for modeling integration and then subtracted from the base-consumption levels within the modeling framework.

\section{Sources:}

(1) FY 2008 Budget Request (2007). Projected Benefits of Federal Energy Efficiency and Renewable Energy Programs FY 2008 Budget Request. March 2007. Prepared by National Renewable Energy Laboratory.

(2) Building Technologies Multi-Year Program Plan (2007)

http://www.eere.energy.gov/buildings/about/mypp.html, Updated January 2007.

\section{Equipment Standards and Analysis}

Project Type/Stage:

Public Infrastructure and Policy

Regulation

Preliminary Audience:

Manufacturers and Federal

Government

Target Sector:

Residential and Commercial

Buildings

\section{End Uses:}

Potentially heating, cooling, water heating, lighting, and plug loads

R\&D Linkage:

Building Technologies R\&D

FY08 Budget Request:

$\$ 13.361$ million

Program/Modeling Contact:

Ron Lewis

Website:

http://www.eere.energy.gov/build ings/appliance standards/ 


\section{Project Description:}

ENERGY STAR is a voluntary labeling program that helps businesses and consumers easily identify high-efficiency products, homes, and buildings that will assist in saving energy and money, all while protecting the environment. ENERGY STAR promotes energy efficiency through more than 20,000 retail partners, 1200 product manufacturers, 400 utility partners, and others.

\section{Market Barriers:}

A general lack of information and awareness exists about the high-efficiency products. Also, some of the newer energy-efficient products face risk aversion in the market due to concerns regarding product reliability (products have not yet demonstrated a long track record). The ENERGY STAR testing and labeling provides a level of reassurance to the riskaverse consumer.

\section{Modeling GPRA Benefits with NEMS:}

The modeling of ENERGY STAR technologies depends in part on the technology. For Compact Fluorescents (CFL), Windows, and Home Performance with ENERGY STAR, technology characteristics-including performance parameters and cost estimates-are provided to the integratedmodeling (i.e., NEMS) process, along with estimated penetration curves and energy savings. For the ENERGY STAR appliances, the Beta1 parameters are adjusted to yield increased market shares of the ENERGY STAR-rated appliances within the NEMS models. Modifying the Beta1 parameter implicitly lowers the average discount rate.

\section{Sources:}

(1) FY 2008 Budget Request (2007). Projected Benefits of Federal Energy Efficiency and Renewable Energy Programs FY 2008 Budget Request. March 2007. Prepared by National Renewable Energy Laboratory.

(2) Interviews with Rich Karney and Carol Jones on February 30, 2007. Additional email conversations with Jim Rannels (Fed. Main Contact).

(3) Building Technologies Multi-Year Program Plan (2007) http://www.eere.energy.gov/buildings/about/mypp.html, Updated January 2007. 


\section{Project Description:}

The Building Application Centers Initiative is designed to create a permanent presence within a region to disseminate regionally focused energyefficient building information, technologies, and practices. The initiative also allows for the provision of technical assistance within the region.

\section{Market Barriers:}

A general lack of information and awareness is prevalent regarding energy-efficient building products, designs, and technologies. A lack of knowledge and technical capacity may inhibit the end-user from efficiently implementing the products, designs, or technologies.

\section{Modeling GPRA Benefits:}

This activity is modeled to represent an increase in the market penetration of Commercial R\&D. Inputs to the modeling effort include estimated load reductions and penetration rates, which assume an increase of $1 \%$ over the expected penetration of Commercial R\&D in building types-except for education and healthcare, which are specifically addressed in other Rebuild America deployment programs.

\section{Sources:}

(1) FY 2008 Budget Request (2007). Projected Benefits of Federal Energy Efficiency and Renewable Energy Programs FY 2008 Budget Request. March 2007. Prepared by National Renewable Energy Laboratory.

(2) Interview with Judy Dyer on February 27, 2007. Additional email conversations with Jim Rannels (Fed. Main Contact).

(3) Building Technologies Multi-Year Program Plan (2007) http://www.eere.energy.gov/buildings/about/mypp.html, Updated January 2007.

\section{Building Application Centers}

Project Type/Stage:

Technology Adoption Supports

Preliminary Audience:

Building Community, Education

Community, and End-Users

Target Sector:

Residential and Commercial

Buildings

End Uses:

Potentially heating, cooling, water heating, lighting, and plug loads

R\&D Linkage:

Building Technologies R\&D

FY08 Budget Request: $\$ 2.834$ million (total for all Rebuild programs)

Program/Modeling Contact: Judy Dyer, NETL

Website:

http://www.eere.energy.gov/build ings/program areas/rebuild.html 
Rebuild America: EnergySmart Hospitals and EnergySmart Schools

Building Technologies Program

\section{Project Description:}

EnergySmart Hospitals is a national campaign designed to substantially improve the energy efficiency, indoor environments, and comfort of the nation's public and private hospitals. EnergySmart Schools is a national campaign focused on improving new school construction so that it is 50\% better than code, and improving existing school buildings by $30 \%$. These objectives will be achieved through the development of innovative financing and tools, the provision of information, resources, and technologies through technical assistance and outreach, along with training and education of building-industry professionals on the benefits of efficient and renewable-energy strategies.

\section{Market Barriers:}

High "first" costs and/or insufficient available financing options to pay for projects may deter implementation. A lack of knowledge and technical capability may further inhibit the builder and end-user from efficiently implementing projects.

\section{Modeling GPRA Benefits:}

As an acceleration of the Commercial R\&D activities for the education and healthcare buildings, inputs to the modeling effort include estimated load reductions and penetration rates.

\section{Sources:}

(1) FY 2008 Budget Request (2007). Projected Benefits of Federal Energy Efficiency and Renewable Energy Programs FY 2008 Budget Request. March 2007. Prepared by National Renewable Energy Laboratory.

(2) Emails with Lani MacRae and Pat LeDonne.

\section{EnergySmart Schools and EnergySmart Hospitals}

Project Type/Stage:

Public Infrastructure and Policy

Regulation

Preliminary Audience:

Hospitals and Schools,

Education Community, Local

Governments

Target Sector:

Commercial Buildings

\section{End Uses:}

Potentially heating, cooling, water heating, lighting, and plug loads

R\&D Linkage:

Building Technologies R\&D

FY08 Budget Request: $\$ 2.834$ million (total for all Rebuild programs)

Program/Modeling Contact:

Patricia LeDonne and Lani MacRae

Website:

http://www.eere.energy.gov/build ings/program areas/rebuild.html Additional email conversations with Jim Rannels (Fed. Main Contact).

(3) Building Technologies Multi-Year Program Plan (2007) http://www.eere.energy.gov/buildings/about/mypp.html, Updated January 2007. 


\section{Building Energy Codes}

Building Technologies Program

\section{Project Description:}

The Building Energy Codes Program supports the upgrading of residential and commercial building energy codes, in addition to serving as a national information resource on all codes. Extensive outreach activities include software tools, a website and resource-center database, conferences, publications, web-based training, and a technicalsupport hotline.

\section{Market Barriers:}

A general lack of information and awareness exists regarding efficient building designs and technologies. In addition, many state and local code officials lack the knowledge and technical capability to efficiently implement the higher building energy-efficiency standards.

\section{Modeling GPRA Benefits:}

GPRA estimates for this activity are based on the future development and adoption of more stringent building energy codes for both residential and commercial sectors. Built up from the state level, the estimates provide a better relate changes in the codes with variations in climates and differences among states in the adoption and enforcement of building codes.

\section{Sources:}

(1) FY 2008 Budget Request (2007). Projected Benefits of Federal Energy Efficiency and Renewable Energy Programs FY 2008 Budget Request. March 2007. Prepared by National Renewable Energy Laboratory.

(2) Interview with Ron Majette on February 20, 2007. Additional email conversations with Jim Rannels (Fed. Main Contact).

(3) "EERE Deployment Inventory Survey Results." Survey results in Excel spreadsheet from survey conducted in 2004 to characterize and evaluate deployment programs in DOE's Energy Efficiency and Renewable Energy Program.

(4) Information gathered on the Internet from: [http://www.energycodes.gov//] on September 2007.

(5) Building Technologies Multi-Year Program Plan (2007) http://www.eere.energy.gov/buildings/about/mypp.html, Updated January 2007.

\section{Building Energy Codes}

Project Type/Stage:

Public Infrastructure and Policy

Regulation

Preliminary Audience:

Code officials and building industry (e.g., builders and architects).

Target Sector:

Commercial Buildings and

Residential Buildings

\section{End Uses:}

Potentially heating, cooling, water heating, lighting, and plug loads

R\&D Linkage:

Building Codes R\&D

FY08 Budget Request:

$\$ 3.751$ million (together with Advanced Energy Codes Initiative)

Program/Modeling Contact: Ron Majette

Website:

http://www.energycodes.gov/ 


\section{Project Description:}

The Advanced Building Codes Initiative will partner with ASHRAE and IESNA to upgrade the model commercial code by $30 \%$ (relative to ASHRAE 90.12004) by 2010 , and assist states in implementation of the model code as well as provide analysis to support the process.

\section{Market Barriers:}

There is a general lack of information and awareness about efficient-building designs and technologies. In addition, many state and local code officials lack the knowledge and technical capability to efficiently implement the higher building-energy efficiency standards.

\section{Modeling GPRA Benefits:}

This initiative is modeled jointly with the Commercial Buildings Codes R\&D adoption.

\section{Sources:}

(1) FY 2008 Budget Request (2007). Projected Benefits of Federal Energy Efficiency and Renewable Energy Programs FY 2008 Budget Request. March 2007. Prepared by National Renewable Energy Laboratory.

(2) Interviews with Ron Majette on February 20, 2007; Carol Jones (Commercial Lighting Challenge) on February 25, 2007; Judy Dyer on February 27, 2007; and Rich Karney and Carol Jones on February 30, 2007. Additional email conversations with Jim Rannels (Fed. Main Contact).

(3) Information gathered on the Internet from: [http://www.energycodes.gov/] on September 2007.

(4) Building Technologies Multi-Year Program Plan (2007) http://www.eere.energy.gov/buildings/about/mypp.html, Updated January 2007.

\section{Advanced Energy Codes Initiative}

Project Type/Stage:

Public Infrastructure and Policy

Regulation

Preliminary Audience:

State Governments and

Code Officials

Target Sector:

Commercial Buildings

End Uses:

Potentially heating, cooling, water hating, lighting, and plug loads

R\&D Linkage:

Building Codes Technologies R\&D

FY08 Budget Request:

$\$ 3.751$ million (together with

Building Energy Codes)

Program/Modeling Contact:

Ron Majette

Website:

http://www.energycodes.gov/ 


\section{Project Description:}

The Commercial Lighting Challenge Initiative strives to improve commercial lighting by $30 \%$ through the development and promotion of guidelines for saving lighting energy within commercial buildings and developing high-profile pilots for advanced lighting.

\section{Market Barriers:}

A general lack of information and awareness exists about the high-efficiency lighting products, designs, and technologies. The high "first-costs" investment required to redesign lighting or include higherefficiency fixtures in a building design can potentially deter implementation. A lack of knowledge and technical capability could potentially inhibit the enduser from efficiently implementing high-efficiency lighting projects. Finally, some of the newer lighting designs and components face risk aversion in the market because of concerns regarding product reliability (products have not yet demonstrated a long track record).

\section{Modeling GPRA Benefits:}

The benefits for this program will be calculated "offline," targeting only those buildings types where integrated-lighting packages are expected to have the most success (primarily retail, education, healthcare, and office). Based on recent market data, market penetration curves are developed assuming that 50 percent of all applicable retail space, 75 percent of all healthcare, and 80 percent of all office space could implement high-efficiency lighting system "packages" in 10 years with the assistance of this program.

\section{Commercial Lighting Challenge}

Project Type/Stage:

Manufacturing and Business Infrastructure

Preliminary Audience:

Commercial building managers, owners, designers, and builders

Target Sector:

Commercial Buildings

\section{End Uses:}

Lighting

R\&D Linkage:

Building Technologies Lighting $R \& D$

FY08 Budget Request:

$\$ 2.834$ million

Program/Modeling Contact:

Rich Karney

Website:

http://www.eere.energy.gov/build ings/tech/lighting/

\section{Sources:}

(1) FY 2008 Budget Request (2007). Projected Benefits of Federal Energy Efficiency and Renewable Energy Programs FY 2008 Budget Request. March 2007. Prepared by National Renewable Energy Laboratory.

(2) Interviews with Carol Jones (Commercial Lighting Challenge) on February 25, 2007; and Rich Karney and Carol Jones on February 30, 2007. Additional email conversations with Jim Rannels (Fed. Main Contact).

(3) Building Technologies Multi-Year Program Plan (2007)

http://www.eere.energy.gov/buildings/about/mypp.html, Updated January 2007. 


\section{Project Description:}

Best Practices works with U.S. industries to implement energy-management practices in industrial plants and also provides a number of resources for corporate executives, plant managers, technical staff, and the general public, including technical publications, website resources, software tools, technical assistance, databases and training. The "Save Energy Now" energysavings assessments reduce U.S. manufacturing-plant natural-gas consumption in support of the Secretary of Energy's "Easy Ways to Save Energy" campaign. The program will also continue to provide technical assistance to industrial plants and energy-intensive data centers. The Department will continue to expand partnerships for leveraging opportunities with trade and technical associations, federal agencies, local governments, and others to facilitate replication and recognition of plantwide assessment results.

\section{Market Barriers:}

A general lack of information, awareness, and technical capacity remains within the industrial sector that may inhibit the end-user from efficiently implementing the product, design, or technology.

\section{Modeling GPRA Benefits:}

The Industrial Technologies Program (ITP) is not currently able to model its deployment programs in the NEMS integrated framework. The program does, however, provide penetration and performance curves, which are estimated outside of the NEMS framework, or "off-line," for the specific technologies impacted, based on information provided to the analysts through the proposal-

\section{Best Practices/Save Energy} Now Program

Project Type/Stage:

Manufacturing and Business Infrastructure

\section{Preliminary Audience:}

Industry, Federal Agencies, and Local Governments, Trade Associations.

Target Sector: Industrial Sector

\section{End Uses:}

Industrial gas and electricity consumption.

R\&D Linkage:

Relevant Industrial R\&D

FY08 Budget Request: $\$ 8.833$ million

Program/Modeling Contact: Peggy Podolak

Website:

http://www1.eere.energy.gov/ind ustry/bestpractices/ review and contracting process. ITP analysis by sector has focused on assessing the industrial processes where energy is actually consumed and in understanding the current and best practices for each proposed technology. The participation of industry experts in this process is crucial to assist in the refinement of the estimates.

\section{Sources:}

(1) FY 2008 Budget Request (2007). Projected Benefits of Federal Energy Efficiency and Renewable Energy Programs FY 2008 Budget Request. March 2007. Prepared by National Renewable Energy Laboratory.

(2) Interviews with Peggy Podolak (PBA) and Michaela Martin (ORNL Modeler) on February 14, 2007.

(3) "EERE Deployment Inventory Survey Results." Survey results in Excel spreadsheet from survey conducted in 2004 to characterize and evaluate deployment programs in DOE's Energy Efficiency and Renewable Energy Program.

(4) Information gathered on the Internet from: [http://www1.eere.energy.gov/industry/bestpractices/iacs.html] on September 2007. 


\section{Project Description:}

The Industrial Technology Program's (ITP) Industrial Assessment Centers (IACs) provide eligible smalland medium-sized manufacturers with no-cost energy assessments. Additionally, the IACs serve as a training ground for the next generation of energyengineers by funding a network of universities, which send graduate engineering students out to smalland medium-sized manufacturers to conduct free energy audits. Additional outreach products include a searchable database, case studies, website, fact sheets, and presentations.

\section{Market Barriers:}

Within the industrial sector, a general lack of information, awareness and technical capability exist that may deter the end-user from efficiently implementing the product, design, or technology.

\section{Modeling GPRA Benefits:}

ITP is currently unable to model its deployment programs in the NEMS integrated framework. The program does, however, provide penetration and performance curves, which are estimated outside of the NEMS framework, or "off-line," for the specific technologies impacted. This is based on information provided to the analysts through the proposal-review and contracting process. ITP analysis by sector has focused on assessing the industrial processes where energy is actually consumed, and in understanding current and best practices for each proposed technology. The participation of industry experts in this process is critical to assist in the refinement of the estimates.

\section{Sources:}

(1) FY 2008 Budget Request (2007). Projected Benefits of Federal Energy Efficiency and Renewable Energy Programs FY 2008 Budget Request. March 2007. Prepared by National Renewable Energy Laboratory.

(2) Interviews with Peggy Podolak (PBA) and Michaela Martin (ORNL Modeler) on February 14, 2007.

(3) "EERE Deployment Inventory Survey Results." Survey results in Excel spreadsheet from survey conducted in 2004 to characterize and evaluate deployment programs in DOE's Energy Efficiency and Renewable Energy Program.

(4) Information gathered on the Internet from:

[http://www1.eere.energy.gov/industry/bestpractices/iacs.html on September 2007.

\section{Industrial Assessment Centers}

Project Type/Stage:

Technology Adoption Supports

Preliminary Audience:

Knowledge Community and Industrial End-Users

Target Sector:

Industrial Sector

\section{End Uses:}

Industrial gas, oil, and electricity usage.

\section{R\&D Linkage:}

All relevant Industrial energy R\&D

FY08 Budget Request: $\$ 4.035$ million

Program/Modeling Contact:

Peggy Podolak

Website:

http://www1.eere.energy.gov/ind ustry/bestpractices/iacs.html 
Federal Energy Management Program

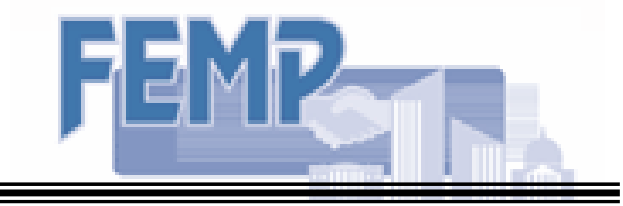

\section{Project Description:}

This portion of the FEMP program allows federal energy managers to identify, design, and implement new construction and facility-improvement projects that incorporate energy efficiency and renewable energy. Working with FEMP, agencies can acquire the most energy-efficient products through procurement training, product-efficiency recommendations, communications and outreach, and assistance in amending agency guide specifications to incorporate requirements for energy-efficient products. The program provides training for federal agency energy managers, and issues publications on energy technologies and best practices.

\section{Market Barriers:}

This program targets a wide range of market barriers including: lack of information awareness, policy and regulation barriers, technical capacity constraints, risk aversion, market fragmentation, and misplaced incentives.

\section{Modeling GPRA Benefits:}

Within the GPRA framework, FEMP's benefits estimates are produced outside the NEMS/MARKAL modeling framework. FEMP utilizes historical data from the previous five years to develop an estimate of energy savings per program dollar. This figure is

Technical Guidance and Assistance

Project Type/Stage:

Technology Adoption Supports

Preliminary Audience:

Federal Agencies

Target Sector:

Federal Buildings

End Uses:

Heating, cooling, water heating, lighting, plug loads, and renewable energy generation

R\&D Linkage:

Applicable EERE R\&D

FY08 Budget Request:

$\$ 6.519$ million

Program/Modeling Contact: Will Lintner

Website:

http://www1.eere.energy.gov/fem p/technologies/technologies.html then multiplied by the budget request to determine the potential forecasted benefits stream, which is adjusted to $80 \%$ of the estimate to ensure that the projected savings estimates are conservative and attainable. The dollar amount does not incorporate the private investment; therefore, a significant variation can occur from year to year in terms of the energy savings per program dollar.

\section{Sources:}

(1) Projected Benefits of Federal Energy Efficiency and Renewable Energy Programs - FY 2008 Budget Request. March 2007. Prepared by National Renewable Energy Laboratory for U.S. Department of Energy, Energy Efficiency and Renewable Energy. NREL/TP-640-41347.

(2) FY 2008 U.S. Department of Energy Budget Request to Congress, Detailed Budget Justifications, Energy and Water Development Appropriations, Volume 3: Energy Supply and Conservation. February 2007. DOE/CF-016, Volume 3.

(3) Interview with Will Lintner (Program Contact) on March 9, 2007. 


\section{Project Description:}

FEMP alternative-financing programs improve agencies' access to private-sector financing to enable funding of needed energy improvements. FEMP assists Federal agencies in using Energy Savings Performance Contracts (ESPCs) and Utility Energy Service Contracts (UESCs) to finance energy-saving improvements without the use of current appropriations. Both programs have a myriad of deployment activities, including websites, publications, databases, conferences, software tools, and training.

\section{Market Barriers:}

This program targets a wide range of market barriers including: lack of information awareness, policy and regulation barriers, cost and financing barriers, technical capacity constraints, risk aversion, market fragmentation, and misplaced incentives.

\section{Modeling GPRA Benefits:}

Within the GPRA framework, FEMP's benefits estimates are produced outside the NEMS/MARKAL modeling framework. FEMP uses historical data from the previous five years to develop an estimate of energy savings per program dollar. This figure is then multiplied by the budget request to determine the potential forecasted benefits stream, which is adjusted to $80 \%$ of the estimate to ensure that the projected savings estimates are conservative and attainable. The dollar amount does not incorporate the private investment; therefore, a significant variation can occur from year to year in terms of the energy savings per program dollar.

\section{Sources:}

(1) Projected Benefits of Federal Energy Efficiency and Renewable Energy Programs - FY 2008 Budget Request. March 2007. Prepared by National Renewable Energy Laboratory for U.S. Department of Energy, Energy Efficiency and Renewable Energy. NREL/TP-640-41347.

(2) FY 2008 U.S. Department of Energy Budget Request to Congress, Detailed Budget Justifications, Energy and Water Development Appropriations, Volume 3: Energy Supply and Conservation. February 2007. DOE/CF-016, Volume 3.

(3) Interview with Will Lintner (Program Contact) on March 9, 2007. 


\section{Project Description:}

This effort supports the Secretary of Energy's

"Transformational Energy Action Management Initiative" (TEAM). FEMP will provide assistance to other DOE offices in support of the use of third-party financing, maximize direct purchases that facilitate new renewable-energy projects, maximize use of DOE land for new renewable-energy projects, and incorporate renewable technologies into the latest construction where feasible. Deployment activities include: 1) establishing alternative fuels infrastructure for DOE Fleets, 2) establishing incentive awards, 3) training of DOE senior management and staff on the Secretarial Initiative, Executive Order and EPACT 2005 compliance, 4) establishing sustainable principles, 5) identifying and deploying energy efficiency, water and renewableenergy technologies, 6) providing information and outreach, 7) assisting with development and implementation of site energy and water plans, 8) supporting ESPC and UESC projects, training, renewable-power purchase agreements, project development, and implementation assistance, and 9) supporting deployment of smart meters on all DOE buildings.

\section{Market Barriers:}

This program targets a wide range of market barriers including: lack of information awareness, policy and regulation barriers, cost and financing barriers, technical capacity constraints, risk aversion, market fragmentation, and misplaced Incentives.

\section{DOE Specific Investments}

Project Type/Stage:

Public Infrastructure and Policy

Regulation

Preliminary Audience:

DOE

Target Sector:

DOE Buildings and Vehicles

\section{End Uses:}

Heating, Cooling, Water Heating, Lighting, Plug Loads, DOE Fleet, and Renewable Energy

R\&D Linkage:

Applicable EERE R\&D

FY08 Budget Request:

New initiative-not included in the FY08 budget request.

Program/Modeling Contact: Will Lintner

Website:

http://www.eere.energy.gov/new s/news detail.cfm/news id=1115 $\underline{4}$

\section{Modeling GPRA Benefits:}

Within the GPRA framework, FEMP's benefits estimates are produced outside the NEMS/MARKAL modeling framework. FEMP utilizes historical data from the previous five years to develop an estimate of energy savings per program dollar. This figure is then multiplied by the budget request to determine the potential forecasted benefits stream, which is adjusted to $80 \%$ of the estimate to ensure that the projected savings are conservative and attainable.

\section{Sources:}

(1) Draft FY 2009 FEMP Budget Request

(2) Website: http://www.eere.energy.gov/news/news_detail.cfm/news_id=11154 
Federal Fleets

FEMP Program

\section{Project Description:}

This activity provides guidance and support to each agency to promote compliance with legislative and executive-order requirements to reduce the dependence on foreign sources of oil. To streamline the compliance process, the program works with the agencies to develop strategies for addressing those issues, and shares the lessons learned with other fleets. The role of the Federal Fleet activity is to implement compliance measures in each agency's fleet activity in support of the Energy Policy Acts of 1992 and 2005, and Executive Order 13149.

\section{Market Barriers:}

This program targets a wide range of market barriers including: lack of information awareness, policy and regulation barriers, cost and financing barriers, technical capacity constraints, risk aversion, market fragmentation, and misplaced incentives.

\section{Modeling GPRA Benefits:}

This activity was transferred to FEMP in FY08 from FreedomCAR/Vehicle Technologies. No modeling methodology is currently in effect.

\section{Sources:}

(1) FY 2008 U.S. Department of Energy Budget Request to Congress, Detailed Budget Justifications, Energy and Water Development Appropriations, Volume 3: Energy Supply and

Federal Fleets

Project Type/Stage:

Public Infrastructure and Policy

Regulation

Preliminary Audience:

Federal

Target Sector:

Government Vehicles

\section{End Uses:}

Federal fleet, vehicle fuel use

R\&D Linkage:

Applicable EERE R\&D

(FreedomCAR and Vehicle

Technologies, Biomass)

FY08 Budget Request:

$\$ 2.337$ million

Program/Modeling Contact:

Will Lintner

Website:

http://www1.eere.energy.gov/fem p/about/fleet requirements.html Conservation. February 2007. DOE/CF-016, Volume 3.

(2) Website: http://www1.eere.energy.gov/femp/about/fleet_requirements.html 
Weatherization Assistance Program

Weatherization and Intergovernmental Program

\section{Project Description:}

The Weatherization Assistance Program provides cost-effective energy-efficiency services free of charge to eligible low-income households that otherwise could not afford the investment, but would benefit significantly from the cost savings of energyefficiency technologies. DOE provides funding to states, which manage the day-to-day details of the program. Low-income families receive services from a network of more than 900 local weatherizationservice providers.

\section{Market Barriers:}

High "first" costs and/or insufficient available financing options to pay for weatherization projects deter implementation.

\section{Modeling GPRA Benefits:}

WIP's estimates are based on energy-savings estimates contained within program-evaluation reports and weatherized household projections by region. A percentage of households weatherized with leveraged funds is also included in the estimate. To develop energy savings by building type, WIP evaluated historical Weatherization Project data (Berry et al. 1997) concerning the types of households weatherized.

\section{Sources:}

(1) FY 2008 Budget Request (2007). Projected Benefits of Federal Energy Efficiency and Renewable Energy Programs FY 2008 Budget Request. March 2007. Prepared by National Renewable Energy Laboratory.

(2) Interviews with Cathy Short (PBA) and Mark Bailey (Acting Program Manager) on February 15, 2007.

(3) "EERE Deployment Inventory Survey Results." Survey results in Excel spreadsheet from survey conducted in 2004 to characterize and evaluate deployment programs in DOE's Energy Efficiency and Renewable Energy Program.

(4) Information gathered on the Internet from: [http://www.eere.energy.gov/weatherization/] on September 2007.

(5) Berry, L.G., M.A. Brown, and L.F. Kinney. 1997. Progress Report of the National Weatherization Assistance Program, ORNL/CON-450, Oak Ridge National Laboratory, Oak Ridge, Tennessee.

\section{Weatherization Assistance Program}

Project Type/Stage:

Public Infrastructure and Policy

Regulation

\section{Preliminary Audience:}

End-Users

Target Sector:

Residential Buildings

\section{End Uses:}

Heating, Cooling, Water Heating, Lighting, and Appliances

R\&D Linkage:

Buildings R\&D

FY08 Budget Request:

\$144 million

Program/Modeling Contact:

Jean Diggs

Website:

http://www.eere.energy.gov/weat $\underline{\text { herization/ }}$ 
State Energy Program

Weatherization and Intergovernmental Program

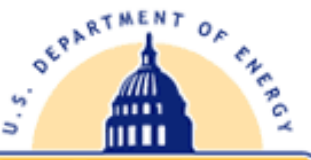

\section{Project Description:}

The State Energy Program provides grants to 50 states, DC, and territories for energy-efficiency and renewable-energy programs. The focus of the program is on accelerating market penetration of renewable and efficiency technologies, and increasing available capital for energy projects. Examples of project areas are: revolving-loan funds, financing-risk reduction, performance contracting, and market-oriented regional consortiums. Outreach activities include publications, websites, databases, conferences, partnerships, software tools, training, and technical assistance.

\section{Market Barriers:}

This program targets a wide range of market barriers including: lack of information awareness, policy and regulation barriers, cost and financing barriers, technical capacity constraints, risk aversion, market fragmentation, and misplaced incentives.

\section{Modeling GPRA Benefits:}

SEP's GPRA estimates are based on an evaluation of the activities funded by SEP during the 2002 program year and on the technical potential calculations developed as part of a market analysis funded by WIP. The evaluation authors developed a series of indicator measurements for a number of activities traditionally funded by SEP's formula grants, which were applied to future expectations of the grant program. Additionally, the formula grants estimates include projected savings due to leveraged

\section{State Energy Program}

Project Type/Stage:

Public Infrastructure and Policy

Regulation

Preliminary Audience:

End-Users, Business, and Public

Target Sector:

Buildings, Industry,

Transportation, and Utilities

\section{End Uses:}

Heating, cooling, water heating, lighting, plug loads, industrial processes, renewable energy, and vehicles

R\&D Linkage:

Applicable EERE R\&D

FY08 Budget Request:

\$45.501 million

Program/Modeling Contact:

Faith Lambert

Website:

http://www.eere.energy.gov/state energy program/ funds. For the SEP competitive grants, the energy savings per dollar invested developed by sector within the WIP market analysis were used to represent that activity's energy savings.

\section{Sources:}

(1) FY 2008 Budget Request (2007). Projected Benefits of Federal Energy Efficiency and Renewable Energy Programs FY 2008 Budget Request. March 2007. Prepared by National Renewable Energy Laboratory.

(2) Interviews with Cathy Short (PBA) and Mark Bailey (Acting Program Manager) on February 15, 2007.

(3) "EERE Deployment Inventory Survey Results." Survey results in Excel spreadsheet from survey conducted in 2004 to characterize and evaluate deployment programs in DOE's Energy Efficiency and Renewable Energy Program. 
Weatherization and Intergovernmental Program

\section{Project Description:}

The Tribal Energy Program builds partnerships with tribal governments to assist in the assessment of Native Americans' energy needs for residential, commercial, and industrial uses. Additionally, the program provides technical and financial assistance concerning energy-efficiency and renewable-energy project development. Deployment activities include publications, website, educational materials, and workshops.

\section{Market Barriers:}

This program targets a wide range of market barriers, including a lack of information awareness, policy and regulation barriers, cost and financing barriers, technical capacity constraints, risk aversion, market fragmentation, and misplaced incentives.

\section{Modeling GPRA Benefits:}

For the GPRA modeling effort, a forecast of the megawatt capacity added each year, along with the capacity factor and percentage wind versus biomass, is provided to the modeling effort.

\section{Sources:}

(1) FY 2008 Budget Request (2007). Projected Benefits of Federal Energy Efficiency and Renewable Energy Programs FY 2008 Budget Request. March 2007. Prepared by National Renewable Energy Laboratory.

(2) Interviews with Cathy Short (PBA) and Mark Bailey (Acting Program Manager) on February 15, 2007.

(3) "EERE Deployment Inventory Survey Results." Survey results in Excel spreadsheet from survey conducted in 2004 to characterize and evaluate deployment programs in DOE's Energy Efficiency and Renewable Energy Program.

(4) Information gathered on the Internet from: [http://www.eere.energy.gov/tribalenergy/] on September 2007. 
International Renewable Energy/Asia Pacific Partnership

Weatherization and Intergovernmental Program

\section{Project Description:}

The Asia Pacific Partnership (APP) encourages clean-energy technology deployment among six countries: Australia, China, India, Japan, South Korea, and the United States. These countries represent about half of the world's economy, population, and energy usage.

\section{Market Barriers:}

This program targets a wide range of market barriers including: lack of information awareness, policy and regulation barriers, cost and financing barriers, technical capacity constraints, risk aversion, market fragmentation, and misplaced incentives.

\section{Modeling GPRA Benefits:}

As the Asia Pacific Partnership's energy savings are expected to accrue outside the U.S., the savings are not currently modeled.

\section{Sources:}

(1) Draft FY2009 WIP Budget

(2) Interviews with Cathy Short (PBA) and Mark Bailey (Acting Program Manager) on February 15, 2007.

(3) "EERE Deployment Inventory Survey Results." Survey results in Excel spreadsheet from survey conducted in 2004 to characterize and evaluate deployment programs in DOE's Energy Efficiency and Renewable Energy Program.

(4) Information gathered on the Internet from: [http://www.eere.energy.gov/wip/international.htm l] on September 2007.

\section{International Renewable EnergylAsia Pacific Partnership}

Project Type/Stage:

Technology Adoption Supports

Preliminary Audience:

International

Target Sector:

International

\section{End Uses:}

Heating, cooling, water heating, lighting, plug loads, renewable technologies, and industrial processes

\section{R\&D Linkage:}

Industrial, Buildings, and Hydrogen R\&D

FY08 Budget Request:

$\$ 7.5$ million

Program/Modeling Contact:

Mark Bailey

Website:

http://www.eere.energy.gov/wip/i nternational.html 
Appendix C - NEMS Modules

MODELING EERE DEPLOYMENT ACTIVITIES 


\section{Appendix C: NEMS Modules and Modeling Structure}

\begin{tabular}{|c|c|c|}
\hline Energy Activity & Categories & Regions \\
\hline Residential demand & $\begin{array}{l}\text { Sixteen end-use services } \\
\text { Three housing types } \\
\text { Thirty-four end-use technologies }\end{array}$ & Nine Census divisions \\
\hline Commercial demand & $\begin{array}{l}\text { Ten end-use services } \\
\text { Eleven building types } \\
\text { Ten distributed generation } \\
\text { technologies } \\
\text { Sixty-four end-use technologies }\end{array}$ & Nine Census divisions \\
\hline Industrial demand & $\begin{array}{l}\text { Seven energy-intensive industries } \\
\text { Eight non-energy-intensive industries } \\
\text { Cogeneration }\end{array}$ & $\begin{array}{l}\text { Four Census regions, shared to } \\
\text { nine } \\
\text { Census divisions }\end{array}$ \\
\hline $\begin{array}{l}\text { Transportation } \\
\text { demand }\end{array}$ & $\begin{array}{l}\text { Six car sizes } \\
\text { Six light truck sizes } \\
\text { Sixty-three conventional fuel-saving } \\
\text { technologies } \\
\text { for light-duty vehicles } \\
\text { Gasoline, diesel, and thirteen } \\
\text { alternative-fuel } \\
\text { vehicle technologies for light-duty } \\
\text { vehicles } \\
\text { Twenty vintages for light-duty vehicles } \\
\text { Narrow and wide-body aircraft } \\
\text { Six advanced aircraft technologies } \\
\text { Medium and heavy freight trucks } \\
\text { Thirty-seven advanced freight truck } \\
\text { technologies }\end{array}$ & Nine Census divisions \\
\hline Electricity & $\begin{array}{l}\text { Eleven fossil generation technologies } \\
\text { Two distributed generation } \\
\text { technologies } \\
\text { Seven renewable generation } \\
\text { technologies } \\
\text { Conventional and advanced nuclear } \\
\text { Marginal and average cost pricing } \\
\text { Generation capacity expansion } \\
\text { Seven environmental control } \\
\text { technologies }\end{array}$ & $\begin{array}{l}\text { Fifteen electricity supply regions } \\
\text { (including } \\
\text { Alaska and Hawaii) based on the } \\
\text { North } \\
\text { American Electric Reliability } \\
\text { Council regions } \\
\text { and subregions } \\
\text { Nine Census divisions for demand }\end{array}$ \\
\hline
\end{tabular}




\begin{tabular}{|c|c|c|}
\hline Energy Activity & Categories & Regions \\
\hline Renewables & $\begin{array}{l}\text { Wind, geothermal, solar thermal, solar } \\
\text { photovoltaic, } \\
\text { landfill gas, biomass, conventional } \\
\text { hydropower }\end{array}$ & Fifteen electricity supply regions \\
\hline Oil supply & $\begin{array}{l}\text { Onshore } \\
\text { Deep and shallow offshore }\end{array}$ & $\begin{array}{l}\text { Six lower } 48 \text { onshore regions } \\
\text { Three lower } 48 \text { offshore regions } \\
\text { Three Alaska regions }\end{array}$ \\
\hline Natural gas supply & $\begin{array}{l}\text { Conventional lower-48 onshore } \\
\text { Lower-48 deep and shallow offshore } \\
\text { Coalbed methane } \\
\text { Gas shales } \\
\text { Tight sands } \\
\text { Canadian, Mexican, and liquefied } \\
\text { natural gas } \\
\text { Alaskan Gas }\end{array}$ & $\begin{array}{l}\text { Six lower } 48 \text { onshore regions } \\
\text { Three lower } 48 \text { offshore regions } \\
\text { Three Alaska regions } \\
\text { Eight liquefied natural gas import } \\
\text { regions }\end{array}$ \\
\hline $\begin{array}{l}\text { Natural gas } \\
\text { transmission } \\
\text { and distribution }\end{array}$ & $\begin{array}{l}\text { Core vs. noncore } \\
\text { Peak vs. offpeak } \\
\text { Pipeline capacity expansion }\end{array}$ & $\begin{array}{l}\text { Twelve lower } 48 \text { regions } \\
\text { Ten pipeline border points }\end{array}$ \\
\hline Refining & $\begin{array}{l}\text { Five crude oil categories } \\
\text { Fourteen product categories } \\
\text { More than } 40 \text { distinct technologies } \\
\text { Refinery capacity expansion }\end{array}$ & $\begin{array}{l}\text { Three refinery regions aggregated } \\
\text { from Petroleum Administration for } \\
\text { Defense } \\
\text { Districts }\end{array}$ \\
\hline Coal supply & $\begin{array}{l}\text { Three sulfur categories } \\
\text { Four thermal categories } \\
\text { Underground and surface mining types } \\
\text { Imports and Exports }\end{array}$ & $\begin{array}{l}\text { Eleven supply regions } \\
\text { Sixteen demand regions } \\
\text { Sixteen export regions } \\
\text { Twenty import regions }\end{array}$ \\
\hline
\end{tabular}

Source: U.S. Department of Energy, Report \#: DOE/EIA-0581(2003). Released March 4, 2003.

Downloaded from the Internet (09/2007) at:

http://www.eia.doe.gov/oiaf/aeo/overview/summary tbl.html 
Figure 5. Residential Demand Module Structure

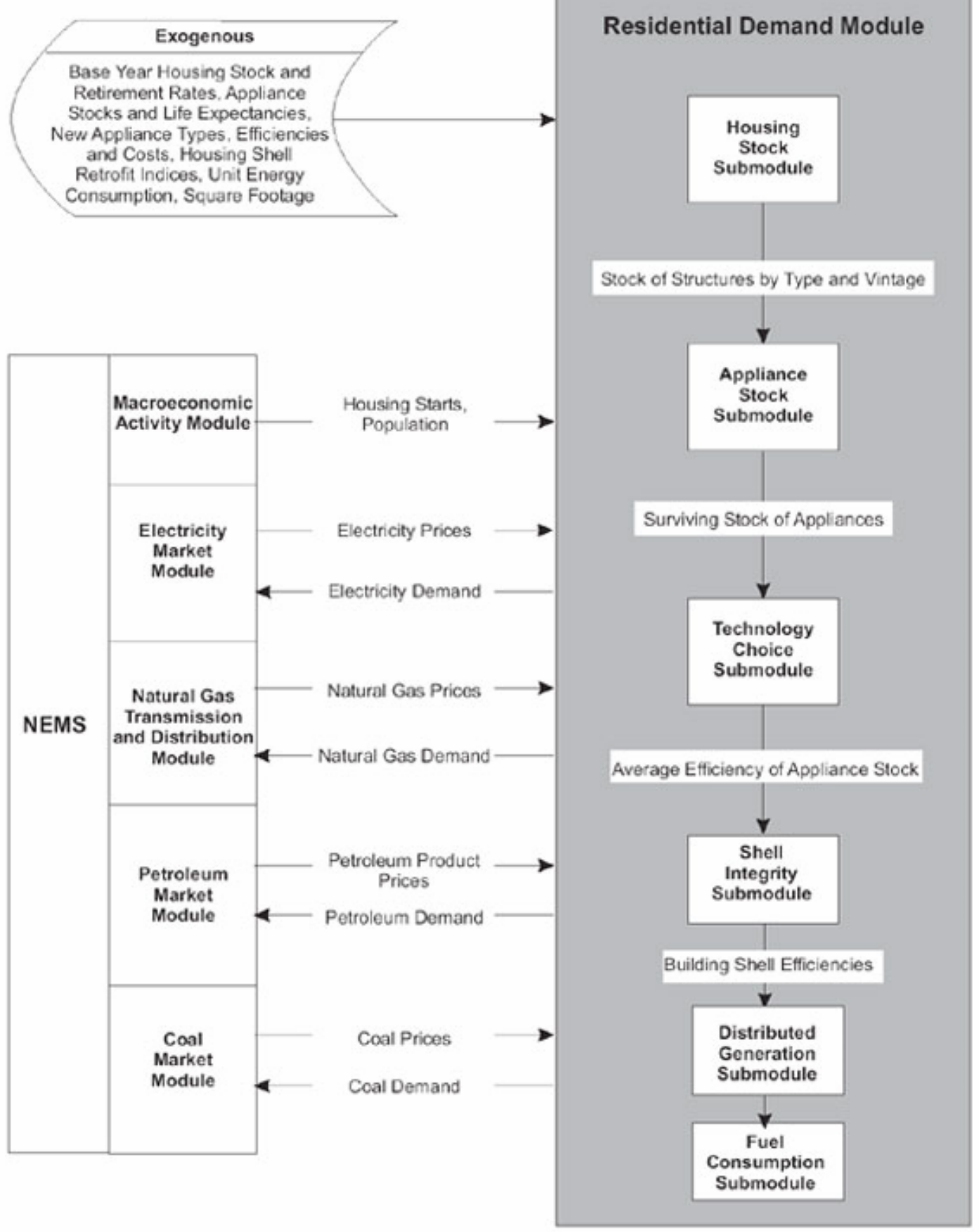

Source: U.S. Department of Energy, Report \#: DOE/EIA-0581(2003). Released March 4, 2003. Downloaded from the Internet (09/2007) at:

http://www.eia.doe.gov/oiaf/aeo/overview/figure 5.html 
Figure 6. Commercial Demand Module Structure

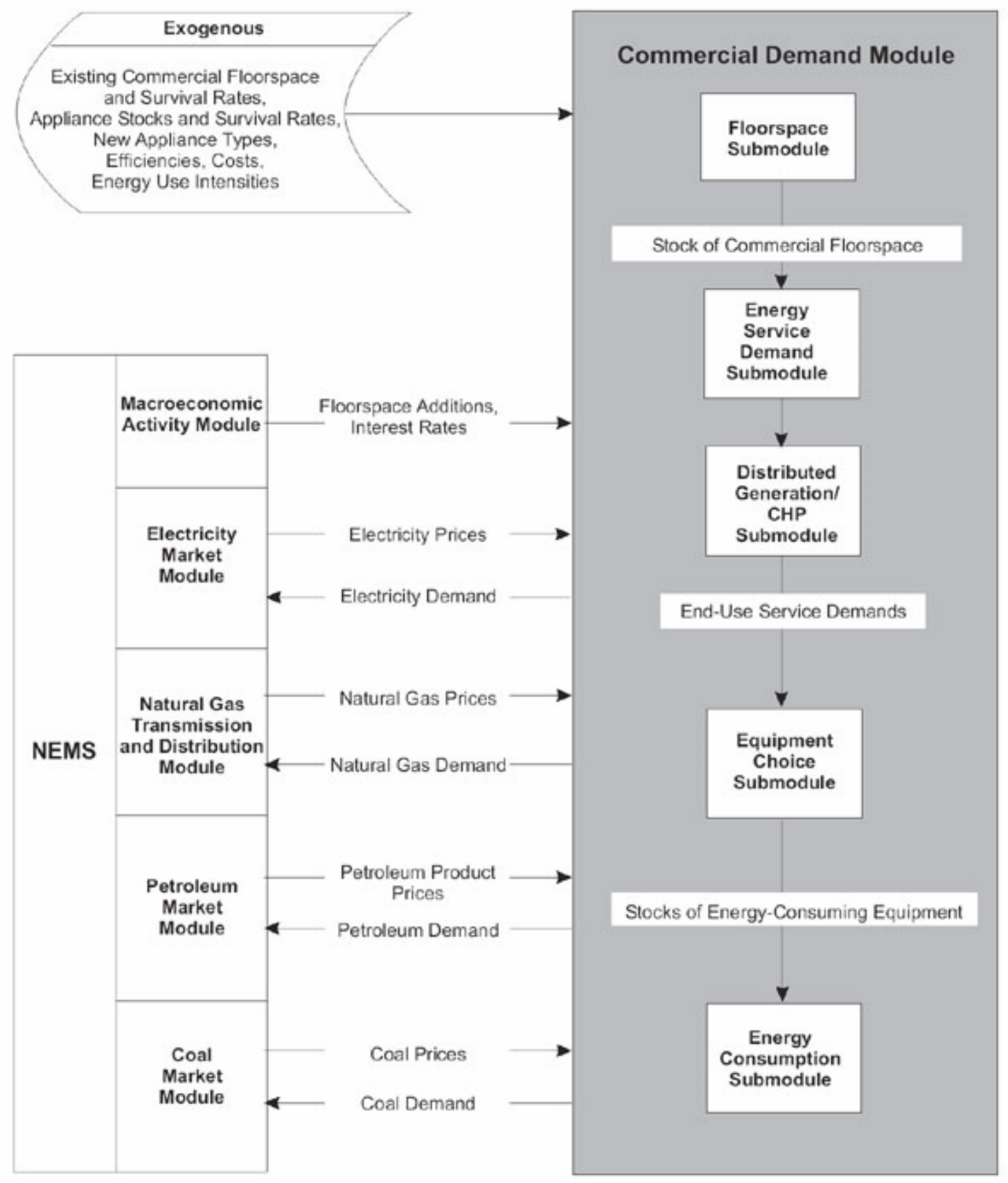

Source: U.S. Department of Energy, Report \#: DOE/EIA-0581(2003). Released March 4, 2003. Downloaded from the Internet (09/2007) at: http://www.eia.doe.gov/oiaf/aeo/overview/figure $6 . \mathrm{html}$ 
Figure 7. Industrial Demand Module Structure

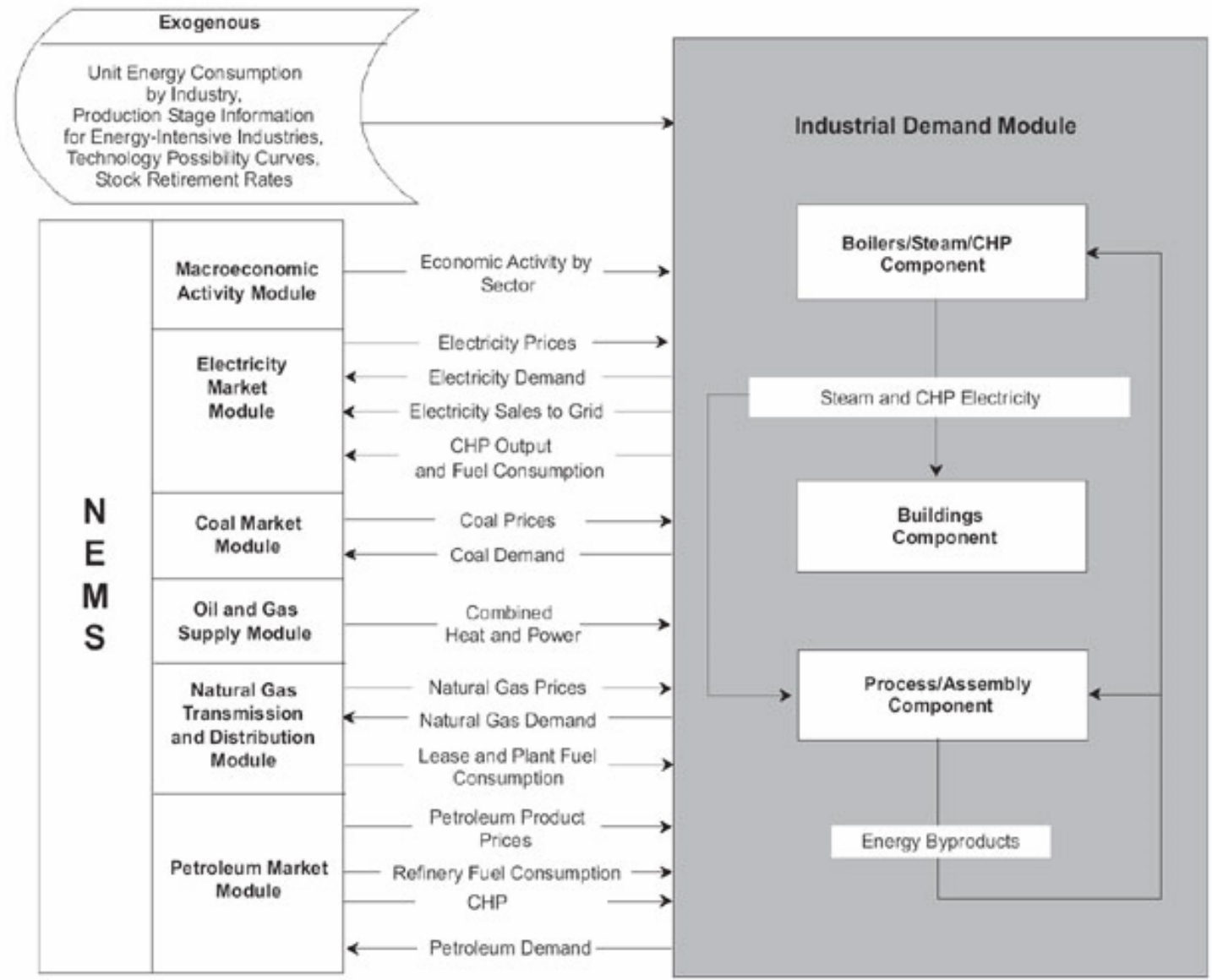

Source: U.S. Department of Energy, Report \#: DOE/EIA-0581(2003). Released March 4, 2003.

Downloaded from the Internet (09/2007) at:

http://www.eia.doe.gov/oiaf/aeo/overview/figure 7.html 
Figure 8. Transportation Demand Module Structure

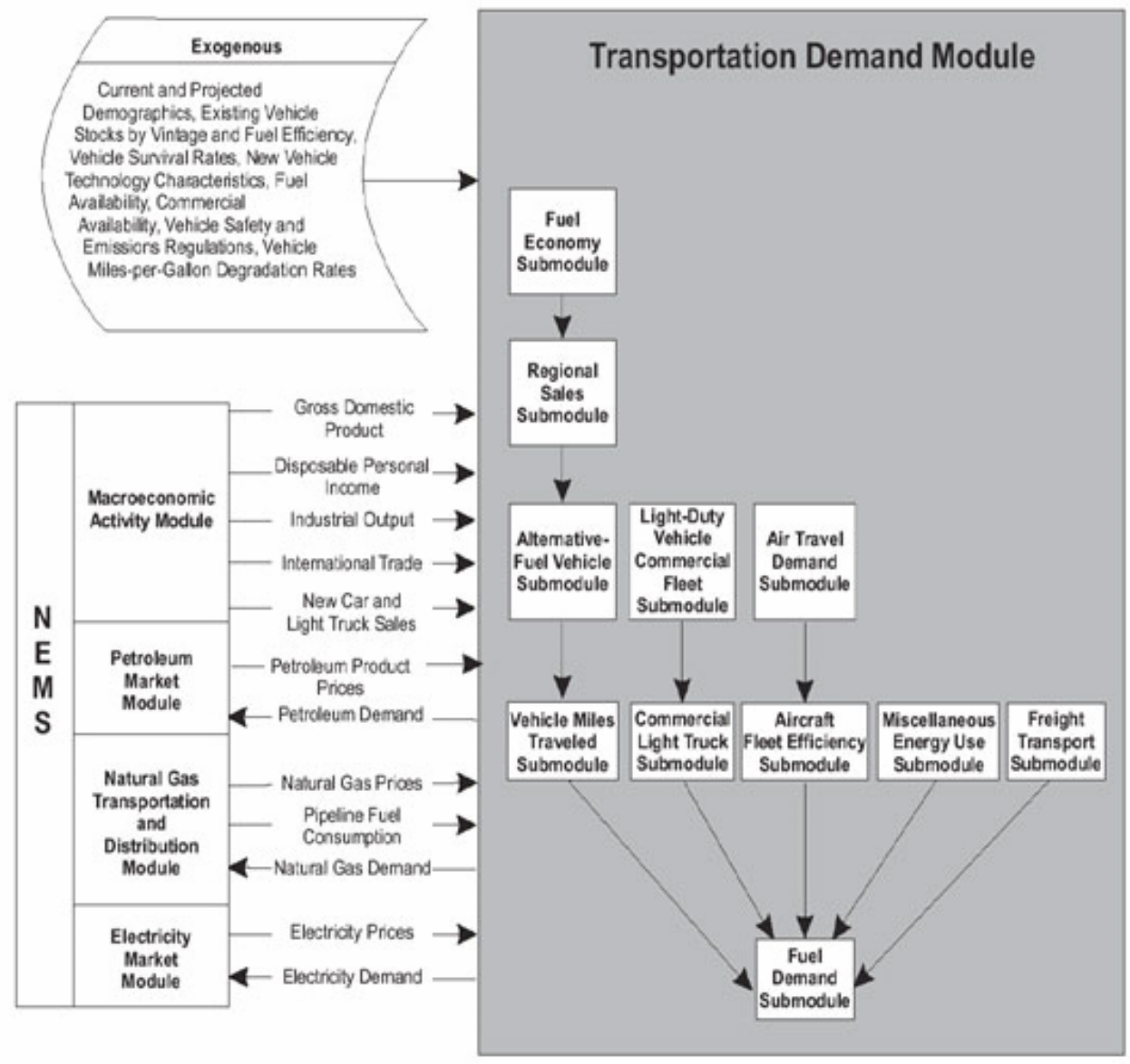

Source: U.S. Department of Energy, Report \#: DOE/EIA-0581(2003). Released March 4, 2003.

Downloaded from the Internet (09/2007) at:

http://www.eia.doe.gov/oiaf/aeo/overview/figure 8.html 
Figure 9. Electricity Market Module Structure

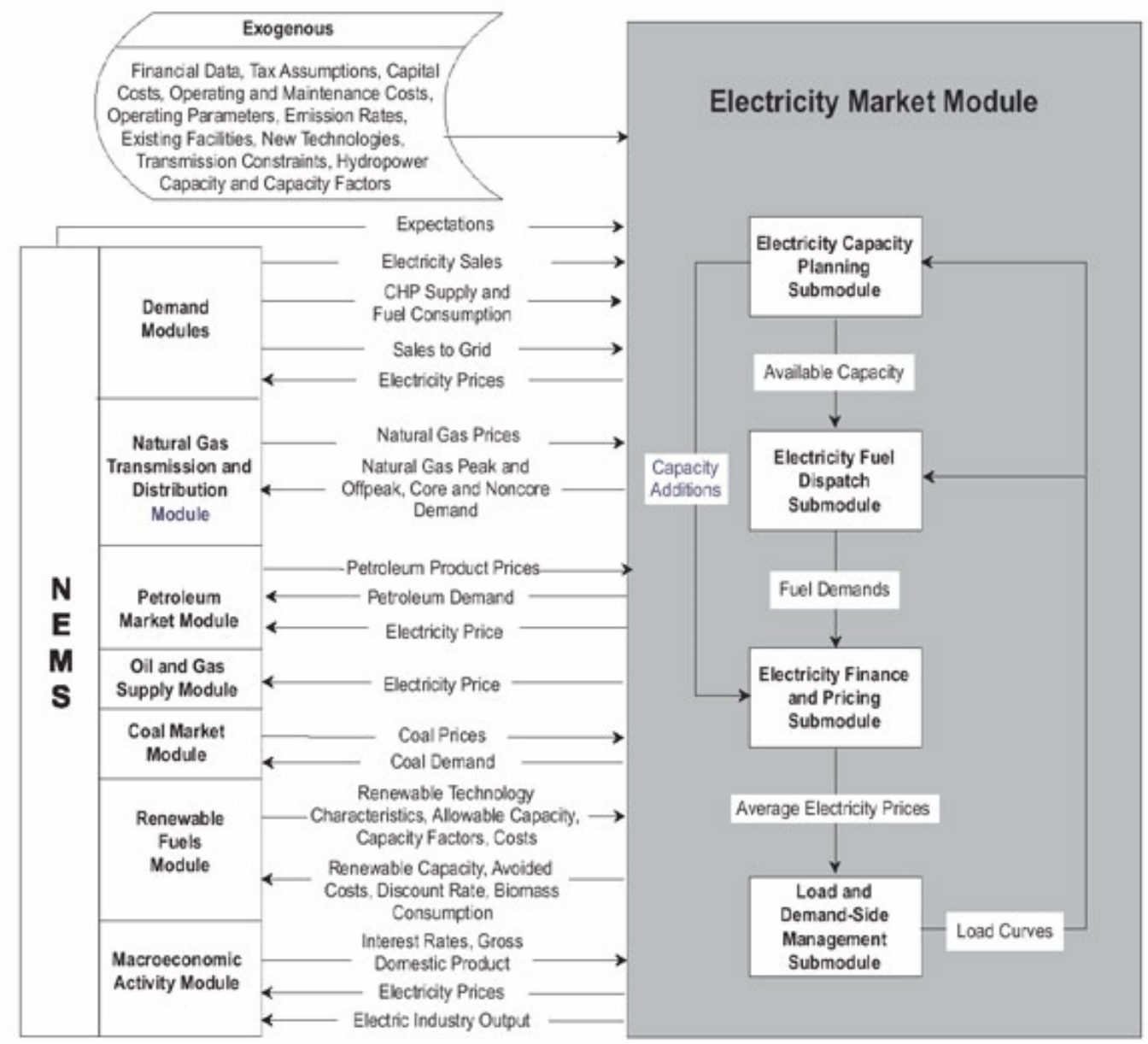

Source: U.S. Department of Energy, Report \#: DOE/EIA-0581(2003). Released March 4, 2003.

Downloaded from the Internet (09/2007) at:

http://www.eia.doe.gov/oiaf/aeo/overview/figure 9.html 
Figure 11. Renewable Fuels Module Structure

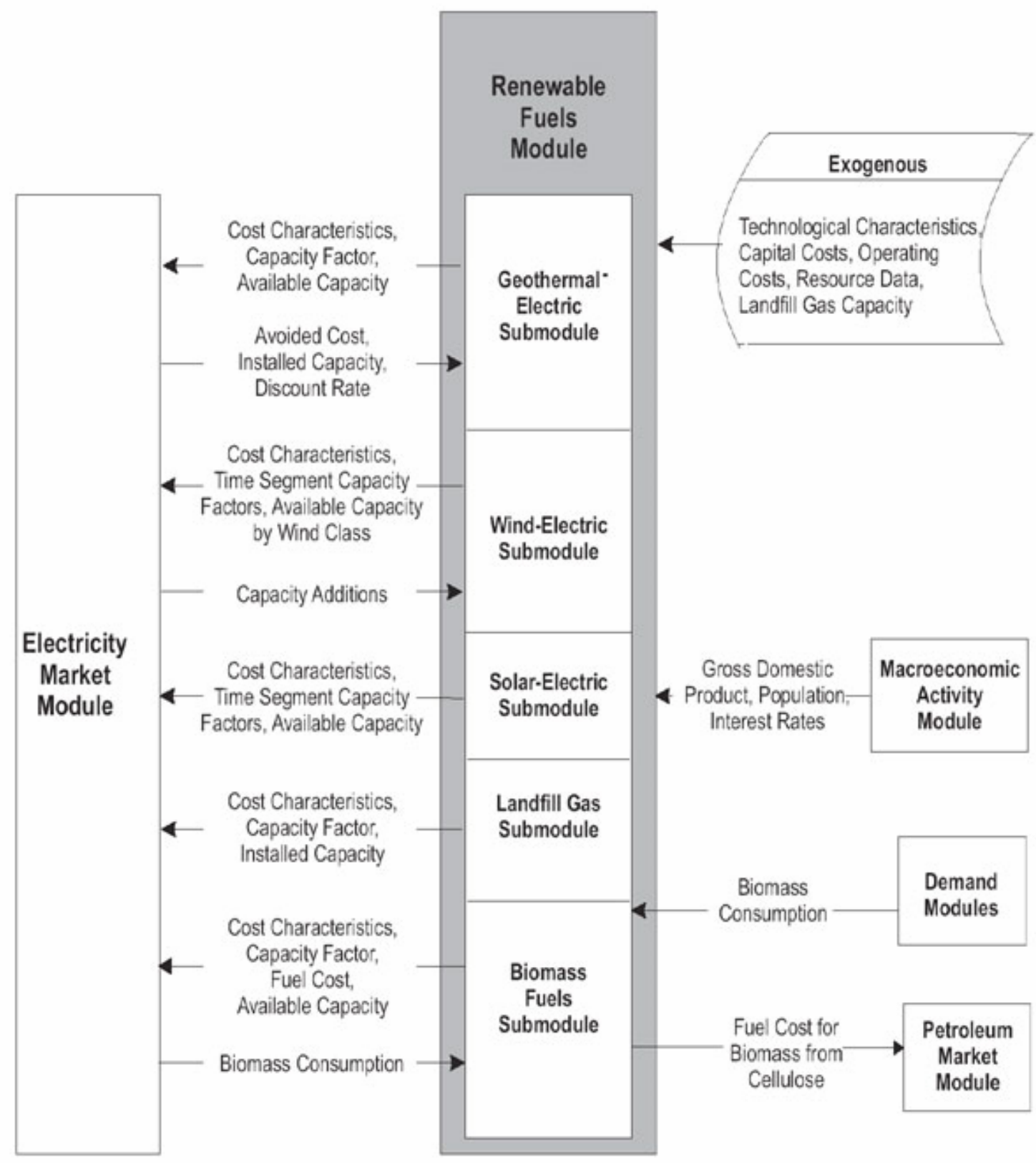

Source: U.S. Department of Energy, Report \#: DOE/EIA-0581(2003). Released March 4, 2003. Downloaded from the Internet (09/2007) at:

http://www.eia.doe.gov/oiaf/aeo/overview/figure 11.html 
Appendix D - ORC Survey Results

MODELING EERE DEPLOYMENT ACTIVITIES 


\section{Appendix D: ORC Surveys, Results, and Analysis}

\section{SURVEY \#1}

\section{EERE Deployment Survey - July 12, 2007}

This report presents the findings of a telephone survey conducted among a national probability sample of 1,021 adults comprising 507 men and 514 women 18 years of age and older, living in private households in the continental United States. Interviewing for this CARAVAN® Survey was completed during the period July 12-15, 2007.

All CARAVAN interviews are conducted using Opinion Research Corporation's computer assisted telephone interviewing (CATI) system. The system is state-of-the-art and offers several distinct advantages such as: full-screen control which allows multi-question screens, fullyprogrammable help and objection screens to aid interviewing, an extremely flexible telephone number management system and powerful data checking facilities. CATI ensures that interviews are conducted in the most efficient manner and allows interviewers easy response recording. This interviewing method also allows for the most accurate form of data entry by guiding the interviewer through the programmed question flow and by providing on-screen interviewer instructions.

The most advanced probability sampling techniques are employed in the selection of households for telephone interviewing. Opinion Research Corporation utilizes an unrestricted random sampling procedure that controls the amount of serial bias found in systematic sampling to generate its random-digit-dial sample. The sample is fully replicated and stratified by region. Only one interview is conducted per household. All sample numbers selected are subject to up to four attempts to complete an interview.

Note that the following questions were only asked of those respondents who had indicated previously that they were the male or female head of household, and that they owned the $d$ welling within which they lived. This reduced the weighted total number of respondents from 1021 to 610. Overall response percentages by question are presented below.

In which of the following types of housing do you live?

Single-family detached home (79\%)

Single-family attached home, such as a duplex or townhouse (7\%)

Multi-family unit, such as an apartment or condo (5\%)

Mobile home (7\%)

REFUSED/NO ANSWER (2\%)

Approximately how old is the house that you live in? Was it built ...

In the year 2000 or more recently (14\%)

In the 1990's (19\%)

In the 1980's (13\%)

In the 1970's (17\%) 
Prior to $1970(37 \%)$

DON’T KNOW $(<1 \%)$

If you were investing in a major renovation to your home and could choose between spending $\$ 10,000$ for aesthetic improvements or amenities, such as hardwood floors, custom tiling, or a kitchen or bathroom facelift, versus $\$ 10,000$ for energy-efficiency improvements such as windows, a heating system, or insulation that would cut your energy bills by $40 \%$, which would you choose?

\section{AESTHETIC/AMENITY IMPROVEMENTS (32\%) \\ ENERGY EFFICIENCY IMPROVEMENTS (62\%) \\ DON'T KNOW (6\%)}

In the PAST 5 YEARS, have you made one or more of the following energy-saving investments to your home?

Purchased new heating or cooling equipment (33\%)

Increased wall and/or attic insulation (25\%)

Installed new energy efficient windows (26\%)

Purchased ENERGY STAR labeled appliances and products to replace aging appliances (56\%)

Installed an active solar component, such as a solar panel or solar water heater (2\%)

NONE OF THESE (26\%)

DON'T KNOW (0\%)

When you invested in [product], how important were the following factors to making your decision to invest and deciding on a product?

*note that the sample size for Solar Panel/WH was a very small base

\begin{tabular}{|l||c||c||c||c||c||}
\hline Cost or Price of Product & $\begin{array}{c}\text { Heat/Cool } \\
\text { Equip }\end{array}$ & Insulation & Windows & $\begin{array}{c}\text { E-Star } \\
\text { Appliance }\end{array}$ & $\begin{array}{c}\text { Solar } \\
\text { Panel/WH }\end{array}$ \\
\hline Very important & $65 \%$ & $53 \%$ & $62 \%$ & $55 \%$ & $58 \%$ \\
\hline Somewhat important & $29 \%$ & $36 \%$ & $29 \%$ & $39 \%$ & $27 \%$ \\
\hline Not very important & $5 \%$ & $7 \%$ & $6 \%$ & $4 \%$ & $0 \%$ \\
\hline Not important at all & $1 \%$ & $4 \%$ & $2 \%$ & $2 \%$ & $10 \%$ \\
\hline Don't know & $0 \%$ & $0 \%$ & $1 \%$ & $<1 \%$ & $5 \%$ \\
\hline
\end{tabular}

\begin{tabular}{|l||c||c||c||c||c||}
\hline $\begin{array}{l}\text { Hassel-Free Installation } \\
\text { and maintenance (e.g., } \\
\text { quick and easy) }\end{array}$ & $\begin{array}{c}\text { Heat/Cool } \\
\text { Equip }\end{array}$ & Insulation & Windows & $\begin{array}{c}\text { E-Star } \\
\text { Appliance }\end{array}$ & $\begin{array}{c}\text { Solar } \\
\text { Panel/WH }\end{array}$ \\
\hline Very important & $59 \%$ & $55 \%$ & $63 \%$ & $58 \%$ & $81 \%$ \\
\hline Somewhat important & $27 \%$ & $30 \%$ & $25 \%$ & $31 \%$ & $4 \%$ \\
\hline Not very important & $9 \%$ & $10 \%$ & $7 \%$ & $8 \%$ & $0 \%$ \\
\hline Not important at all & $3 \%$ & $4 \%$ & $3 \%$ & $2 \%$ & $5 \%$ \\
\hline Don't know & $2 \%$ & $1 \%$ & $2 \%$ & $1 \%$ & $10 \%$ \\
\hline
\end{tabular}




\begin{tabular}{|l||c||c||c||c||c||}
\hline $\begin{array}{l}\text { Product Reputation (i.e., } \\
\text { delivers benefits as claimed) }\end{array}$ & $\begin{array}{c}\text { Heat/Cool } \\
\text { Equip }\end{array}$ & Insulation & Windows & $\begin{array}{c}\text { E-Star } \\
\text { Appliance }\end{array}$ & $\begin{array}{c}\text { Solar } \\
\text { Panel/WH }\end{array}$ \\
\hline Very important & $71 \%$ & $65 \%$ & $75 \%$ & $69 \%$ & $81 \%$ \\
\hline Somewhat important & $24 \%$ & $29 \%$ & $19 \%$ & $26 \%$ & $4 \%$ \\
\hline Not very important & $4 \%$ & $5 \%$ & $3 \%$ & $4 \%$ & $0 \%$ \\
\hline Not important at all & $1 \%$ & $1 \%$ & $2 \%$ & $1 \%$ & $5 \%$ \\
\hline Don't know & $0 \%$ & $0 \%$ & $1 \%$ & $<1 \%$ & $10 \%$ \\
\hline
\end{tabular}

\begin{tabular}{|c|c|c|c|c|c|}
\hline $\begin{array}{l}\text { Visual aesthetics or other } \\
\text { aesthetic features such as } \\
\text { noise level or size }\end{array}$ & $\begin{array}{c}\text { Heat/Cool } \\
\text { Equip }\end{array}$ & Insulation & Windows & $\begin{array}{c}\text { E-Star } \\
\text { Appliance }\end{array}$ & $\begin{array}{c}\text { Solar } \\
\text { Panel/WH }\end{array}$ \\
\hline Very important & $35 \%$ & $32 \%$ & $59 \%$ & $47 \%$ & $52 \%$ \\
\hline Somewhat important & $35 \%$ & $20 \%$ & $32 \%$ & $37 \%$ & $31 \%$ \\
\hline Not very important & $21 \%$ & $23 \%$ & $6 \%$ & $11 \%$ & $3 \%$ \\
\hline Not important at all & $8 \%$ & $24 \%$ & $2 \%$ & $5 \%$ & $14 \%$ \\
\hline Don’t know & $2 \%$ & $2 \%$ & $2 \%$ & $<1 \%$ & $0 \%$ \\
\hline
\end{tabular}

\begin{tabular}{|c|c|c|c|c|c|}
\hline $\begin{array}{l}\text { Energy-efficiency features - } \\
\text { or how much energy it is } \\
\text { expected to save }\end{array}$ & $\begin{array}{c}\text { Heat/Cool } \\
\text { Equip }\end{array}$ & Insulation & Windows & $\begin{array}{c}\text { E-Star } \\
\text { Appliance }\end{array}$ & $\begin{array}{c}\text { Solar } \\
\text { Panel/WH }\end{array}$ \\
\hline Very important & $77 \%$ & $85 \%$ & $77 \%$ & $70 \%$ & $85 \%$ \\
\hline Somewhat important & $18 \%$ & $12 \%$ & $20 \%$ & $25 \%$ & $0 \%$ \\
\hline Not very important & $3 \%$ & $2 \%$ & $2 \%$ & $5 \%$ & $0 \%$ \\
\hline Not important at all & $1 \%$ & $1 \%$ & $1 \%$ & $0 \%$ & $10 \%$ \\
\hline Don't know & $1 \%$ & $1 \%$ & $<1 \%$ & $<1 \%$ & $5 \%$ \\
\hline
\end{tabular}


When you invested in [product], on which information source or sources did you rely on MOST for making this purchase?

*note that the sample size for Solar Panel/WH was a very small base

\begin{tabular}{|c|c|c|c|c|c|}
\hline & $\begin{array}{l}\text { Heat/Cool } \\
\text { Equip }\end{array}$ & Insulation & Windows & $\begin{array}{c}\text { E-Star } \\
\text { Appliance }\end{array}$ & $\begin{array}{c}\text { Solar } \\
\text { Panel/WH }\end{array}$ \\
\hline $\begin{array}{l}\text { Consumer Reports or } \\
\text { other consumer } \\
\text { information publications }\end{array}$ & $17 \%$ & $11 \%$ & $11 \%$ & $24 \%$ & $4 \%$ \\
\hline Internet Searches & $8 \%$ & $4 \%$ & $10 \%$ & $13 \%$ & $31 \%$ \\
\hline $\begin{array}{l}\text { Contractor/Builder } \\
\text { recommendations }\end{array}$ & $26 \%$ & $29 \%$ & $21 \%$ & $5 \%$ & $5 \%$ \\
\hline $\begin{array}{l}\text { Word-of-mouth, from } \\
\text { people you consider } \\
\text { knowledgeable }\end{array}$ & $26 \%$ & $18 \%$ & $24 \%$ & $15 \%$ & $25 \%$ \\
\hline $\begin{array}{l}\text { Advertisements (TV, } \\
\text { radio, newspaper, } \\
\text { Internet) }\end{array}$ & $6 \%$ & $3 \%$ & $7 \%$ & $5 \%$ & $7 \%$ \\
\hline $\begin{array}{l}\text { Labels, such as “Energy } \\
\text { Star” }\end{array}$ & $4 \%$ & $4 \%$ & $6 \%$ & $15 \%$ & $0 \%$ \\
\hline Sales people in the store & $5 \%$ & $11 \%$ & $8 \%$ & $14 \%$ & $21 \%$ \\
\hline $\begin{array}{l}\text { Utility-sponsored } \\
\text { programs and information }\end{array}$ & $4 \%$ & $9 \%$ & $2 \%$ & $2 \%$ & $0 \%$ \\
\hline $\begin{array}{l}\text { Government-produced } \\
\text { informational brochures } \\
\text { and websites (e.g., } \\
\text { Department of Energy, } \\
\text { State and City } \\
\text { departments) }\end{array}$ & $1 \%$ & $5 \%$ & $4 \%$ & $3 \%$ & $0 \%$ \\
\hline Other: [Specify] & $1 \%$ & $2 \%$ & $2 \%$ & $1 \%$ & $0 \%$ \\
\hline None of these & $1 \%$ & $3 \%$ & $1 \%$ & $1 \%$ & $0 \%$ \\
\hline Don’t know & $1 \%$ & $<1 \%$ & $2 \%$ & $1 \%$ & $8 \%$ \\
\hline
\end{tabular}

In the NEXT 3 YEARS, do you plan on making one or more of the following energy-saving investments to your home?

Purchase new heating or cooling equipment (17\%)

Increase wall and/or attic insulation (13\%)

Install new energy efficient windows (17\%)

Purchase ENERGY STAR labeled appliances and products to replace aging appliances (38\%)

Install an active solar component, such as a solar panel or solar water heater (8\%)

NONE OF THESE (46\%)

DON'T KNOW $(<1 \%)$ 
If you could reduce your home energy bills by $\$ 100$ each year by having a reputable contractor install energy efficiency measures such as insulation, weather stripping, or other low-cost measures, how much would you be willing to pay?

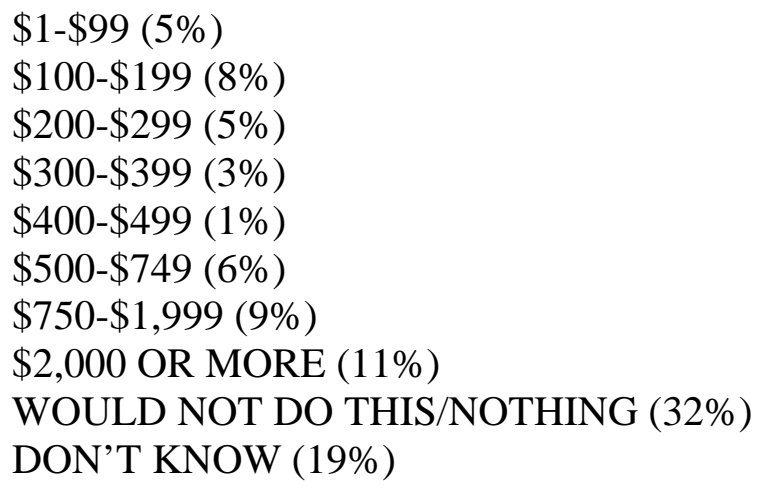

Suppose you could have a solar panel professionally installed in your home that costs $\$ 1,500$ and is expected to reduce your energy bill by $\$ 500$ each year. This means that the savings would pay back the initial investment within 3 years. How likely would you be to make this investment? Would you be ...

Very likely (16\%)

Somewhat likely (30\%)

Neither likely nor unlikely (7\%)

Somewhat unlikely (12\%)

Very unlikely (35\%)

DON'T KNOW (1\%)

In your view, is global climate change a ...

Very serious problem (39\%)

Somewhat serious problem (29\%)

Not too serious problem (12\%)

Not a problem $(19 \%)$

DON'T KNOW (2\%)

Do you think it's possible for individuals to reduce the effects of global climate change?

YES (71\%)

NO (26\%)

DON'T KNOW (3\%) 


\section{EERE Deployment Survey Analysis}

There were seven population segments of interest as defined by:

- Gender

- Age (18-34, 35-64, 65 and older)

- Region (North, South)

- Household income (< \$35K, \$35K- less than \$75K , \$75K+)

- Education (college, no college)

- $\quad$ Age of home ( built in 90's and later, built in 70's - 80's, built prior to 1970's)

- Type of housing (single family unit, multifamily unit)

Several response groups were not represented by enough population to be eligible for significance testing. Therefore these groups were either omitted from the discussion or aggregated into larger segments. The omitted group is mobile home owners. The aggregated segments are:

- $\quad$ Some of the age groups (18-24 and 25-34 were combined into 18-35 age segment)

- Income categories of $<\$ 25 \mathrm{~K}$ and $\$ 25 \mathrm{~K}-\mathrm{LT} \$ 35 \mathrm{~K}$, which were aggregated into one group (income LT\$35K)

- Single-family detached and single-family attached housing types that were treated as one segment (single-family housing)

- HS incomplete and HS grad that are treated as "no college” category; college incomplete and college grad combined into "college education” segment.

Two different types of results are discussed when analyzing the survey data. The first one, rating, refers to the percentage of responses either given by the sample segment (e.g.: \% of particular income segment invested in a certain good), or accounted towards specific attribute/good (e.g.: product reputation rated/scored at $100 \%$ ). The second one, ranking, is obtained by ordering attributes/goods in accordance with their ratings (e.g.: energy-efficiency was ranked above product reputation). The order itself is referred to as preference structure or preference ordering. If two population segments ranked the attributes in the exact same order, it is referred to as identical preference structure.

\section{Summary of Findings}

Type of residence

A total $86 \%$ of respondents live in a single family home defined as either single-family detached, or single-family attached.

Age of residence

A total of 33\% of respondents live in a home that was constructed in 1990 or is newer. Likewise, 67\% of respondents live in a home that was built before 1990. 
Investing in major renovation

Fully $62 \%$ of respondents indicated if they had the choice, they would spend $\$ 10,000$ on energyefficiency renovation projects rather than $\$ 10,000$ on aesthetic improvements. The highest percentage (74\%) is represented by the population segment earning less than $\$ 35 \mathrm{~K}$.

Within the age segment, $66 \%$ of the $18-34$ group, $62 \%$ of the $35-65$ group and $61 \%$ of respondents 65+ years old would chose energy efficient upgrades over aesthetic improvements. In the household income category, 74\% of the respondents within “less than \$35,000" group would chose energy improvements, when only $60 \%$ and $59 \%$ of respondents within the two remaining categories, (“\$35,000 to $\$ 75,000$ ” and “\$75,000 and up”) accordingly, revealed similar preference ordering, (i.e. prefer energy-efficient upgrades over aesthetic improvements).

\section{Energy saving investments}

A net total of $74 \%$ of respondents have made energy saving investments to their home within the past 5 years. The breakdown of energy saving investments across segments with the most variation is presented for each group of products.

\section{Products and Attributes}

Question 5 directly addressed specific energy-efficiency products and product attributes. Of the $74 \%$ of respondents that made energy investments in their homes within the past 5 years, there were several clear distinctions when asked about their respective investment.

\section{Energy Star Appliances}

As a percent of the total, the highest degree of implementation (56\%) was observed in those purchasing ENERGY STAR labeled appliances and products. The benchmark characteristics that exposed the most of the variation in the implementation degree, or percentage of the segment that has made the investment, are age of respondents and household income. The respondents earning in excess of $\$ 75 \mathrm{~K}$ comprise the segment with the highest degree of implementation, since $66 \%$ of this subset made energy investments within the last 5 years. The lowest percentage is observed for the age group of 65 and over scoring at $45 \%$, as well as income category of less than $\$ 35 \mathrm{~K}$, which score is $46 \%$.

According to respondents, primary value was placed equally on product energy-efficiency defined as expected energy savings, and product reputation defined as benefits delivered as claimed. Both of these values measured as important in $95 \%$ of the respondents, with well over two-thirds in both groups indicating it was very important. Cost, or price of product, came in a close $3^{\text {rd }}$ place; $94 \%$ of respondents indicated price was important, with $55 \%$ of those indicating price was very important. Attributes that rated lowest were visual aesthetics and ease of installation.

When importance of attributes is compared across the population segments, some difference in ratings was detected. Within the age benchmark, the group of 18-34 assigns primary value to the product reputation (100\%); product price is valued over the energy efficiency at 100\% and 91\% correspondingly. They are followed by the visual aesthetic features, which are preferred over the ease of installation with the 6\% lead. The age group of 35-65 chooses energy efficiency (97\%) above production reputation and cost/price factors (94\% for each). The age group of $65+$ values 
hassle-free installation just as much as the product reputation (95\%) followed by energy efficiency at $93 \%$ and cost/price considerations at $89 \%$.

Within the household income segment, the group earning less than $\$ 35 \mathrm{~K}$ has preferences ordered similarly to general population result, but the remaining two categories value energy efficiency of the product above product reputation and cost considerations. Visual aesthetics is ranked slightly above the hassle-free installation by the group with income of $\$ 75 \mathrm{~K}$ and above. When broken down by the housing type, the preference structure differs significantly from the rest of the segments. Respondents residing in the multi-family housing units assigned the highest value to the ease of installation and maintenance (100\%). This outcome is expected since it is consistent with basic reasons for choosing multi-family dwelling.

\section{Heating and Cooling Equipment}

The next highest degree of implementation was observed in the purchasing of new heating and/or cooling equipment at 33\%. Details across benchmark characteristics reveal that the segment, which invested the most in the heating and cooling equipment within the last 5 years, is the respondents living in homes built prior to 1970's (39\%). The lowest investment is observed for the age segment of 18 to 34 rating at $22 \%$.

Consistent with the purchasing of ENERGY STAR appliances, similar attributes are weighted almost identically. The most important attribute is energy-efficiency at 95\%. Within that attribute, the largest difference was found in education level with $73 \%$ of those without a high school education versus $98 \%$ of those at least some college education responding that it was important. It is noted that the small total sample size of those without high school degrees may limit the usefulness of this percentage, although across almost all attributes for heating and cooling equipment, the only one they measured higher than the net was importance placed on aesthetics.

Within the gender segment, male respondents have the highest value assigned to energyefficiency (98\%), followed by product reputation and cost factors with $89 \%$ of respondents voting for each attribute. Female respondents ranked efficiency lower (93\%) than cost and reputation (97\%). Within the age segment, the attribute preference of the first two subgroups is identical to that for the energy star appliances, but the category of respondents with the age of 65 and over values price/cost factor (97\%) above product reputation and energy efficiency (92\%).

Within the income segment, cost/price factors and product reputation were rated as equally important by the respondents of the groups with income levels of 35K-75K (at 97\%) and $>75 \mathrm{~K}$ (at 91\%). For $>\$ 75 \mathrm{~K}$ category energy efficiency considerations were chosen over the product reputation by $7 \%$, while for the $35 \mathrm{~K}-75 \mathrm{~K}$ income range energy efficiency scored behind product reputation and cost factor by $3 \%$. The income group of $<\$ 35 \mathrm{~K}$ rated cost considerations and hassle free installation as the most important factors in the decision making (96\%), closely followed by the energy efficiency and product reputation (93\%). The hassle-free installation and maintenance was selected as the highest value attribute among multi-family residence owners (100\%), which is 11\% higher than energy efficiency and product reputation (89\%). 
Aesthetics, defined as visual aesthetics or other aesthetic features such as noise level or size, were consistently ranked as the least important across all population segments. Note that for heating and cooling equipment the noise and size are more representative of the operational/functional characteristics rather than aesthetics/appearance of the product. Therefore it might be instrumental to separate these attributes from purely aesthetic features for the future survey questions.

\section{Energy Efficient Windows}

Coming in at 26\% implementation, windows, as expected, had energy-efficiency as the highest valued attribute at $97 \%$ considered important. This was followed closely by product reputation at 94\%. With a highly visible product though, window purchasers placed as much value on price as they did on aesthetics as $91 \%$ of the respondents considered these attributes important. Note that the respondents were presented with a multiple choice question, where one of the proposed answers explicitly mentioned size as an aesthetic attribute.

The lowest implementation degree was observed for the age segment of 18 to 34 (14\%), as well as for the houses built after 1990's (15\%). Most of the investment in the energy efficient windows was done by those respondents residing in homes that were built prior to 1970's (33\%).

When compared across the gender benchmark, female respondents rated product cost to be the second most important factor (97\%), while male population ranked cost to be the least important consideration (83\%). Within the age segment, the category of 18 to 34 ranked cost of the product at the top (100\%). Reputation, energy efficiency and aesthetics received the same level of importance (88\%). Respondents from the remaining two age groups have the preference structure reflected by the overall percentage ratings, with energy efficiency and reputation being the two leading choices.

The group of respondents with income of $\$ 75 \mathrm{k}$ and above assigned the same importance to aesthetic features as to the energy efficiency scoring $94 \%$ each. Again, this may be explained by the fact that size is an essential decision-defining characteristic specific to the nature of the product, rather than just secondary attribute. But the wording of the proposed multiple-choice question explicitly mentions size and noise as an example of aesthetic features. Size and visual appeal would have to be treated as separate attribute categories for this group of products in the future surveys.

As was also consistent with heating and cooling equipment, the age of the home had a substantial impact on the value placed on purchases. Occupants of homes built prior to 1980, the population segment with higher implementation levels, show energy efficiency as the most important decision factor. It is closely followed by the product reputation. Cost and aesthetic factors were rated as equally important. This might be explained by the direct functional dependence of product price on its size, with the latter being treated by the survey as aesthetics attribute.

Wall and Attic Insulation

As a function of investment made, wall and attic insulation came in slightly behind energy efficient windows, at 25\% implementation from the available product options. The highest investment was observed for the respondents living in the houses built prior to 1970’s, which 
accounted for 31\% of the segment. Owners of the houses built in 90's and later scored at 16\%, which is the lowest among all benchmarks.

Leading attributes were energy-efficiency features (97\%), followed by product reputation at 93\%. Interestingly, for a product that can't be seen or heard, 52\% still thought aesthetics were important. Reason for this particular outcome, again, could be the result of size and noise being treated by the questionnaire as aesthetic features regardless of the product nature.

\section{Solar Panel or Solar Water Heater}

The total number of purchases for this product category is quite small. Only 12 respondents answered the implementation question positively making percentage values ineligible for proportion testing. There are several indications however, which are qualitatively descriptive of the population investing in solar products. No one under the age of 35 made a purchase, and as might be expected, the higher the household income, the more likely they were to buy a solar product. Another interesting aspect is that every single attribute had almost the same net importance placed on it, with minor deviations detectable only when assessing 'very important' versus 'somewhat important'.

\section{Products and Attitudes}

To gain insight into consumer behavior, several questions were asked regarding potential future investment in energy-efficiency products, and financial willingness to invest.

\section{Potential investment in the next 3 years}

On one hand, this information about potential investment in energy-efficient products, closely matched what had actually been purchased in the previous 5 years. It should be noted that those planning on making an investment in the next three years (54\% net), was significantly lower than those that actually had made an investment in the past five years (74\% net). Specific to investment options though, the highest percentage of those polled indicated that ENERGY STAR labeled products and appliances would be their primary purchase (38\%), followed next by heating and cooling equipment (17\%), windows (17\%), insulation (13\%), and finally active solar equipment (8\%).

An interesting distinction is observed when looking at education level; those at or below high school level education are significantly less likely to plan on making an energy saving investment to the home. However, when asked if they actually had made an investment in the previous 5 years, they aren't significantly different from those respondents with college degrees. This may indicate that education level may impact perception, but not degree of implementation. Moreover, the preference structure for future product investment is identical regardless of the education.

For the age segment, the $66 \%$ of respondents in the group of 18-34 are likely to make an investment, $55 \%$ of the $35-64$ group and only $42 \%$ of the respondents of age 65 and older will consider investing in energy saving products. Preference structure across the product variety is consistent with that mentioned earlier. 
There is also a variation across the household income benchmark. The group that showed the highest interest in energy-saving investments (61\%) is the respondents with income between $\$ 35 \mathrm{~K}$ and $\$ 75 \mathrm{~K}$. It is followed by $55 \%$ of the group earning $\$ 75 \mathrm{~K}+$ and $49 \%$ of the respondents with income of $\$ 35 \mathrm{~K}$ or less. The second group also shows investment in windows being preferred over investment in heating or cooling equipment.

The benchmark comparison revealed that the only two categories which showed equal interest in solar component investment as other products, namely insulation, were income group of $\$ 35 \mathrm{~K}$ to $\$ 75 \mathrm{~K}$, as well as those respondents that own houses built in 70’s - 80’s. More so, the only segment which is more interested in purchasing solar component for their home (16\%) than insulation (13\%) or windows (9\%), is the residents of multi-family dwellings. For the rest of the population groups solar component was the least likely choice.

Interestingly, as a percentage of the total, there wasn't a significant deviation between those who thought it was possible as an individual to reduce the effect of global climate change, and their frequency of spending on energy projects or aesthetic improvements. By this, an average 25 to $30 \%$ of respondents who indicated they do not think it possible to impact global climate change, were still inclined at similar percentages to invest in products, suggesting they aren't purchasing for overly altruistic reasons.

Lastly, with regard to potential investment in the next three years, $46 \%$ do not intend to invest in any of the listed products and tended to trend from low to high relative to age. Regarding market entry, this suggests high discount rates for higher perceived market entry costs may not necessarily impact broad acceptance.

Consumer spend to capture $\$ 100$ annual energy savings

From a financial perspective, two similar questions were asked. One question asked, “...in order to reduce the energy bill by $\$ 100$ annually, how much would you be willing to pay?”

Approximately half of respondents indicated they would be willing to pay something (49\%), with the remainder indicating they either didn't know (19\%), or would not be willing to spend at all (32\%). Particularly compelling though is that as a percent of the total, as many respondents were willing to pay $\$ 2000$ or more (11\%), as those willing to spend only less than \$200 (14\%). Subset analysis indicates that $14 \%$ were willing to pay from $\$ 1-200$; $9 \%$ were willing to pay from $\$ 200-\$ 500$; and a surprising $27 \%$ were willing to pay more than $\$ 500$. Such a variation in willingness to invest suggests that the distribution of paybacks should be used rather than an average payback.

Broken out to reflect ROI as a payback period (assuming \$100 annual savings):

\begin{tabular}{|l|l|l|}
\hline Spend & $\begin{array}{l}\text { \% willing } \\
\text { of total }\end{array}$ & $\begin{array}{l}\text { Payback } \\
\text { Period }\end{array}$ \\
\hline$\$ 0-\$ 200$ & 14 & $<2$ years \\
\hline$\$ 200-\$ 500$ & 9 & $<5$ years \\
\hline$>\$ 500$ & 27 & $>5$ years \\
\hline$>\$ 2000$ & 11 & $>20$ years \\
\hline
\end{tabular}


This can be further broken out into a subset which reflects the percentage of respondents willing to spend greater than $\$ 300$ in order to capture $\$ 100$ in annual savings. As discussed in the following segment, $31 \%$ of respondents were willing to spend greater than $\$ 300$ when technology specific references are not made.

Further subgroup analysis revealed the difference in willingness to invest across the gender benchmark. $24 \%$ of women and $30 \%$ of men are willing to pay in excess of $\$ 500$. Investments less than $\$ 200$ are appealing to $18 \%$ of male and $10 \%$ of female respondents.

Significant difference in the investment levels was found when comparing age subgroups. Investment over $\$ 500$ is appealing to $44 \%$ of the $18-35$ age group, $26 \%$ of $35-65$ and only to $13 \%$ of the respondents of the age 65 and over. If $10 \%$ of the first two groups are willing to consider investment between $\$ 200$ and $\$ 500$, only 3\% of the last category is interested in investing within this range. Payment below $\$ 200$ is considered by $11 \%, 14 \%$ and $10 \%$ of each subgroup correspondingly.

Results of the income subset comparison are somewhat surprising. Same degree of willingness to invest over $\$ 500$ was shown by respondents earning less than $\$ 35 \mathrm{~K}$ as by those paid $\$ 75 \mathrm{~K}$ and above (24\% and 23\%). Moreover, $10 \%$ within each of the two income groups would be willing to pay over $\$ 2000$ for energy-efficiency measures that expect to reduce energy bills by $\$ 100$ a year. 34\% of the respondents earning $\$ 35 \mathrm{~K}$ to $<\$ 75 \mathrm{~K}$ are interested in investing sums above $\$ 500$, with over a third of this percentile falling into $>\$ 2000$ investment category. The investment options below $\$ 200$ and within $\$ 200$ - \$400 range were appealing to $11 \%$ and $10 \%$ of this income group.

When contrasted with the answers regarding the perception of individuals' impact on reduction of global climate change, a peculiar aspect was exposed. It appears that percentage of those who believe it is possible for an individual to have an impact and who are willing to invest in excess of \$500 in the energy-saving measures (29\%), is relatively close to the percentage of those who do not believe an individual has a role in changing climate, but is willing to consider same investment category of $\$ 500$ and over (20\%). This implies that sharing the belief does not directly translate into the investment decision, and investment is done primarily for other reasons rather than altruistic, i.e. the belief is neither a necessary nor sufficient condition for investment.

In addition, the investment above $\$ 2000$ has almost equal appeal to both of the mentioned subgroups (12\% and 10\%). These last results are consistent with the previously derived conclusion that perception of individual's role in global climate change is not an essential decision-making factor when investment in the energy efficient technologies is considered.

This question was previously asked in an ORC survey for BTP in December of 2005. At that time, when asked how much they would be willing to pay to obtain a $\$ 100$ reduction in their annual fuel bill, $24 \%$ responded $\$ 100$ or less, $40 \%$ didn't know or wouldn't make the investment, and remaining $24 \%$ split their response over 6 ranges with the highest at $8 \%$ (\$500-749). 


\section{Consumer willingness to meet 3 year ROI}

In a following question, respondents were asked specifically about active solar technology installations; would a 3 year ROI encourage investment? Almost half of respondents (47\%) indicated they were unlikely, with $75 \%$ of those indicating very unlikely, to invest $\$ 1500$ in order to capture $\$ 500$ per year savings. Relative to the previous question, $31 \%$ of respondents were willing to spend $\$ 300$ or more in order to capture $\$ 100$ annual savings (3 year ROI). Specific to solar technology, respondents are much less likely to make an investment despite meeting an applicable payback period.

Benchmark comparison across gender shows that $50 \%$ of male and $41 \%$ of female respondents are likely to invest in a solar component with a 3 year payback. Significant reduction in likeliness to invest in solar panel or heater is observed across age subgroups. If 53\% of 18-35 and $49 \%$ of 35-64 age groups are likely to invest, only 30\% of that respondent of age 65 and over finds this investment appealing at all.

$40 \%$ of respondents earning up to $\$ 35 \mathrm{~K}$ are likely to invest, which is only $8 \%$ lower than the other two income categories.

Results reveal that education plays a significant role in this investment decision. 50\% of collegeeducated respondents are likely to invest in a solar panel, while only $36 \%$ of the segment with no education beyond high school showed any interest.

Interestingly, 32\% of those who do not believe an individual has an impact on the global climate change would pursue an opportunity to invest in the solar energy component. Yet $41 \%$ of those respondents that do believe they as individuals can have some impact are not willing to consider investing in the technology which directly addresses the issue of global climate change. $29 \%$ of the respondents in this segment specified such an investment to be very unlikely.

A similar question was asked previously in an ORC survey for BTP in December of 2005. While not specific to solar, it did ask about a generic $\$ 1,500$ investment that would save $\$ 500$ on the annual heating bill. Nearly $50 \%$ of the respondents said they were very likely to make the investment, $17 \%$ were neutral to unlikely, and over $35 \%$ were very unlikely or didn't know.

\section{Global Climate Change}

When asked if global climate change was a problem at all, 79\% (net) of respondents indicated that it was, with $85 \%$ thinking it was a serious problem. The exceptions are age, college education and gender.

The age segment with the highest positive poll numbers is the respondents between 18 and 35 years of age (86\%), followed by the segment of 35-65 scoring at 79\%. The respondents 65 years old and over is the segment with $74 \%$ portion believing it is a problem at all.

There is a slight deviation when results are compared across the gender benchmark. $84 \%$ of women recognize global climate change being a problem with $74 \%$ indicating it as a serious problem. $74 \%$ of male respondents consider it a problem at al and $60 \%$ see it as being a serious one. 
Those with at least some college education think the issue was more serious than those with no college education (83\% vs 73\%). Interestingly though, this subset also appears to be the most optimistic. When asked if they think it's possible for individuals to reduce the effects of global climate change, a higher percentage of respondents without a high school education (68\%) replied they can reduce the impact than those that actually think it's a problem at all (63\%).

Type of housing is another benchmark characteristic that exposed difference in perception of individuals' impact on the global climate change. $88 \%$ of those residing in the multi-family units positively answered this question as compared to $71 \%$ of the single-family unit residents.

Also addressing the ability to impact global climate change, the younger the respondent, the more likely they were to believe they could impact the outcome ranging from a high of 86\% (1834 yr. old) to a low of 57\% for those over 65 years old.

\section{Products and Information Sources}

Starting with the most widely implemented product, the following information addresses what was the primary source(s) of information used by respondents when making the purchase.

\section{Energy Star Appliances}

Among those listed, the most widely purchased product was Energy Star appliances. They primarily relied on consumer reports/consumer information programs (24\%). The next 4 sources were all distributed evenly at 13-15\% including word-of-mouth, Energy Star Label programs, instore sales people, and internet searches. Although statistically difficult to quantify due to sample size, the 18-24 year old segment used the internet heavily at $85 \%$, with the only other measurable source as being from consumer reporting.

\section{Heating and Cooling Equipment}

Of those purchasing heating and cooling equipment, respondents relied on two primary sources of information: contractor/builder recommendations and word-of-mouth equally at $26 \%$ each. The widest discrepancy was in 25-34 year olds, who relied on word-of-mouth at $47 \%$ (well above the average), and contractor recommendations at a mere $6 \%$ (well below the average). It is also worth noting that 'non-metro' respondents favored word-of-mouth heavily (39\%), in addition to the lowest household income earners (40\%).

\section{Energy Efficient Windows}

For respondents in the window market, the primary means of sourcing information was through word-of-mouth at $24 \%$. This was followed closely by contractor recommendations at $21 \%$, with consumer reports, internet searches, and in store sales people rounding out the top 5. Unlike Energy Star appliances, the label program for windows generates very little activity at a mere $6 \%$. Internet use, as an information source, drops consistently with age from a high of $24 \%$ with 18-24 year old, down to $2 \%$ with 65 + year old. With exception only to insulation, in 4 of 5 products, word-of-mouth is the primary information source for $65+$ year olds. 
Wall and Attic Insulation

As might be expected, information was primarily gleaned from contractors. An interesting observation can be seen with regard to household income, with the lowest and highest income brackets as relying heavily on contractors, and the middle income respondents relying less on contractors and more on alternate sources. It is worth noting that utility-sponsored programs regarding insulation captured their highest percentage of audience in this category. It was carried by the 35-44 year old population, as well as those households making $\$ 75 \mathrm{~K}$ or more per year. This is particular interesting in that it is most likely not the intent of utilities to be appealing primarily to the educated wealthy.

\section{Solar Panel or Solar Water Heater}

There were very few solar products purchased as reported by respondents. However, the internet and word-of-mouth are clearly the primary sources of information. As is consistent throughout the data, there is a strong geographic preference for solar products, dominated by the south at over $66 \%$, followed by the west at just under $25 \%$. Solar products are primarily purchased by middle age (35-55) respondents (77\%). 


\section{ORC Vehicles and Wind Survey - August 9, 2007}

The ORC Vehicles and Wind Survey was conducted on August 9, 2007 and was composed of 10 questions, two of which were open-ended and required specific answer from the participant. The survey was presented to 1,010 respondents. The questions and overall results are presented

below.

1. Assume that a HYBRID vehicle and a clean DIESEL vehicle both would cost \$3,000 more than a comparable GASOLINE vehicle and both would reduce your annual fuel use by $30 \%$. Which of the following would you choose for your NEXT NEW vehicle purchase?

$$
\begin{aligned}
& \text { Gasoline - 33\% } \\
& \text { Diesel - 12\% } \\
& \text { Hybrid - 52\% } \\
& \text { Don't know - 4\% }
\end{aligned}
$$

2. Why did you make this choice? Any other reasons?

3. Which ONE of the following attributes would be MOST IMPORTANT in your choice of your next vehicle?

Fuel economy - 21\%

Dependability - 30\%

Low price - 7\%

Quality - 17\%

Safety - 24\%

Don’t Know- 3\%

4. As you may know, some utility companies use wind power to generate electricity. These utilities must install large utility scale wind turbines to do so. Have you seen, first hand, any of these large windmills or wind turbines in the U.S.?

$$
\begin{aligned}
& \text { Yes - 57\% } \\
& \text { No - } 43 \% \\
& \text { Don't know - 1\% }
\end{aligned}
$$

5. How would you feel about having a wind turbine located in your community? Please use a scale of 1 to 5 where 1 is you would strongly object and 5 is you would not object at all.

Would strongly object (1) - 7\%

(2): 5\%

(3): $14 \%$

(4): $13 \%$ 
Would not object at all (5) - 60\%

Don’t know - 2\%

6. Why do you say that? Anything else?

7. Would your attitude change if you could see the wind turbine from your home?

Yes, would change - $18 \%$

No, would not change - $79 \%$

Don’t know - 3\%

8. I am going to read you a list of 5 types of power generating facilities and then ask you to rank them in order of the one you would be MOST willing to have in your community down to the one you would be LEAST willing to have in your community.

First, which one of these generating facilities would you be MOST willing to have in your community? Second most willing to have in your community? Third most?

Fourth?

These responses are for the first "most willing".

Windmill or wind turbine - $28 \%$

Nuclear - $5 \%$

Coal - 3\%

Natural gas - $13 \%$

Solar power $-50 \%$

None of these - $1 \%$

Don't know - $1 \%$

9. How important do you view wind power as contributing to each of the following? Would you say very important, somewhat important, not very important or not at all important?

Very important

Somewhat important

Not very important

Not at all important

DON'T KNOW

Responses are for wind power being very important:

A Stimulating local economic activity: $44 \%$

B Stabilizing electricity prices: $56 \%$

C Saving family farms: $58 \%$

D Saving water for other uses: $64 \%$

E Lowering air emissions: $64 \%$

F Mitigating climate change: $44 \%$ 
10. How much MORE would you be willing to pay on your monthly electricity bill to purchase wind power that contributed to these benefits? Would you be willing to pay ...

Less than one dollar more per month: $21 \%$

One to two dollars more per month: $15 \%$

Three to four dollars: $10 \%$

Five to nine dollars: $15 \%$

Ten to fourteen dollars: $12 \%$

Fifteen to twenty dollars more per month: $10 \%$

More than twenty dollars more per month: $9 \%$

Nothing: $6 \%$

Don't know: 3\%

\section{ORC Vehicles and Wind Survey Results Analysis}

There were six population segments of interest:

Gender

Age (18-34, 35-64, 65+)

Region (North-East, North Central, South, West)

Metro/non-metro

Household income ( $<$ \$35 , \$35K-LT\$75K, \$75K+)

Education (college, no college)

\section{Vehicles}

The first three questions asked the respondents what option they would choose for the next new vehicle purchase, given that a hybrid and a clean diesel options are available at $\$ 3000$ above the price of gasoline vehicle and both would reduce the annual fuel use by $30 \%$; why they made such a choice and which attributes were the most important in making this consideration.

\section{$\underline{\text { Vehicle Choice }}$}

The top choice was given to a hybrid vehicle (52\%) followed by a gasoline-fueled car (33\%). Clean diesel received low consideration (12\%). Slight differences were detected when comparing results across key population segments.

The most interest in the hybrid vehicle (57\%) was expressed by the age group of 18 to 34, while only $45 \%$ of the respondents 65 years old and over gave it a consideration. Percentage of the sample that gave the vote to gasoline vehicle is somewhat similar across the age segments (30\%, $33 \%$ and $37 \%$ correspondingly). Fraction of the respondents in the first two age categories (1834 and 35-64) that gave their vote to the clean diesel fuel (13\%) is almost twice as high as the percentage of $65+$ year old respondents that share the same preference $(7 \%)$. 
$17 \%$ of men and only $7 \%$ of women would be interested in a clean diesel vehicle. Also, $57 \%$ of respondents residing in metro areas would prefer hybrid as compared to $45 \%$ residing in a nonmetro setting.

Significant variation is observed when population is compared based on education level. The segment with no additional education beyond high school gave $43 \%$ of their votes in favor of hybrid. The same option was selected by $57 \%$ of college-educated respondents. The ratings for diesel were very close; gasoline was chosen by $39 \%$ of the respondents with no college training as compared to $29 \%$ of those who had any college experience.

\section{Reasoning}

The polled sample was further subdivided into three categories based on the answers to the previous question. The respondents were asked to elaborate on the reason for their choice of vehicle.

\section{Gasoline}

Among the respondents who selected gasoline vehicle for their future new car purchase option, the most frequently mentioned reason was familiarity (25\%). $19 \%$ of the poll participants explained that they used only gasoline vehicles before and were not familiar with other technologies. $6 \%$ of the sample specified that they were not familiar with hybrid technologies at all. Also the same percentage of respondents mentioned that wide availability of gasoline dictated their choice of vehicle. In general, positive mentions of gasoline account for $20 \%$ of the answers.

$19 \%$ of population had negative considerations regarding hybrid technology therefore gasoline was chosen by default. Some of the frequently stated reasons are hybrid technology not being proven/perfected yet (7\%) and small size of hybrid vehicles (2\%). 13\% of respondents explicitly stated that they would choose gasoline vehicle because hybrid was more expensive. Interestingly, when asked to order car attributes based on their importance, price was ranked as the least important consideration. Other noted cost factors included cost of fuel, which was mentioned by $13 \%$ of the respondents within this category.

Diesel was discussed in a negative context by $10 \%$ of the sample subset, with reasons ranging from the bad smell of diesel fumes and noise of the vehicle to just not liking diesel for no particular reason.

Energy efficiency and conservation was cited by $2 \%$ of the respondents that chose gasoline as preferred option for their next car purchase. This result is somewhat interesting since fuel economy was rated as the third most important attribute in vehicle selection.

\section{Diesel}

Out of the sample subset that would pick diesel-fueled vehicle, $47 \%$ of respondents mentioned diesel in positive context. The most frequently cited features were diesel having more power (11\%), engine lasting longer (7\%) and biodiesel being used for fuel (5\%). 15\% mentioned cost of fuel as the reason for selecting diesel with $10 \%$ explicitly stating that it was less expensive. 
Better fuel mileage and general energy economy/conservation reasons were cited by $15 \%$ of the respondents. Same portion of the respondents mentioned hybrid in the negative context with primary concerns being unperfected hybrid technology (6\%) and small size of the vehicle (2\%).

$15 \%$ of this sample segment also stated that diesel was better for the environment. $10 \%$ gave their votes in favor of diesel because they owned diesel vehicle before or were most familiar with this type of technology. Cost was mentioned as a consideration only by $2 \%$ of this segment.

\section{Hybrid}

The respondents that would choose hybrid for their next new vehicle gave a rating of $49 \%$ to the environmental considerations stating that hybrid was better, cleaner and less polluting technology. Energy efficiency and conservation reasons were listed by $29 \%$ of this subsample with lead votes given to better fuel economy/mileage (16\%) and reduction of gas/oil consumption (12\%).

Cost of fuel was the second top choice scoring at $26 \%$ with the most frequently mentioned factor hybrid being a less expensive option (16\%). 6\% also stated that gasoline was too expensive and price was going up.

Only 3\% of the subsample justified their choice of hybrid by familiarity with the technology or current ownership of a hybrid vehicle. Interestingly, this subsample has the fewest negative mentions of other suggested fuel options (1\% for gasoline and 5\% for diesel).

\section{Attributes}

The respondents were asked to rate each of the attributes that impacted the vehicle purchasing decision above in order of their importance. Top rating was given to dependability (30\%) as the most important attribute. This result is consistent across all populations segments. Safety was rated as the most important feature by $24 \%$ of population. It was closely followed by the fuel economy and quality, which scored at $21 \%$ and $17 \%$ correspondingly. Low price received the lowest rating across all population segments scoring an average of $7 \%$.

\section{Wind Energy}

Next question asked the respondents if they had ever seen a windmill or a wind turbine firsthand. $57 \%$ of the sample answered this question positively. The percentage of positive answers across different population segments is not consistent. The age group of 18-35 had 51\% of respondents with positive answers, while over $60 \%$ of respondents $65+$ years old said "yes". The variation in responses across regional segments is up to $27 \%$ between South and West with the latter one having the lead, which can be easily explained by the wind farm locations.

There is a significant difference when answers are compared across ethnic backgrounds. The sample data shows that only 32\% of black/African-American (non-Hispanic) respondents 
positively answered the question, while the same answer was given by $46 \%$ of Hispanic respondents (any race) and $62 \%$ of white sample segment ${ }^{1}$.

Other benchmark characteristics that revealed variation across the population segments are college education and income. 61\% of college-educated respondents answered positively as compared to $48 \%$ of respondents with no education beyond high school. In addition, the proportion of positive answers changed from low $48 \%$ of the $<\$ 35 \mathrm{~K}$ income group to high $66 \%$ for $>\$ 75 \mathrm{~K}$ category. Note that some of the factors listed above are interdependent (region and ethnic background, income and college education), thus making it problematic to separate their individual impacts.

\section{Openness to having windmill in the community}

The following question intended to expose how open the respondents were to the idea of having a windmill or wind turbine in their community. Only those poll participants that indicated they had seen a turbine before were asked this question. The answers ranged from "Would not object at all" (60\%) to "Would strongly object" (7\%) . Overall, 89\% of population answered this question positively. There is some variation in tolerance to having a wind turbine in the community when results are compared across different income levels. If $68 \%$ of the group earning less than $\$ 35 \mathrm{~K}$ would not object at all, same answer was given by $58 \%$ of the $\$ 35 \mathrm{~K}-$ $<\$ 75 \mathrm{~K}$ and $60 \%$ of the respondents whose income is $\$ 75 \mathrm{~K}$ and above. There is also a $10 \%$ difference between non-metro and metro poll participants with the latter group leading at $68 \%$.

The sample data shows that significant variation is contained in the responses across the ethnic background benchmark. 42\% of black-only (non-Hispanic) respondents gave a positive answer followed by the 53\% of Hispanic respondents (any race). The white-only (non-Hispanic) population segment scored at $64 \%$. The first two groups also have the highest fraction of population responding "strongly object" (13\% and 11\% correspondingly). Again, this variation most likely has more to do with regional affiliations than with ethnicity (See footnote \#1).

\section{$\underline{\text { Reasons }}$}

In the next question $89 \%$ of respondents that did not mind having a wind turbine in their community were asked to elaborate on the reasoning. The most of the votes were given to social benefit (64\%). In addition, high number of respondents answered "yes" to the previous question simply because they did not have any specific objections at all and did not see any harm in having a windmill around (11\%). $13 \%$ of the subsample stated that it is a good/alternative energy source. $5 \%$ of answers were given to each of the following: it conserves/saves electricity, reduces dependence on fossil fuels or it is a good idea in general (no specific reason given).

\footnotetext{
${ }^{1}$ This result is most likely due to the fact these ethnicity is not distributed uniformly across the country, but rather people from similar ethnic backgrounds tend to concentrate in specific regions. For example, black/African-American populations tend to concentrate in the south, while wind generation primarily takes place in the west.
} 
Another frequently cited reason is environmental considerations (29\%) with environmental safety and cleanliness of technology scoring at 15\% and 11\% correspondingly. Only 3\% mentioned renewability.

Only $16 \%$ gave their votes to cost considerations. Neutral answers were provided by $7 \%$ of the sample saying that it depended on the closeness of windmill to their residence and its appearance.

Those respondents that had some objections were also asked to discuss their reasons. The windmill appearance received $18 \%$ of the negative votes. Other frequent mentions discussed not having enough room in town and not wanting windmill near the residence (11\% each).

The largest share of neutral answers was given due to the fact that respondents either needed more information (15\%), did not have any specific reasons to agree or object (11\%), or it depended on closeness to the residence/location (10\%).

\section{$\underline{\text { Visibility }}$}

All respondents that expressed their opinion regarding having a windmill in the community were asked whether their attitude would change, if the windmill were to be seen from their home. $79 \%$ gave a negative response, and 18\% stated they would indeed change their mind.

\section{Power source rankings}

Next question listed 5 types of power generating facilities such as solar power, windmill/ wind turbine, natural gas, nuclear and coal. Respondents were asked to rank them in order of the one they would be most willing to have in their community down to the ones they would be the least willing in their community. Solar power is the energy source that received the highest ranking closely followed by the windmill/wind turbine. The third place was given to the natural gas. Coal plants were ranked below the natural gas facilities. The type of power generating facilities that is the least appealing to the respondents is nuclear power plants. This power option was mentioned at the very bottom of the list with fair bit of consistency across all population segments.

\section{Wind power contribution}

When rating the importance of wind power contribution the respondents were given 6 possible factors:

- Lowering air emissions

- Mitigating climate change

- Saving family farms

- Saving water for other uses

- Stabilizing electricity prices

- Stimulating local economic activity 
The sample data shows that respondents assigned top place in the category "Very important" to saving water for other uses. This answer was selected by $64 \%$ of all poll participants. $2{ }^{\text {nd }}$ place was assigned to lowering air emissions, which scored at $62 \%$. Saving family farms and stabilizing electricity prices scored close to each other at 58\% and 56\% correspondingly. Stimulation of local economic activity and mitigation of climate change concluded the list at low $44 \%$.

\section{Willingness to invest}

In order to directly measure willingness to invest, the respondents were asked to specify how much more they would be willing to pay on the monthly electricity bill to purchase wind power that contributed to the benefits listed in the previous question. $91 \%$ of the population would be willing to pay extra for wind power, $6 \%$ would not even consider such an option.

When categorical data are combined, the results look as follows:

\begin{tabular}{|c|c|c|c|c|c|c|}
\hline$<\$ 1$ & $\$ 1-\$ 2$ & $\$ 3-\$ 4$ & $\$ 5-\$ 9$ & $\$ 10-\$ 14$ & $\$ 15-\$ 20$ & $>\$ 20$ \\
\hline $21 \%$ & $15 \%$ & $10 \%$ & $15 \%$ & $12 \%$ & $10 \%$ & $9 \%$ \\
\hline
\end{tabular}

The most frequently mentioned category was the incremental increase not exceeding $\$ 1.00$. Just as many respondents would be willing to pay $\$ 1.00-\$ 2.00$ as $\$ 5.00-\$ 9.00$ scoring $15 \%$ each. Overall results show that $46 \%$ of population would be interested in paying up to $\$ 5.00$ more per month for purchasing wind power. Payment in excess of $\$ 10$ would be considered by 31\%.

Significant variation in the willingness to invest is observed several benchmark characteristics. Interest in investing any money at all seems to have a negative correlation with age. 95\% of the age group 18-34 showed their interest, which decreased to $81 \%$ for the age segment of $65+$.

Interestingly, the desire to invest up to nine dollars reduced as income went up. Respondents earning less than $\$ 35 \mathrm{~K}$ showed the most interest scoring at $68 \%$ followed by the population segment making between $\$ 35 \mathrm{~K}$-lesss than $\$ 75 \mathrm{~K}$ (64\%). The least interested in the payment up to $\$ 9.00$ was the subset earning in excess of $\$ 75 \mathrm{~K}$, whose positive votes accounted for $52 \%$ of the segment. Also, college education played a role, as the willingness to pay below $\$ 9.00$ decreased from $67 \%$ for the respondents without college education to $58 \%$ for the respondents with college experience.

As the payment amount increased above $\$ 10$, the vote distribution changed. Higher willingness to invest was revealed by the respondents earning above $\$ 75 \mathrm{~K}$, which scored at $41 \%$. They were followed by the middle-income category scoring at 31\%. The lowest number of votes (23\%) for this payment category was received from those respondents that make below \$35K. Again, 34\% of the sample subset with college education voted for the payment in excess of $\$ 10$, which is $11 \%$ higher than the fraction of the respondents without college education that selected the same investment category.

Even stronger negative dependence was observed for the age benchmark. The percentage of respondents from the fist age group (18-34) gave 38\% of the votes to paying above $\$ 10$ more on 
each monthly bill to buy wind power. Only 18\% of the respondents 65 years of age and older were interested in the same payment range.

Only 9\% of the whole sample was interested in paying above \$20. Respondents earning more than $\$ 75 \mathrm{~K}$ gave the highest number of positive answers (16\%). The least interest was shown by those, who were age 65 and older, as well as by the segment earning below $\$ 35 \mathrm{~K}$ (5\% for each). 